\title{
ANDRÉ CAROLI ROCHA
}

ESTUDO CLÍNICO, RADIOGRÁFICO, MICROSCÓPICO E TERAPÊUTICO DE AMELOBLASTOMAS

São Paulo

2008 


\section{André Caroli Rocha}

Estudo clínico, radiográfico, microscópico e terapêutico de ameloblastomas

Tese apresentada à Faculdade de Odontologia da Universidade de São Paulo, para obter o título de Doutor pelo Programa de Pós-Graduação em Odontologia.

Área de Concentração: Diagnóstico Bucal

Orientador: Prof. Dr. Jayro Guimarães Júnior

São Paulo 
Catalogação-na-Publicação

Serviço de Documentação Odontológica

Faculdade de Odontologia da Universidade de São Paulo

\section{Rocha, André Caroli}

Estudo clínico, radiográfico, microscópico e terapêutico de ameloblastomas / André Caroli Rocha; orientador Jayro Guimarães Júnior. -- São Paulo, 2008. 146p. : fig., tab.; $30 \mathrm{~cm}$.

Tese (Doutorado - Programa de Pós-Graduação em Odontologia. Área de Concentração: Diagnóstico Bucal) -- Faculdade de Odontologia da Universidade de São Paulo.

1. Amelobastoma - Terapia 2. Diagnóstico Bucal

AUTORIZO A REPRODUÇÃO E DIVULGAÇÃO TOTAL OU PARCIAL DESTE TRABALHO, POR QUALQUER MEIO CONVENCIONAL OU ELETRÔNICO, PARA FINS DE ESTUDO E PESQUISA, DESDE QUE CITADA A FONTE E COMUNICADA AO AUTOR A REFERÊNCIA DA CITAÇÃO.

São Paulo,

Assinatura:

E-mail: 


\section{FOLHA DE APROVAÇÃO}

Rocha AC. Estudo clínico, radiográfico, microscópico e terapêutico de ameloblastomas [Tese de Doutorado]. São Paulo: Faculdade de Odontologia da USP; 2008.

São Paulo, / /

\section{Banca Examinadora}

1) $\operatorname{Prof}(a) . \operatorname{Dr}(a)$

Titulação:

Julgamento:

Assinatura:

2) $\operatorname{Prof}(a) \cdot \operatorname{Dr}(a)$

Titulação:

Julgamento:

Assinatura:

3) $\operatorname{Prof}(a) . \operatorname{Dr}(a)$.

Titulação:

Julgamento:

Assinatura:

4) $\operatorname{Prof}(a) \cdot \operatorname{Dr}(a)$.

Titulação:

Julgamento:

Assinatura:

5) $\operatorname{Prof}(a) . \operatorname{Dr}(a)$.

Titulação:

Julgamento:

Assinatura: 


\section{DEDICATÓRIA}

Aos meus pais, Antonio e Lourdes, pelas bases morais e familiares que em muito facilitam minha caminhada em busca de meus objetivos pessoais e profissionais. 


\section{AGRADECIMENTOS}

Ao meu orientador, Prof. Dr. Jayro Guimarães Júnior, pela boa vontade e confiança em mim depositadas durante a realização deste trabalho.

Aos professores e funcionários da Disciplina de Estomatologia Clínica, pelo período em que compartilhamos ensinamentos e amizade.

Aos colegas da pós-graduação, pelo companheirismo, auxílio e amizade, que cultivamos.

Ao Hospital das Clínicas - FMUSP, que forneceu toda estrutura para realização deste trabalho e para minha formação profissional.

À Dra. Maria Paula Siqueira de Melo Peres, diretora da Divisão de Odontologia do HC - FMUSP e Dr. Gustavo Grothe Machado, Diretor do Serviço de Cirurgia e Traumatologia Buco-Maxilo-Facial, pela compreensão e maleabilidade neste período.

Aos Profs. Drs. Décio dos Santos Pinto e Luciano Lauria Dib, pelas bases filosóficas e inspiração, que me estimularam ao estudo do tema deste trabalho.

Aos assistentes e residentes do Hospital das Clínicas - FMUSP, Hospital AC Camargo e Hospital Regional Sul pelo constante auxílio, troca de conhecimentos e amizade, que caracterizam nossas relações.

Às patologistas Reneé Zon Filippi, Sílvia Lourenço e Aline Abrahão pelo auxílio na revisão das lâminas e classificação histopatológica das lesões.

À colega Gabriela Ártico pela colaboração na estruturação do trabalho. 
Ao amigo e companheiro de ideais, Daniel Galera Bernabé, ex-orientado, que hoje se tornou conselheiro e orientador.

A minha noiva, Thaís Bianca Brandão, pelo amor, dedicação, auxílio e paciência, durante este período. Além do minucioso trabalho na reabilitação destes pacientes.

Aos pacientes, único motivo de nossa atuação profissional, que depositaram em nós sua confiança e nos ajudaram a evoluir pessoal e profissionalmente. 
"Não se pode defender o que não se ama e não se pode amar o que não se conhece."

(Autor desconhecido)

"Menos é mais"

(PI-Branemark) 
Rocha AC. Estudo clínico, radiográfico, microscópico e terapêutico de ameloblastomas [Tese de Doutorado]. São Paulo: Faculdade de Odontologia da USP; 2008.

\section{RESUMO}

Introdução: O ameloblastoma é uma neoplasia odontogênica invasiva localmente e de grande significado clínico. Este estudo avaliou o tratamento do ameloblastoma comparando dois métodos terapêuticos: curetagem e curetagem seguida de crioterapia. Método: análise retrospectiva de 53 pacientes portadores de ameloblastoma tratados no Serviço de Cirurgia e Traumatologia Buco-Maxilo-Facial do Hospital das Clínicas da Faculdade de Medicina da Universidade de São Paulo entre 1997 e 2006. Dados demográficos, clínicos, radiográficos e histopatológicos foram analisados. Análise estatística foi realizada para avaliar diferenças na ocorrência de recidiva entre os dois tipos de tratamento conservador e outras variáveis referentes ao tumor. Resultados: 25 pacientes eram homens e 28 mulheres, com idade média de 27,1 anos. A mandíbula foi afetada em 49 casos (92,5\%). Radiograficamente, a imagem mais comum foi a multilocular $(67,3 \%)$. O tamanho radiográfico médio das lesões foi de $62 \mathrm{~mm}$ (5 a $115 \mathrm{~mm}$ ). Os padrões histopatológicos predominantes foram o folicular e o plexiforme com 17 casos $(32,1 \%)$ cada, seguido pelo misto com 11 casos (20,8\%). Ameloblastoma unicístico representou $11,3 \%$ da amostra com seis casos. O tratamento consistiu de curetagem seguida de crioterapia em 30 casos (56,6\%), curetagem em 18 (33,9\%), mandibulectomia segmentar em quatro $(7,6 \%)$ e ressecção de partes moles em um (1,9\%). Não houve diferença estatística no índice de recidiva entre as duas formas 
de tratamento conservador. Localização, tipo histopatológico, aspecto radiográfico e histórico de tratamento prévio do tumor não tiveram relação com índice de recidiva. Deiscência foi a complicação mais freqüente em ambos os tratamentos. Fratura patológica da mandíbula e formação de seqüestro ósseo foram complicações associadas predominantemente com a crioterapia, quando comparadas à curetagem. Conclusão: A taxa de recidiva do ameloblastoma tratado por curetagem $(5,5 \%)$ e curetagem seguida de crioterapia (10\%) foi baixa em comparação com a maioria dos estudos da literatura. Recidivas diagnosticadas e tratadas em tempo oportuno não representaram insucesso do tratamento.

Palavras-Chave: Ameloblastoma - Neoplasias Maxilomandibulares - Terapia Combinada - Crioterapia - Curetagem - Recidiva Local de Neoplasia 
Rocha AC. Clinical, radiographic, histopathologic and therapeutic study of ameloblastomas [Tese de Doutorado]. São Paulo: Faculdade de Odontologia da USP; 2008.

\section{ABSTRACT}

Introduction: The ameloblastoma is a locally aggressive odontogenic neoplasm with important clinical implications. This study evaluated the effectiveness of ameloblastoma treatment comparing two therapeutic methods: curettage and curettage followed by cryotherapy. Method: Retrospective review of fifty three patients with ameloblastoma from the Service of Maxillofacial Surgery and Traumatology of the Clinics Hospital, Faculty of Medicine, São Paulo University, from 1997 to 2006. The demographics aspects, clinics, radiographics and histologic types of the lesions were analysed. Additionally, the results and the postoperative complications related to both treatment modalities were also evaluated. Statistical analysis to observe the difference in the local recurrence rate and clinical variations between the two techniques was performed. Results: Eighteen patients (33.9\%) were treated with curettage, 30 (56.6\%) with curettage following by cryotherapy, segmentar mandibulectomy in four (7.6\%) and ressection of soft parts in one (1.9\%). Of the 53 patients, twenty five were female and twenty eight were male, with a mean age of 27.1 years. The mandible was the most affected site (92.5\%). Radiographically, the most common aspect was multilocular image (67.3\%) with a medium size of $62 \mathrm{~mm}$. Follicular and plexiform ameloblastoma were the most common histological type (32.1\%, each), followed by mixed of two or more histological types (20.8\%) and unicystic type (11.3\%). No statistical difference was 
revealed concerning the local recurrence rates. In addition, the site of occurrence, histologic types, radiographics aspects or previous history of ameloblastoma treatment did not show any correlation with local recurrence. Dehiscence was the complication more frequent of the both treatments. Pathological jaw fractures and formation of bony kidnapping were the complications predominantly associated with curettage following by cryotherapy. Conclusion: The recurrence rate of the ameloblastomas treated by curettage (5.5\%) and curettage following by cryotherapy (10\%) was low in comparison with most of the studies of the literature. Recurrences diagnosed and treated in opportune time did not represent failure of the treatment.

Keyworks: Ameloblastoma - Jaw Neoplasms - Combined Modality Therapy Cryotherapy - Curettage - Neoplasm Recurrence, Local 


\section{LISTA DE ILUSTRAÇÕES}

Gráfico 5.1- Distribuição do número de pacientes por faixa etária .76

Gráfico 5.2 - Distribuição do número de pacientes por localização do tumor .....78

Gráfico 5.3 - Distribuição dos pacientes quanto ao tipo histológico. .80

Gráfico 5.4 - Sobrevida livre de doença........ .89 


\section{LISTA DE TABELAS}

Tabela 5.1 - Medidas resumo para a idade dos pacientes.

.77

Tabela 5.2 - Distribuição do número de pacientes por tipo e tempo de queixa

Tabela 5.3 - Medidas resumo da idade de acordo com o padrão radiográfico .79

Tabela 5.4 - Medidas resumo da idade de acordo com o tipo histológico. .80

Tabela 5.5 - Distribuição dos pacientes de acordo com o tratamento prévio .81

Tabela 5.6 Distribuição dos pacientes de acordo com o tipo de tratamento realizado

Tabela 5.7 - Complicações de acordo com tipo de tratamento realizado .82

Tabela 5.8 - Alteração do contorno facial de acordo com o tipo de tratamento realizado 83 
Tabela 5.9 - Tempo de acompanhamento de acordo com o tipo de tratamento realizado

Tabela 5.10 - Distribuição dos casos em relação à recidiva por tipo de tratamento

Tabela 5.11 - Medidas resumo da idade de acordo com a ocorrência de recidiva

Tabela 5.12 - Distribuição dos casos em relação à recidiva, por localização do tumor 86

Tabela 5.13 - Recidiva de acordo com tratamento prévio .86

Tabela 5.14 - Recidiva de acordo com o aspecto radiográfico .87

Tabela 5.15 - Correlação entre tamanho da lesão inicial e recidiva .88

Tabela 5.16 - Recidiva de acordo com o tipo histológico .88 


\section{LISTA DE ABREVIATURA E SIGLAS}

$\begin{array}{ll}\text { AD } & \text { Ameloblastoma desmoplásico } \\ \text { AP } & \text { Ameloblastoma periférico } \\ \text { ASM } & \text { Ameloblastoma sólido ou multicístico } \\ \text { AU } & \text { Ameloblastoma unicístico } \\ \text { cm } & \text { centímetro } \\ \text { HCFMUSP } & \text { Hospital das Clínicas da Faculdade de Medicina da Universidade de } \\ & \text { São Paulo } \\ \text { IOT } & \text { Instituto de Ortopedia e Traumatologia } \\ \text { mm } & \text { milímetro } \\ \text { OMS } & \text { Organização Mundial da Saúde } \\ \text { TC } & \text { Tomografia computadorizada }\end{array}$




\section{SUMÁRIO}

p.

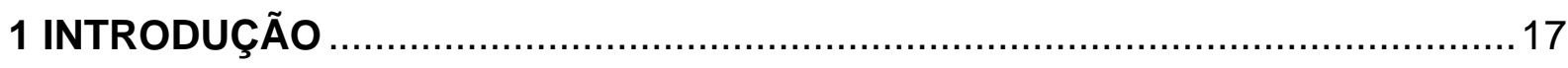

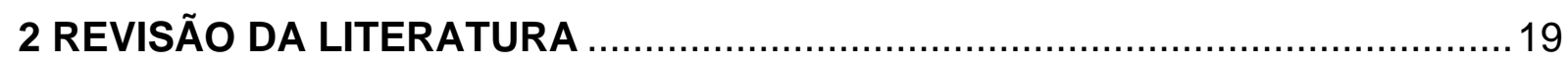

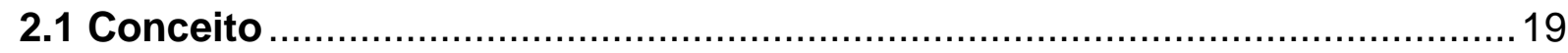

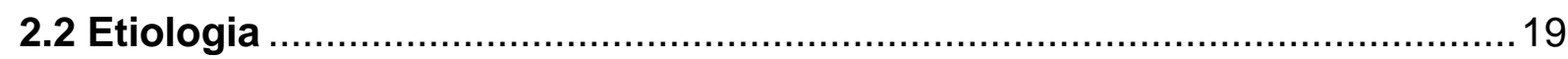

2.3 Características clínicas e epidemiológicas...................................... 20

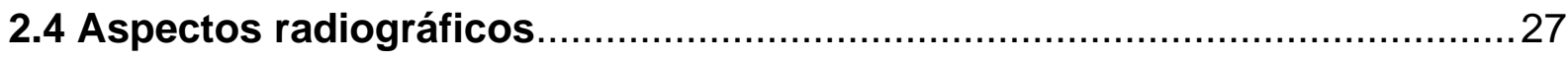

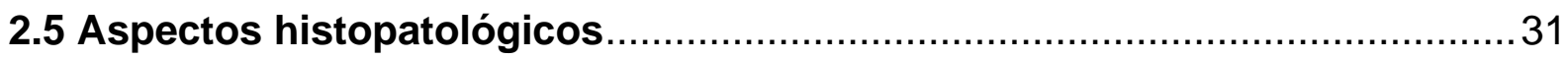

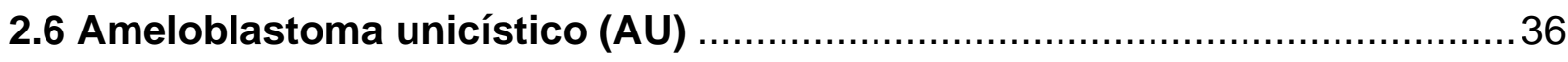

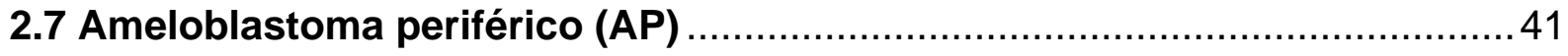

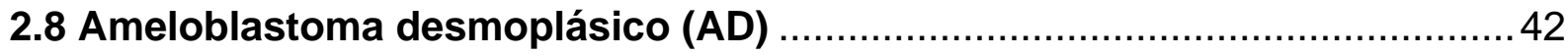

2.9 Relação entre ameloblastoma e estruturas anatômicas adjacentes ...........43

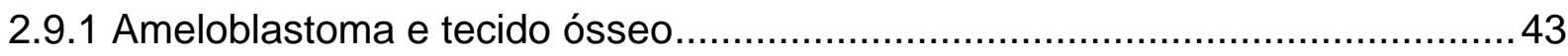

2.9.2 ameloblastoma e nervo alveolar inferior ......................................... 45

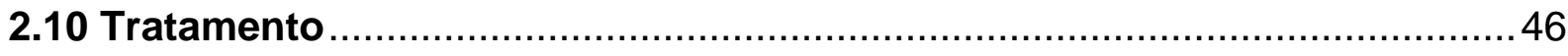

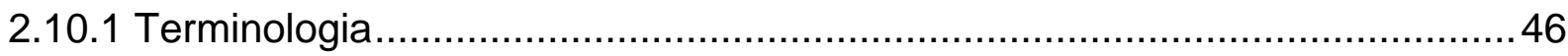

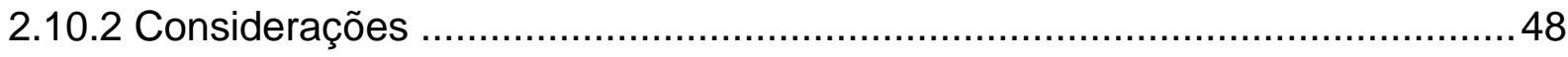

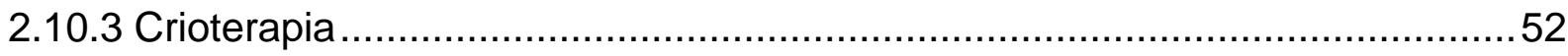

2.10.4 Marsupialização / descompressão ................................................... 54

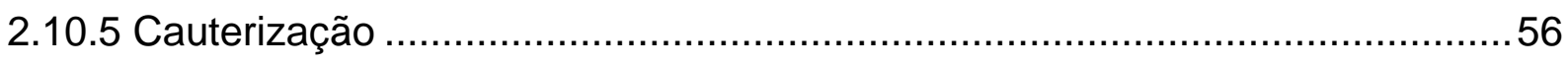

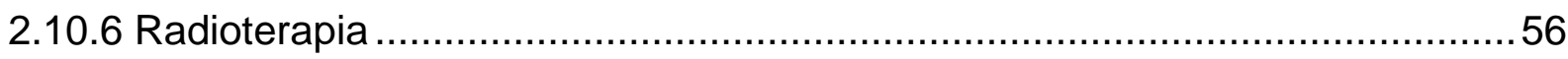

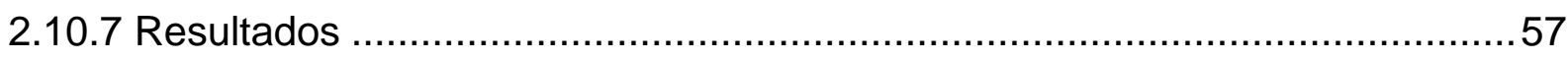

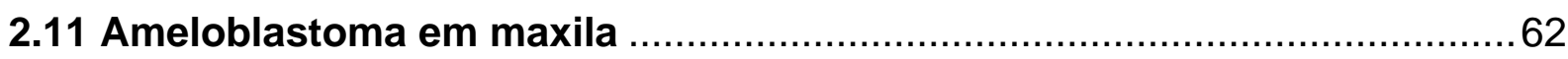

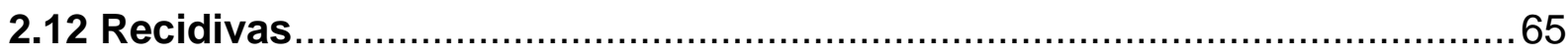




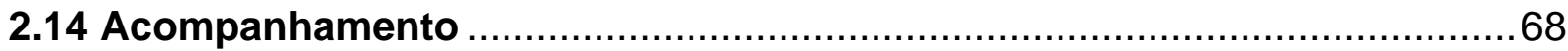

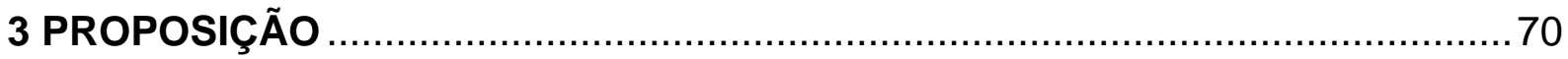

4 CASUÍSTICA - MATERIAL E MÉTODOS …............................................ 71

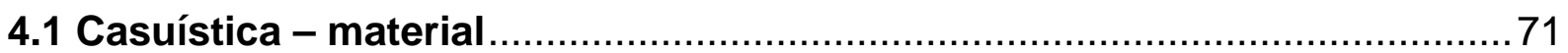

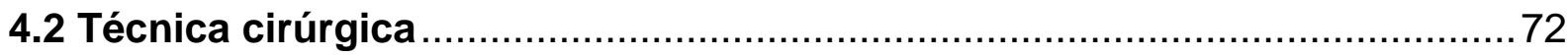

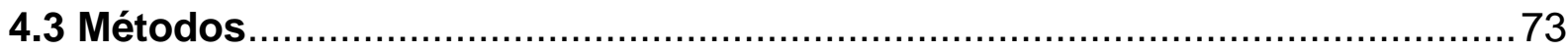

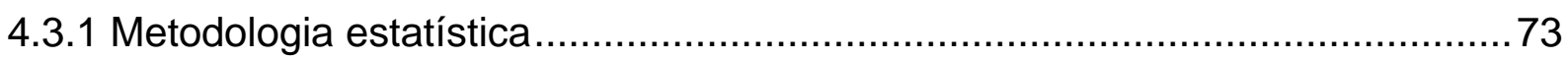

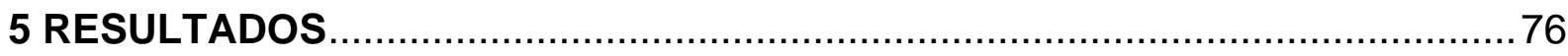

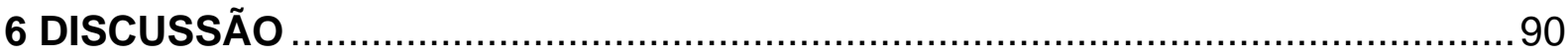

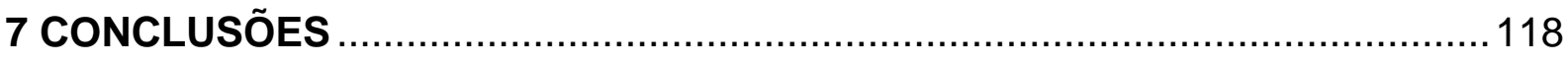

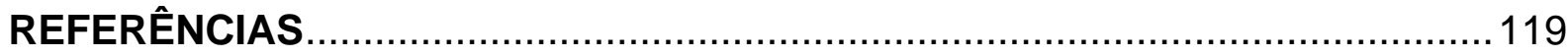

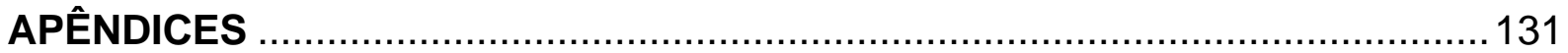

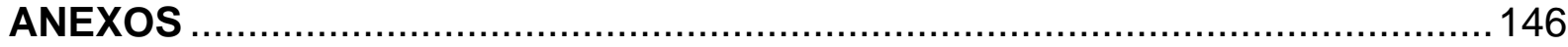




\section{INTRODUÇÃO}

O ameloblastoma representa um dos tumores odontogênicos de maior ocorrência e conhecido pelo seu comportamento invasivo local com alto poder de destruição óssea (MULLER; SLOOTWEG, 1985; REICHARD; PHILIPSEN; SONNER, 1995). Clinicamente, a doença se manifesta por aumento de volume de evolução lenta e geralmente assintomática, porém dor, parestesia e mobilidade dental podem estar eventualmente presentes. Ocorre com maior freqüência entre a segunda e sexta década de vida, não havendo predileção por sexo. A mandíbula é afetada em cerca de $85 \%$ dos casos, especialmente na região posterior. O envolvimento da maxila, apesar de incomum, exige avaliação cautelosa, pelos riscos relacionados à recidiva próxima da base de crânio (CURI; DIB; PINTO, 1997; KIM; JANG, 2001; ZANE, 1991). Radiograficamente, se manifesta como imagem radiolúcida uni ou multilocular, com aspecto de "bolhas de sabão" ou "favos de mel", associada a expansão e ruptura das corticais ósseas. Deslocamento dental e reabsorção radicular são achados freqüentes (MULLER; SLOOTWEG, 1985; YOKOBAYASHI et al., 1983).

De acordo com a classificação histológica dos tumores odontogênicos da Organização Mundial de Saúde (OMS) (GARDNER et al., 2005), há quatro tipos histológicos de ameloblastomas com características clínicas e histológicas distintas: ameloblastoma sólido ou multicístico (ASM); ameloblastoma unicístico (AU); ameloblastoma desmoplásico (AD) e o ameloblastoma periférico (AP). O ASM e o AU são os tipos mais comuns sendo o $\mathrm{AU}$, mais prevalente em pacientes jovens (PHILIPSEN; REICHART, 1998). Apesar de sabermos que o índice de recidiva do 
ASM é maior do que o do AU (GARDNER, 1984; NAKAMURA et al., 1995; ROBINSON; MARTINEZ, 1977), recentemente foi levantada a hipótese de que o AU não apresente um comportamento biológico tão menos agressivo quando comparado com o ASM (ROSENSTEIN et al., 2001).

Os tratamentos mais utilizados para o ameloblastoma são a curetagem, a curetagem seguida de crioterapia ou ostectomia periférica e a ressecção marginal ou segmentar (CARLSON; MARX, 2006; CURI; DIB; PINTO, 1997; FEINBERG; STEINBERG, 1996; SACHS, 2006; SAMPSON; POGREL, 1999; WILLIAMS, 1993). Devido aos altos índices de recidiva associados ao tratamento conservador relatados em alguns estudos (MÜLLER; SLOOTWEG, 1985; SEHDEV et al., 1974), a ressecção da mandíbula ou maxila tem sido a técnica cirúrgica mais recomendada para o tumor. Entretanto, questiona-se se a recidiva implica necessariamente em insucesso do tratamento e sabe-se que o tratamento radical está associado a várias complicações, como a dificuldade de reconstrução da grande quantidade de osso perdida e o restabelecimento da estética e função mastigatória (NAKAMURA et al., 2002). Trata-se também de procedimento de maior porte cirúrgico e com maior morbidade. Sendo assim, a possibilidade do emprego de técnicas cirúrgicas mais conservadoras continua sendo investigada. 


\section{REVISÃO DA LITERATURA}

\subsection{Conceito}

O ameloblastoma é uma neoplasia odontogênica benigna de origem epitelial, com comportamento localmente invasivo (OLAITAN; ADEOLA; ADEKEYE, 1993; ZANE, 1991). Origina-se do ectoderma odontogênico e representa, aproximadamente, $10 \%$ dos tumores odontogênicos e $1 \%$ de todos os cistos e tumores dos maxilares (SMALL; WALDRON, 1955). É conceituado pela Organização Mundial da Saúde (OMS) como uma neoplasia polimorfa, que freqüentemente tem um padrão folicular ou plexiforme em um estroma fibroso (TORRES-LAGARES et al., 2005).

\subsection{Etiologia}

O ameloblastoma origina-se do epitélio odontogênico sem a participação do ectomesênquima, podendo advir de remanescentes celulares do órgão do esmalte, revestimento epitelial de um cisto odontogênico ou células da camada basal epitelial da mucosa oral, porém sua origem é altamente controversa. Segundo Kahn (1989) e Leider, Eversole e Barkin (1985), os ameloblastomas formam-se de cistos dentígeros, preferindo denominá-los de ameloblastoma cístico ao invés de unicístico. Gardner e Pecak (1980), Maia Campos (1990) e Neville et al. (2004), descrevem que 
podem se formar também a partir dos remanescentes epiteliais de Serres e Mallassez e do epitélio da cavidade bucal. Contudo, sua origem a partir da lâmina dental tem sido mais aceita (CURI; DIB; PINTO, 1997; GOMES et al., 2002; POON; WU; SO, 1996; SANTOS et al., 2006; WILLIAMS, 1993).

Maia Campos (1990) filosofou que o ameloblastoma origina-se de células epiteliais remanescentes da fase embrionária, reativadas de seu estado latente e engajadas em uma vã tentativa de realizar suas funções originais - formar um dente - uma obrigação que elas, tendo sido despertadas em um mundo diferente e em outro tempo, não estão aptas a concluir.

\subsection{Características clínicas e epidemiológicas}

O ameloblastoma é caracterizado por expansão indolor de crescimento lento, mas persistente, que ocasiona infiltração nos tecidos adjacentes (FERRETTI; POLAKOW; COLEMAN, 2000). Seu padrão de desenvolvimento pode ocasionar grande deformidade facial e diagnóstico tardio (CURI; DIB; PINTO, 1997). Segundo Carlson e Marx (2006), pode ter um comportamento mais agressivo e com maior risco de morte que algumas neoplasias malignas da região maxilofacial.

A mandíbula é quatro vezes mais afetada que a maxila, e pouco mais de dois terços das lesões mandibulares envolvem a região posterior (molar e ramo). $\mathrm{Na}$ maxila, a região mais afetada também é a posterior (ZANE, 1991). Adekeye (1980) relatou uma prevalência de lesões mandibulares sobre as maxilares em 99\% de seus casos. Olaitan, Adeola e Adekeye (1993) referem que na população nigeriana parece haver uma predileção pela região anterior da mandíbula. 
O tumor acomete pacientes de todas as idades, havendo um pico de incidência na $3^{\mathrm{a}}$ e $4^{\mathrm{a}}$ décadas de vida (OLAITAN; ADEOLA; ADEKEYE, 1993; ZANE, 1991).

Vários autores demonstraram igual distribuição entre os sexos (CHIDZONGA, 1996; CURI; DIB; PINTO, 1997; MARTINS et al., 1999; REICHART; PHILIPSEN; SONNER, 1995), enquanto outros relataram preponderância para o sexo masculino (ADEBIYI et al., 2006; BECELLI et al., 2002; KIM; JANG, 2001; NAKAMURA et al., 2002; OLAITAN; ADEOLA; ADEKEYE, 1993; POON; WU; SO, 1996).

Tipicamente, sinais e sintomas precoces estão ausentes e estes tumores raramente são diagnosticados em estágios precoces de desenvolvimento (ZANE, 1991). A apresentação clínica usual é de um abaulamento intra ou extra-oral assintomático de crescimento lento. Este achado está presente em cerca de $75 \%$ dos pacientes. Dor, hipoestesia, odontalgia, mobilidade dental, perda de adaptação de prótese, maloclusão, ulceração, drenagem sinusal, obstrução nasal ou epistaxe podem ser outras ocorrências que levam o paciente a procurar auxílio (ZANE, 1991). A mucosa regional permanece, freqüentemente, com aspecto de normalidade e, raramente, apresenta solução de continuidade ou infecção (KIM; JANG, 2001). Fratura patológica é uma ocorrência muito rara. Por vezes, a lesão é diagnosticada incidentalmente em exame radiográfico de rotina.

Larsson e Almeren (1978) descreveram uma incidência de 0,3 casos de ameloblastoma por 1 milhão de pessoas na Suécia. Devido a sua raridade, não há estudos prospectivos publicados sobre a abordagem deste tumor.

Olaitan, Adeola e Adekeye (1993) avaliaram 315 pacientes tratados em um período de 20 anos, encontrando $195(61,9 \%)$ homens e $120(38,1 \%)$ mulheres. A relação foi de 1,6:1. A idade variou de 3 a 70 anos, com média de 31,2 anos. Um 
número significante de pacientes $(210-63,5 \%)$ foi afetado pela doença na $3^{a}$ e $4^{a}$ décadas de vida. Do total, $254(77,1 \%)$ pacientes desenvolveram a doença antes dos 40 anos. A mandíbula foi envolvida em 298 casos (94,6\%), a maxila em 13 $(4,1 \%)$ e os tecidos moles em quatro $(1,3 \%)$, sendo estes, recidivas de tumores previamente ressecados. A região anterior da mandíbula, isoladamente, foi acometida em sete casos (2,4\%) e associada à porção posterior em 124 casos (41,6\%). Todos pacientes apresentavam expansão progressiva. Deformidade foi a queixa de 135 (42,9\%) deles, 46 (14,6\%) tinham deformidade e dor, $21(9,5 \%)$ dor apenas, dois $(0,6 \%)$ mobilidade dental, cinco $(1,6 \%)$ ulceração e um $(0,3 \%)$ sangramento bucal. Todos pacientes com lesão maxilar tinham expansão acentuada das corticais vestibular e palatina. Na mandíbula, expansão isolada da cortical lingual ocorreu em dois casos $(0,6 \%)$ e da cortical vestibular em nove casos $(2,9 \%)$. Todos os outros apresentaram envolvimento de ambas corticais.

Reichart, Philipsen e Sonner (1995) realizaram uma extensa revisão dos casos relatados na literatura, envolvendo 3.677 pacientes. A idade média encontrada foi de 36 anos, porém ao se considerar os relatos de caso isoladamente, a maior freqüência está na $2^{\mathrm{a}}$ década de vida. Nos países em desenvolvimento, a lesão ocorreu em pacientes mais jovens (média de 27,7 anos) e 1,8\% tinham menos de 10 anos. A idade média na América do Sul foi de 13,2 anos, mas apenas 11 casos haviam sido relatados. Nos países desenvolvidos, a média de idade foi de 39,1 anos. Não houve predileção por sexo (53\% homens e $47 \%$ mulheres). As mulheres eram 4 anos mais jovens quando acometidas e os tumores parecem ser maiores nelas. Os principais sinais encontrados foram: expansão (701 casos), dor (187 casos), atraso na erupção (119 casos), ulceração (90 casos), mobilidade dental (68 casos) e deslocamento dental (57 casos). O tempo decorrido entre o início dos 
sintomas e o diagnóstico foi em média de 27 meses (6,5 meses a 40 anos) para os relatos de caso. Nos países em desenvolvimento, a média foi de 32,6 meses, e nos países desenvolvidos, 24,5 meses. A relação entre mandíbula e maxila foi de 5:1. As lesões mandibulares ocorreram 12 anos antes que as da maxila. A região de molares inferiores foi a mais afetada, com exceção dos negros, nos quais predominou a região anterior. A freqüência do ameloblastoma comparada a outros tumores odontogênicos variou de 11 a 92\%. Considerando apenas tumores dos maxilares, 13 a 54\% representavam ameloblastomas. Apenas 0,02 a 0,7\% das biópsias na região maxilo-facial eram ameloblastomas.

Poon, Wu e So (1996) relataram 50 casos de ameloblastoma na população chinesa. Em sua amostra, houve discreta predileção por homens (1,4: 1). A média de idade foi de 30,5 anos (3 a 73 anos); 42 (84\%) tumores ocorreram na mandíbula, sendo $32(76,1 \%)$ na região posterior, seis $(14,3 \%)$ na região anterior e dois $(4,8 \%)$ em ambas. Outros oito (16\%) casos envolveram a maxila.

Chidzonga (1996) avaliou a prevalência de ameloblastomas em crianças do Zimbábue. De 117 pacientes tratados em um período de 10 anos, 20 (17,1\%) tinham idade menor ou igual a 18 anos, tendo o mais jovem 11 anos. A amostra era representada por 10 pacientes de cada sexo com idade média de 15,5 anos. A mandíbula foi afetada em 19 casos (principalmente a sínfise e região de prémolares) e a maxila em um. As principais queixas foram a deformidade facial e a perda dental, sendo a dor uma ocorrência rara e associada à infecção. O tempo de queixa variou de 2 a 6 anos.

Curi, Dib e Pinto (1997) relataram 36 casos de ameloblastomas, sendo 18 em cada sexo, com idade média no diagnóstico de 31 anos (12 a 70). A mandíbula foi envolvida em $34(94,4 \%)$ casos, sendo $30(83,3 \%)$ na região posterior (pré-molar a 
côndilo) e quatro $(11,1 \%)$ na região anterior (canino a canino); outras duas lesões $(5,6 \%)$ afetaram a maxila.

Martins et al. (1999) revisaram 29 casos de ameloblastoma em um período de 17 anos. A mandíbula foi afetada em 27 casos e a maxila em dois. A idade variou da $2^{\mathrm{a}}$ a $7^{\mathrm{a}}$ década, com predominância para a $3^{\mathrm{a}}$, acometendo 15 homens e 14 mulheres.

Takahashi, Miyauchi e Sato (1998) publicaram 27 casos de ameloblastoma tratados em um período de 13 anos. Destes, seis (22\%) tinham menos que 16 anos, com média de 12,3 anos. Não houve diferença entre sexo e todos os casos acometeram a região posterior da mandíbula.

Sampson e Pogrel (1999) relataram 26 pacientes com ameloblastoma, cuja idade variou de 14 a 78 anos (média de 34,7) em 14 homens e 12 mulheres. O tamanho variou de 1 a $10 \mathrm{~cm}$, com média de $5 \mathrm{~cm}$. Todas as lesões eram mandibulares, sendo 12 na região de ângulo e ramo, 11 no corpo e seis na sínfise.

Farzard (2000) relatou oito casos de ameloblastoma tratados em um período de 27 anos. A média de idade foi de 49,5 anos (14 a 90 anos), afetando cinco homens e três mulheres. Quanto à localização, sete casos afetaram a mandíbula, sendo um na região anterior e seis na posterior; outro era uma lesão periférica de maxila. Todas as lesões intra-ósseas apresentavam expansão e um paciente referia dor.

Bataineh (2000) relatou 23 pacientes tratados em um período de 10 anos. Todas as lesões eram mandibulares, sendo $21(91,3 \%)$ na região posterior e duas (8,7\%) na região anterior. A idade variou de 11 a 65 anos (média de 27 anos), em 13 homens e 10 mulheres. O achado clínico mais comum foi a expansão. 
Kim e Jang (2001) relataram 71 pacientes tratados em um período de 10 anos, sendo 39 homens e 32 mulheres com idade entre 11 e 70 anos (média de 30 anos). Em 62 casos (87,3\%), o tumor localizava-se na mandíbula e em quatro $(5,6 \%)$ na maxila. Expansão foi o sinal mais comum, estando presente em 27 (38\%) pacientes.

Santos et al. (2001) encontraram 39 casos $(0,73 \%)$ de ameloblastoma em um arquivo de 5.289 lesões diagnosticadas na Universidade Federal do Rio Grande do Norte em um período de 30 anos. O tumor representou 30,7\% de 127 neoplasias odontogênicas. Foram envolvidas 22 mulheres e 17 homens, com predominância na $3^{\mathrm{a}}$ e $5^{\mathrm{a}}$ décadas de vida. A idade variou de 12 a 71 anos (média de 38,2 anos). Todas as lesões localizaram-se na mandíbula, sendo 35 casos de ASM, 3 AU e 1 AP.

Hatada et al. (2001) revisaram 190 casos de ameloblastomas tratados em um período de 29 anos. A relação entre sexo masculino e feminino foi de 1,6:1, com 117 homens $(61,6 \%)$ e 73 mulheres (38,4\%). A idade variou de 7 a 82 anos (média de 34,7). A faixa etária de 10 a 30 anos compreendeu 120 pacientes (63,2\%). A mandíbula foi envolvida em 176 casos (92,6\%) e a maxila em $14(7,4 \%)$.

Nakamura et al. (2002) avaliaram 78 casos de ameloblastomas tratados em um período de 35 anos. A idade variou de 9 a 72 anos, envolvendo 46 homens e 32 mulheres. A classificação clínico-patológica foi de 27 casos de ameloblastoma unicístico (AU) e 51 casos de ameloblastoma sólido ou multicístico (ASM).

Becelli et al. (2002) trataram 60 pacientes com ameloblastoma em um período de 22 anos, sendo 39 homens (65\%) e 21 mulheres (35\%). A idade média foi de 32 anos. Apenas 39 pacientes (65\%) apresentaram sintomas, sendo 23 (38,3\%) com expansão, oito $(13,3 \%)$ com hipoestesia, seis (10\%) com alteração de oclusão e dois $(3,3 \%)$ com anestesia do nervo alveolar inferior. Diagnóstico feito a partir de exame 
radiográfico de rotina ocorreu em 21 pacientes (35\%) assintomáticos. Todas as lesões acometeram a mandíbula, sendo cinco (8,3\%) na sínfise, 14 (23,3\%) no corpo e $41(68,3 \%)$ no ângulo e ramo. Em 18 pacientes (30\%), o aspecto clínicoradiográfico era de $\mathrm{AU}$ e em 42 pacientes (70\%) de ASM.

A incidência de ameloblastomas em uma população holandesa (Nizmegen) em um período de 21 anos foi de 0,7/1 milhão/ano (12 casos/720.000 pessoas) (CHAPELLE et al., 2004).

Adebiyi, Odukoya e Taiwo (2004) revisaram 197 tumores odontogênicos epiteliais na Nigéria em um período de 21 anos. O ameloblastoma foi o tipo histológico mais freqüente com 174 casos (83,3\%). Foi mais comum em homens que em mulheres na proporção de 1,5:1 (104/70). A idade média de ocorrência foi 31 anos (9 a 82) com pico na $3^{a}$ década de vida. A mandíbula foi afetada em $83,3 \%$ dos casos, com predomínio da região de pré-molares/molares em 75 casos (70,1\%).

A maxila é acometida em cerca de $20 \%$ dos casos. Na mandíbula ( $80 \%$ dos ameloblastomas), 70\% localizam-se na região molar e ramo, 20\% na região de prémolares e $10 \%$ na região anterior. São usualmente diagnosticados entre a $4^{a}$ e $5^{a}$ décadas de vida, exceto o $\mathrm{AU}$, cujo diagnóstico ocorre entre 20 e 30 anos. $\mathrm{O}$ ameloblastoma é praticamente assintomático, exceto pela ocorrência de abaulamento na maioria dos casos (TORRES-LAGARES et al., 2005). Estes autores relataram seis casos de ameloblastoma mandibular, afetando cinco mulheres e um homem, com média de idade de 42,3 anos (25 a 65).

Ghandhi et al. (2006) revisaram 22 casos de ameloblastoma atendidos em Glasgow (Escócia) e 28 casos em San Francisco (Califórnia) em um período de 20 anos. A idade dos pacientes variou de 13 a 74 anos (média de 41) e de 14 a 83 anos (média de 32) respectivamente. A relação homem/mulher foi de 8:14 e 15:13 e a 
relação mandíbula/maxila foi de 18:4 e 26:2 respectivamente. Nos casos de Glasgow, 16 lesões mandibulares ocorreram na região posterior e duas na região anterior. O achado principal em todos pacientes foi a expansão; dor foi relatada em 13 casos e parestesia em dois. Nos pacientes de San Francisco, oito lesões acometeram a região anterior da mandíbula e 18 a região posterior. Expansão ocorreu em todos os casos, dor em seis e parestesia em três.

Adebiyi et al. (2006) revisaram 77 casos de ameloblastomas na população nigeriana. A idade variou de 11 a 70 anos, com pico de incidência na $3^{a}$ década. Os homens foram mais afetados, com exceção dos que apresentavam ameloblastoma folicular. A mandíbula foi acometida em 72 casos, a maxila em dois e três casos era de tecido mole.

Vayvada et al. (2006) relataram 11 casos de ameloblastoma tratados em um período de 4 anos, afetando oito homens e três mulheres com média de idade de 25,4 anos (18 a 38). Todos apresentavam expansão na região afetada, quatro parestesia, um anestesia e três alteração oclusal e dor. O corpo mandibular foi afetado em cinco casos e o ângulo em seis casos.

Hong et al. (2007) publicaram uma casuística de 239 casos de ameloblastoma, sendo 139 em mulheres e 100 em homens, cuja idade variou de nove a 83 anos (34,5 anos). A mandíbula foi afetada em 210 casos e a maxila em 29.

\subsection{Aspectos radiográficos}

O diagnóstico do ameloblastoma não pode ser feito apenas pelo aspecto radiográfico. Há, entretanto, várias características radiográficas que permitem uma 
suspeita diagnóstica. A lesão pode apresentar-se como uma imagem radiolúcida unilocular, de limites bem definidos com ou sem esclerose marginal, freqüentemente associada a um dente incluso, assemelhando-se muito a um cisto odontogênico simples. Cerca de metade dos casos exibe um aspecto multilocular com septos internos e padrão em bolhas de sabão ou favos de mel. As loculações podem ser ovais ou arrendondadas com dimensões variáveis. São lesões caracteristicamente expansivas, podendo apresentar margens festonadas (bem definidas na maioria dos casos), perfurar cortical óssea e invadir tecidos moles adjacentes. Esclerose cortical irregular nas margens do tumor é um achado típico. Quando ocorre adjacente a dentes, perda de lâmina dura, reabsorção radicular e deslocamento dental são ocorrências comuns (SÁ et al., 2004; ZANE, 1991).

A incidência de reabsorção radicular é muito maior no ameloblastoma que nos cistos odontogênicos. A multilocularidade e reabsorção radicular são os sinais radiográficos mais comuns do ameloblastoma. O diagnóstico diferencial com lesões multiloculares engloba o querubismo, lesão central de células gigantes, mixoma, cisto ósseo aneurismático, queratocisto, entre outros (YOKOBAYASHI et al., 1983). A expansão de corticais ósseas é freqüente no ameloblastoma e incomum no queratocisto (CHAPELLE et al., 2004).

Numa casuística de 311 casos de ameloblastoma intra-ósseo avaliados por radiografias convencionais, Olaitan, Adeola e Adekeye (1993) encontraram 40 casos $(12,9 \%)$ com radiolucência multilocular em favos de mel, 30 casos $(9,2 \%)$ com radiolucência unilocular e 241 casos (77,5\%) com radiolucência em bolhas de sabão.

Em um extenso trabalho de revisão, Reichart, Phillipsen e Reichart (1995) encontraram que $50 \%$ das lesões tinham aspecto multilocular de limites bem definidos. 
Poon, Wu e So (1996) relataram que o grupo de lesões unicísticas (oito casos) foi mais freqüentemente associado à reabsorção radicular (51\%) e impacção dental $(37,5 \%)$ do que o grupo de aspecto radiográfico clássico (42 casos) com 7,1\% e $11,9 \%$, respectivamente.

Chidzonga (1996) encontrou aspecto multilocular em $80 \%$ e unilocular em $20 \%$ de 20 pacientes com idade menor ou igual a 18 anos. Kim e Jang (2001) relataram 71 casos, sendo $42(59,2 \%)$ uniloculares com bordas bem definidas e 14 $(19,7 \%)$ multiloculares. O padrão unilocular foi mais freqüente nos pacientes mais jovens. Takahashi, Miyauchi e Sato (1998) encontraram em seis pacientes com menos de 16 anos, quatro lesões uniloculares e duas multiloculares. Bataineh (2000) publicou 23 casos, sendo $16(69,6 \%)$ com aspecto radiográfico multilocular e sete $(30,4 \%)$ com aspecto unilocular. A borda posterior e inferior da mandíbula esteve intacta em todos os casos. Ghandhi et al. (2006), numa revisão de 22 casos tratados em Glasgow, encontraram oito lesões uniloculares e 14 multiloculares. De 28 casos tratados em San Francisco, sete eram uniloculares e 21 multiloculares.

Nakamura et al. (2002) constataram que as lesões multiloculares, especialmente com aspecto de bolhas de sabão, têm características mais invasivas do que as lesões uniloculares.

Sampson e Pogrel (1999) ressaltaram a importância do uso da tomografia computadorizada (TC) em todos os casos de ameloblastoma para adequado planejamento cirúrgico, exceto em lesões com menos de $1 \mathrm{~cm}$. As contribuições da TC também são ressaltadas por Ferretti, Polakow e Coleman (2000) na avaliação da extensão látero-medial do tumor e na visualização de locais anatômicos onde as radiografias planas são deficientes, como maxila e fossa infratemporal. Os aspectos do tumor na TC incluem áreas císticas hipoatenuantes associadas a áreas de maior 
atenuação, representando porções sólidas. Gümgüm e Hosgören (2005) acrescentaram que a aparência de septos na radiografia representa, normalmente, reabsorção diferencial da cortical pelo tumor e não separação real de porções da lesão. A TC é útil na determinação dos limites da lesão e sua extensão dentro do tecido mole. A ressonância magnética pode ser útil na visualização de projeções papilares dentro da cavidade cística e na avaliação da extensão de um ameloblastoma avançado de maxila.

O ameloblastoma pode simular radiograficamente uma lesão periapical, levando a tratamento inadequado (HOLLOWS; FASANMADE; HAYTER, 2000).

Nakamura et al. (2001) avaliaram a relação do ameloblastoma com o nervo alveolar inferior em 22 casos. Encontraram o canal mandibular intacto em dois casos, deslocado em 13 e reabsorvido em sete. Todos os tumores unicísticos mostraram deslocamento do canal. Ressaltaram a importância dos cortes coronais da TC na avaliação da relação entre o tumor e o nervo alveolar inferior.

Ogunzalu et al. (2006) propuseram uma nova classificação radiográfica baseada em 19 casos de ameloblastoma em jamaicanos com menos de 20 anos. Lesões uniloculares representaram $42 \%$ da amostra e 58\% eram multiloculares. Dentes não irrompidos e reabsorção radicular ocorreram em 32\% dos casos. Inferem que as lesões multiloculares, sem dentes inclusos e com margens não corticalizadas representam o padrão radiográfico mais agressivo.

Para Sachs (2006), a avaliação radiográfica permanece a mais simples e importante ferramenta no planejamento cirúrgico do ameloblastoma. A avaliação inclui radiografia panorâmica, periapical e oclusal para avaliar a relação da lesão com os dentes adjacentes, nervo alveolar inferior, seio maxilar e cavidade nasal. Deve-se dar ênfase à relação com as margens corticais medial, lateral, inferior e 
superior, identificando potenciais áreas de continuidade óssea estável. A TC refina a avaliação da relação do tumor com as estruturas adjacentes.

\subsection{Aspectos histopatológicos}

Vickers e Gorlin (1970) descreveram as alterações celulares de lesões císticas relacionadas ao diagnóstico de ameloblastoma:

$\Rightarrow$ Hipercromatismo nuclear das células basais do epitélio de revestimento do cisto.

$\Rightarrow$ Células basais em paliçada e polarização do núcleo para a extremidade distal da célula - polarização invertida.

$\Rightarrow$ Vacuolização do citoplasma das células basais.

Microscopicamente, o ameloblastoma é composto de ninhos, ilhas e cordões de epitélio ameloblástico, todos separados por quantidade relativamente pequena de estroma de tecido conjuntivo fibroso. Os dois padrões predominantes são o folicular e o plexiforme (ZANE, 1991). De acordo com Pinheiro, 2002, o padrão folicular consiste de ilhas de células tumorais imersas em estroma de tecido conjuntivo fibroso. Estas ilhas são semelhantes ao folículo dental normal, daí a origem do nome. Em um exame mais aproximado observamos na periferia das ilhas, células colunares com polarização reversa (núcleo polarizado voltado para o interior da ilha e o citoplasma para o estroma). As células da porção central da ilha são semelhantes ao retículo estrelado. É comum a formação de cistos ou microcistos neste tipo de ameloblastoma. No ameloblastoma plexiforme, o epitélio odontogênico 
é arranjado em longos cordões que parece envolver o estroma. Estes cordões também apresentam células com polarização reversa envolvendo células semelhantes ao retículo estrelado.

Os padrões histológicos incluem: folicular, plexiforme, célula granular, acantomatoso e basilar (GARDNER; PECAK, 1980).

Gardner (1996) comenta sobre as dificuldades de se estabelecer diagnóstico histológico precoce de ameloblastoma em várias situações. Os critérios de Vickers e Gorlin podem não estar presentes ou estar presentes apenas em algumas áreas da lesão. Outras áreas podem exibir apenas hipercromatismo das células basais. Ambas as situações representam provavelmente ameloblastomas que não exibiram características microscópicas clássicas do tumor.

Ilhas de epitélio hiperplásico podem estar presentes na parede de cisto radicular e dentígero, induzindo a um diagnóstico errôneo de ameloblastoma. A distinção entre epitélio hiperplásico e ameloblastoma unicístico plexiforme também pode ser difícil. Sempre que possível, deve-se buscar outras áreas de ameloblastoma típico, porém isto é raro. O tecido conjuntivo delicado e vascular do AU plexiforme é um sinal útil e mais típico. O epitélio hiperplásico ocorre somente em cisto dentígero inflamado, enquanto o ameloblastoma geralmente não é inflamado. É comum no cisto radicular, mas o ameloblastoma é normalmente diferente clinicamente deste. Apesar disto, a distinção precoce entre ameloblastoma e epitélio não neoplásico ainda é um desafio.

Yokobayashi et al. (1983) relataram dois casos em que a biópsia incisional foi inconclusiva para o diagnóstico de ameloblastoma. Ressaltam que em muitos casos de lesões císticas, a pressão intracística causa achatamento das células tumorais, assemelhando-as a um epitélio escamoso, indistingüível do epitélio de um cisto 
odontogênico. Adebiyi et al. (2006) também afirmaram que a avaliação histológica baseada em biópsia incisional é inadequada.

Para Crawley e Levin (1978) o comportamento microscópico do ameloblastoma sugere que ele seja tratado conservadoramente.

O ameloblastoma exibe uma variedade de padrões histológicos, que é importante apenas para que seja reconhecido como ameloblastoma. Estas variações não têm valor em determinar o comportamento clínico ou biológico, o grau de invasividade de casos individuais ou prever os casos extremamente raros de metástase (GARDNER, 1996; GARDNER; PECAK, 1980; KRAMER, 1963).

Bianchi et al. (1998), em sua revisão e relato de caso relacionado à recidiva de ameloblastoma em enxerto ósseo autógeno, após ressecção segmentar, afirma que o tipo microscópico inicial não parece influenciar no desenvolvimento de recidiva.

Martins et al. (1999) apresentaram 29 casos de ameloblastoma, cuja escolha terapêutica foi baseada na classificação do tipo histológico ou estabelecendo a relação entre comportamento clínico e padrão histopatológico de acordo com a idade e localização da lesão. Ameloblastoma folicular somou 11 casos, plexiforme cinco e unicístico três. Ferretti, Polakow e Coleman (2000) afirmaram haver consenso de que a variante histológica não deve modificar o tratamento.

Sauk (1985) avaliou o padrão de marcação de componentes da membrana basal (colágeno tipo IV e laminina) de cinco ameloblastomas, sendo dois plexiformes, dois foliculares e um acantomatoso. O padrão de marcação foi o mesmo para todos os casos. Demonstraram que o ameloblastoma mantinha a integridade das estruturas da membrana basal durante sua proliferação. Isto sugere que esta neoplasia não invade os tecidos por degradação das barreiras 
compartimentais da membrana basal, mas expande provavelmente pelo aumento do seu volume compartimental. Em contrapartida, o único caso de ameloblastoma maligno estudado não preservava os limites da membrana basal.

Para Maia Campos (1990), o aspecto folicular observado em muitas das ilhas celulares do tumor representa apenas uma tentativa frustra do tecido neoplásico formar um dente. Explica que o tumor não produz tecido calcificado porque a diferenciação das células conjuntivas em odontoblastos não ocorre e, conseqüentemente, matriz de dentina não é formada ou calcificada. As células semelhantes a ameloblastos na periferia das ilhas tumorais não formam matriz de esmalte, provavelmente pela ausência de um estrato intermediário adjacente a elas. O estrato intermediário não está presente pela falta do epitélio externo nas ilhas neoplásicas.

Muller e Slootweg (1985) descreveram as características histológicas de crescimento do ameloblastoma e a reação do tecido adjacente em 31 espécimes cirúrgicos. Apresentaram quatro conclusões principais:

$\Rightarrow$ Infiltração de osso medular é vista freqüentemente.

$\Rightarrow$ Há pouca tendência de infiltração de osso cortical.

$\Rightarrow$ O periósteo geralmente forma uma barreira contra o crescimento do tumor.

$\Rightarrow$ Nenhuma cápsula pode ser vista onde o tumor está contíguo à mucosa bucal.

No artigo de revisão de Reichart, Phillipsen e Sonner (1995), 1/3 dos casos eram do tipo plexiforme $(30,2 \%), 1 / 3$ folicular $(33,9 \%), 11,3 \%$ acantomatoso, ocorrendo em pacientes mais velhos, 2\% desmoplásico e 15,5\% misto. Houve diferença na taxa de recidiva entre o padrão folicular $(29,5 \%)$, o plexiforme $(16,7 \%)$, o misto $(14,3 \%)$, o acantomatoso $(4,5 \%)$ e o unicístico $(13,7 \%)$. 
Poon, Wu e So (1996), em seus 48 casos relatados de ASM, $15(35,7 \%)$ eram plexiforme, $12(28,6 \%)$ folicular, $13(31 \%)$ misto e dois $(4,7 \%)$ desmoplásico. Dos oito $\mathrm{AU}$, quatro (50\%) tinham padrão plexiforme, três $(37,5 \%)$ folicular e um $(12,5 \%)$ misto. Os tipos plexiforme e folicular foram encontrados em iguais proporções nas lesões expansivas e infiltrativas. Houve quatro recidivas, sendo três no padrão folicular e uma no misto.

Bataineh (2000) relatou 23 casos, sendo 14 (60,9\%) predominantemente císticos e nove $(39,1 \%)$ sólidos com pequenas áreas císticas. O tipo folicular ocorreu em sete pacientes $(30,4 \%)$, o plexiforme em $11(47,8 \%)$ e o misto em cinco $(21,7 \%)$.

De 71 casos relatados por Kim e Jang (2001), 25 (35,2\%) tinham padrão plexiforme e 21 (29,6\%) padrão folicular. De 15 recidivas, seis (40\%) eram de tumores com padrão plexiforme, quatro padrão folicular misto, um plexiforme/folicular e três folicular/acantomatoso. O padrão plexiforme foi mais freqüente em pacientes mais jovens ( $2^{\mathrm{a}}$ década).

Santos et al. (2001) revisaram 39 casos de ameloblastoma, sendo 8 do tipo folicular, 10 plexiforme, 12 folicular/plexiforme, 2 variantes de células basais, 1 acantomatoso e 1 de células granulares.

Em seis pacientes portadores de ameloblastoma com menos de 16 anos relatados por Takahashi, Miyauchi e Sato (1998), quatro tinham padrão plexiforme, um folicular e um misto.

Nakamura et al. (2001) estudaram a relação de 22 ameloblastomas com o nervo alveolar inferior. Destes, nove eram do padrão plexiforme, sete folicular e seis unicísticos. Todos os tumores multicísticos radiograficamente mostraram padrão folicular; o padrão plexiforme predominou nas lesões sólidas e foi menos invasivo em relação ao nervo. Nos AU que mostravam deslocamento do nervo inferiormente, 
o osso esponjoso da região alveolar foi freqüentemente invadido por pequenos ninhos de tumor folicular.

Nakamura et al. (2002) relataram 78 casos de ameloblastoma. Destes, 19 tinham padrão folicular, 23 plexiforme, 9 misto, 24 unicístico e três desmoplásico. Recidiva ocorreu em 15 casos, dos quais 26,3\% tinham padrão folicular, 21,7\% padrão plexiforme, $33,3 \%$ padrão misto, $8,3 \%$ unicístico e nenhum padrão desmoplásico.

Adebiyi, Odukoya e Taiwo (2004) descreveram 174 casos de ameloblastoma na população nigeriana, na qual o padrão folicular foi o subtipo histológico mais comum (109 casos $-62,6 \%$ ), seguido pelo plexiforme (39 casos $-22,4 \%$ ), misto (26 casos - 14,9\%), células granulares (nove casos - 5,2\%) e células basais (três casos $-1,7 \%)$.

Artés-Martinez et al. (2005) relataram dois casos de ameloblastomas, cujas recidivas foram diagnosticadas por punção aspirativa por agulha fina. A coloração citológica revelou um fundo granular com macrófagos, células gigantes multinucleadas isoladas e uma celularidade epitelial abundante de aparência basalóide arranjadas em grupos coesivos, formando imagem de células periféricas em paliçada.

\subsection{Ameloblastoma unicístico (AU)}

Esta variante foi primeiramente citada por Robson e Martinez (1977) como sendo uma entidade distinta de outras lesões com aspecto cístico. Gardner e Pecak 
(1980) definiram o AU como uma lesão cística que apresenta uma ou mais das seguintes situações:

$\Rightarrow$ Epitélio de revestimento ameloblastomatoso;

$\Rightarrow$ Um ou mais nódulos de projeção ameloblástica no lúmen cístico;

$\Rightarrow$ Epitélio ameloblastomatoso de revestimento proliferado no tecido conjuntivo da parede do cisto;

$\Rightarrow$ Ilhas de ameloblastoma no tecido conjuntivo da parede do cisto.

Ackerman, Altini e Shear (1988) renomearam os subtipos do AU como Grupo $1,2,3 \mathrm{~A}$ e $3 \mathrm{~B}$.

O AU normalmente se assemelha clínica e radiograficamente a um cisto dentígero, embora alguns não estejam associados a dentes inclusos. Ocorre tipicamente em pessoas mais jovens, principalmente na $2^{\mathrm{a}}$ e $3^{\mathrm{a}}$ décadas de vida, com grande predileção pela região posterior da mandíbula. O diagnóstico se baseia no aspecto unilocular clínica e radiograficamente e no exame microscópico, que deve mostrar uma lesão cística única com revestimento epitelial consistindo de ameloblastoma (GARDNER, 1996; GARDNER; PECAK, 1980).

Histologicamente, o AU é essencialmente uma lesão monocística, que mostra uma ampla cavidade cística com um revestimento composto focalmente, ou raramente, inteiramente de células ameloblásticas. Além disso, pode apresentar um ou mais nódulos projetando-se no lúmen da cavidade cística, representado por epitélio odontogênico com um padrão plexiforme. Alguns AU podem conter um ou mais nódulos murais ou espessamento focal da parede cística (PHILIPSEN; REICHARD, 1998).

Há uma tendência em se considerar que toda lesão unilocular com diagnóstico de ameloblastoma é um AU. Esta avaliação é inadequada, pois muitos 
são ameloblastomas intra-ósseos clássicos. O diagnóstico de AU só pode ser emitido com a análise histopatológica de toda a peça, quando também se verifica se há infiltração da cápsula por ameloblastoma. A lesão deve ser removida preferencialmente intacta. A biópsia incisional pode apenas sugerir o diagnóstico de AU, associando-se a idade e características radiográficas da lesão (GARDNER, 1996).

Há indicação de que o $\mathrm{AU}$ apresenta um comportamento clínico menos agressivo, com menor tendência a recidiva e melhor prognóstico quando comparado ao ASM (CURI; DIB; PINTO, 1997; GARDNER, 1984; NAKAMURA et al., 1995; POON; WU; SO, 1996; ROBINSON; MARTINEZ, 1977). Exceção feita ao AU com invasão da cápsula, que pode ser tratado como um ASM (REICHART; PHILIPSEN; SONNER, 1995). A taxa de recidiva do AU tratado por curetagem é de $15 \%$ (GARDNER, 1984).

O diagnóstico pós-operatório de um AU luminal ou intraluminal não leva a necessidade de nenhum tratamento adicional. Entretanto, se a cápsula estiver invadida por tumor, é indicada ressecção (GARDNER; PECAK, 1980). Ferretti, Polakow e Coleman (2000) consideram que para evitar a necessidade de tratamentos complementares, todo AU deveria ser tratado como se apresentasse invasão capsular, através de enucleação e terapia adjuvante.

Robinson e Martinez (1977) relataram 20 pacientes com AU, cuja idade variou de 10 a 29 anos. Tratamento por enucleação foi realizado em 17 casos, havendo três recidivas.

Nakamura et al. (1995) apresentaram 24 casos de ameloblastomas císticos, sendo 15 em homens e nove em mulheres. A idade variou de 11 a 63 anos, com média de 27 anos. Todos acometeram a mandíbula, principalmente a região molar e 
ramo com 16 casos. Radiograficamente, 15 casos eram uniloculares e nove multiloculares.

Na casuística de Reichart, Philipsen e Sonner (1995), o AU representou 6\% da amostra e a idade média dos pacientes foi de 22 anos. A taxa de recidiva foi de $13,7 \%$, menor que nos ameloblastomas não unicísticos, cuja taxa foi de $22,7 \%$. O padrão plexiforme foi descrito em $15,7 \%$ dos casos, o folicular em $8,8 \%$, o misto em $5,9 \%$ e o acantomatoso em $2 \%$.

De 50 casos de ameloblastoma tratados por Poon, Wu e So (1996) em um período de 12 anos, oito (16\%) eram AU. A taxa homem mulher foi igual e a idade média foi de 22 anos (13 a 37). A região posterior da mandíbula foi acometida em sete casos e posterior da maxila em um. Todos os casos mostraram invasão da cápsula cística por ilhas e folículos de ameloblastoma. Isto sugere que a simples curetagem desta variante pode ser inadequada, no mínimo em uma significante porcentagem dos casos, levando a um alto risco de recidiva, semelhante ao ASM.

Sampson e Pogrel (1999) relataram quatro recidivas em quatro AU tratados por curetagem.

Na casuística de Kim e Jang (2001), o AU representou 8,5\% da amostra (6 de 71).

Rosenstein et al. (2001) publicaram 21 casos de AU, cuja idade dos pacientes variou de 12 a 72 anos (média de 35), envolvendo 10 homens e 11 mulheres. A região posterior da mandíbula foi acometida em 18 casos, a região anterior em dois e o corpo em um. Reabsorção radicular ocorreu em seis lesões (29\%), outras seis (29\%) tinham aspecto multilocular. Dor foi a queixa de três pacientes (14\%). Recidiva foi observada em nove casos (43\%) em um período de 9 meses a 10 anos. Todos estes haviam sido tratados por enucleação e curetagem. Devido a alta taxa 
de recidiva apresentada neste estudo, os autores sugerem um tratamento mais invasivo através de ressecção em bloco ou curetagem associada à crioterapia ou solução de Carnoy.

Al-Khateeb e Ababneh (2003) relataram 10 casos de ameloblastoma em pacientes com menos de 21 anos. Destes, seis foram AU acometendo a região posterior da mandíbula. Um dos casos apresentava imagem radiográfica multilocular. Todos receberam tratamento conservador por enucleação e ostectomia periférica. Não houve recidiva em um acompanhamento médio de 7,6 anos e os resultados estéticos e funcionais foram considerados excelentes.

Torres-Lagares et al. (2005) também apresentaram três casos de AU, dos quais dois tinham aspecto radiográfico multilocular.

Adebiyi, Odukoya e Taiwo (2004) relataram 174 casos de ameloblastoma, sendo que $13(7,5 \%)$ eram AU. Destes, três apresentavam proliferação mural e luminal e 10 apenas proliferação mural.

Ghandhi et al. (2006) identificou uma alta taxa de recidiva relacionada ao tratamento conservador de AU em duas populações. Em Glasgow, três recidivas em quatro casos e, em San Francisco, duas recidivas em quatro casos. Baseado nisto, sugerem tratamento radical desta variante.

Lau e Samman (2006) fizeram uma revisão sistemática dos métodos de tratamento associados com taxa de recidiva para o AU. Foram identificadas quatro modalidades de tratamento. A taxa de recidiva foi de 3,6\% para ressecção, 30,5\% para enucleação, 16\% para enucleação e aplicação de solução de Carnoy e $18 \%$ para marsupialização seguida ou não de outro tratamento. 


\subsection{Ameloblastoma periférico (AP)}

É definido como um tumor odontogênico com características histológicas de um ameloblastoma intra-ósseo, mas ocorrendo apenas na gengiva e mucosa alveolar. Apresenta-se como uma lesão nodular pediculada ou séssil, não ulcerada e indolor, medindo, normalmente, menos que $2 \mathrm{~cm}$. Não exibe comportamento agressivo ou destrutivo e não invade osso subjacente (GARDNER, 1996; GARDNER; PECAK, 1980; NEVILLE et al., 2004; ZANE, 1991). Algumas vezes, o osso subjacente pode apresentar reabsorção por pressão com depressão em forma de pires (GARDNER; PECAK, 1980).

Na revisão de 3.677 casos de ameloblastoma feita por Reichart, Phillipsen e Sonner (1995), o ameloblastoma periférico representou $2 \%$ dos casos. A média de idade dos pacientes afetados foi de 51 anos. A relação mandíbula/maxila foi de 5:1, envolvendo a região de incisivos/pré-molares em $64,8 \%$ dos casos e a região molar/ramo em 35,2\%. A variante histológica mais freqüente foi a mista $(44,4 \%)$ e acantomatoso $(16,7 \%)$.

As lesões requerem excisão com mínima margem e raramente recorrem. O bom prognóstico deve-se pela lesão ser visível no início do aparecimento, sendo tratada precocemente e pelo fato da cortical óssea servir como barreira contra a invasão do tumor (GARDNER; PECAK, 1980; ZANE, 1991). 


\subsection{Ameloblastoma desmoplásico (AD)}

Esta variante foi descrita inicialmente por Eversole, Leider e Hansen (1984), caracterizando-se por uma profunda colagenização do estroma, que se encontra permeado por pequenas ilhas e cordões e epitélio tumoral odontogênico. Por apresentar características clínicas e radiográficas próprias, o ameloblastoma desmoplásico foi recentemente, reclassificado pela OMS (PHILIPSEN; REICHART, 1998).

Acomete predominantemente a região anterior dos maxilares. Apresenta aspecto radiográfico de uma lesão mista, de limites pobremente definidos, mais típico de lesão fibro-óssea benigna do que de ameloblastoma. Não parece exibir comportamento clínico diferente do ameloblastoma típico (GARDNER 1996; KAWAI et al., 1999). Nakamura et al. (2002) descreveram uma baixa tendência de recidiva para esta variante. Os três casos de sua série (n: 78) tratados com terapia conservadora não recidivaram.

Waldron e el Mofty (1987) descreveram o aspecto histológico como pequenas ilhas ovóides e cordões de epitélio odontogênico amplamente separados por tecido conjuntivo fibroso denso moderadamente celularizado. Células colunares com polaridade reversa estão presentes nas ilhas epiteliais, mas não representam a característica dominante. Trabéculas ósseas lamelares maduras são encontradas em íntimo contato com o tumor, indicando potencial invasivo e justificando a imagem radiográfica difusa. A lesão pode exibir um comportamento mais agressivo que outros subtipos, sendo quase impossível localizar o limite exato entre a lesão e o osso normal, o que torna o tratamento cirúrgico especialmente difícil. 
Apesar das diferenças quanto à distribuição anatômica, aparência histológica e aspecto radiográfico do ameloblastoma desmoplásico, a idade e a distribuição por gênero não diferem dos outros subtipos (MINTZ; VELES, 2002).

\subsection{Relação entre ameloblastoma e estruturas anatômicas adjacentes}

\subsubsection{Ameloblastoma e tecido ósseo}

Uma das mais importantes características do ameloblastoma relacionada ao seu tratamento é a capacidade do tumor invadir os espaços intertrabeculares do osso esponjoso, mas não o osso compacto, embora possa erodi-lo. Desta forma, as bordas posterior e inferior da mandíbula são consideradas margens verdadeiras, não necessitando ser removidas, pois agem como barreira contra a disseminação do tumor. Apesar disto, grandes lesões podem rompê-las, invadir periósteo e tecido mole (GARDNER, 1996; GARDNER; PECAK, 1980; KRAMER, 1963). A infiltração do osso medular não é acompanhada por alteração radiográfica, portanto, o tumor se estende além dos limites radiográficos (GARDNER, 1996; KRAMER 1963).

Crawley e Levin (1978) indicaram ainda a preservação das corticais lateral e medial, removendo apenas o necessário para o acesso cirúrgico. Gardner e Pecak (1980) consideraram que este procedimento poderia complicar a cirurgia indevidamente, sem trazer vantagem real para o paciente. 
A verdadeira extensão de células neoplásicas em direção ao osso esponjoso é desconhecida. Marx et al. (1993) encontraram infiltração de 2,3 a 8 mm além da aparência radiográfica. Barbachan ${ }^{1}$ (1999, apud GOMES et al., 2002) demonstrou extensão variando de 1 a $14 \mathrm{~mm}$ em osso medular. Carlson $2000^{2}$ (apud, CARLSON; MARX, 2006) revisou 82 peças cirúrgicas de ameloblastomas ressecados, mostrando que os tumores se estendem de 2 a $8 \mathrm{~mm}$ (média de 4,5 $\mathrm{mm}$ ) histologicamente além da demarcação radiográfica.

Sauk (1985) demonstrou que a expansão do tumor nos espaços teciduais se dá por aumento do volume compartimental.

Muller e Slootweg (1985) analisaram histologicamente a característica de crescimento do ameloblastoma no tecido adjacente em 31 peças cirúrgicas. Também demonstraram que a infiltração em osso esponjoso é vista freqüentemente, havendo pouca tendência de invasão do osso cortical. O periósteo também age como barreira contra o crescimento tumoral.

De 50 casos tratados por Poon, Wu e So (1996), 26 (52\%) mostravam infitração óssea intertrabecular no osso esponjoso adjacente e invasão subperiostal ou da mucosa. Dos pacientes com AU (oito casos), dois mostravam erosão do osso alveolar e invasão mucosa. Infiltração intertrabecular não foi identificada neste grupo.

Gortzak et al. (2006) trataram cinco pacientes com extensos ameloblastomas mandibulares por cirurgia radical e analisaram os espécimes cirúrgicos. Demonstraram padrão invasivo no osso esponjoso, com ilhas neoplásicas estendendo-se até $5 \mathrm{~mm}$ da margem do tumor. Crescimento expansivo e invasivo

\footnotetext{
${ }^{1}$ Barbachan JJD, et al. Estudo comparativo entre os limites radiográfico e histológico em ameloblastomas. Rev Fac Odontol Porto Alegre 1999;40(1):49-54.

${ }^{2}$ Carlson ER. Ameloblastoma. In: Symposium on Odontogenic tumors, AAOMS $82^{\text {nd }}$ Annual Meeting and Scientific Sessions, San Franscisco, CA, September 23; 2000.
} 
nos canais harvesianos também foi observado. O periósteo foi invadido, mas não perfurado, representando uma barreira efetiva contra a disseminação do tumor.

\subsubsection{Ameloblastoma e nervo alveolar inferior}

Nakamura et al. (2001) avaliaram as características de crescimento de ameloblastomas envolvendo o nervo alveolar inferior através de estudo clínico e histopatológico de 22 mandíbulas ressecadas. Em 11 casos havia osso entre o tumor e o nervo e em sete casos tecido conjuntivo separando-os. Infiltração ao redor do nervo foi observada em quatro lesões com padrão folicular. Ilhas epiteliais foram identificadas no tecido conjuntivo perineural, mas a bainha neural ou o nervo não foram infiltrados.

Bataineh (2000) afirmou que se o nervo alveolar inferior estiver em contato com a lesão, o mesmo deve ser removido. Porém, em todos os casos tratados pelos autores, o nervo foi preservado.

Al-Khateeb e Ababneh (2003) ressecaram o nervo alveolar inferior em dois tumores de aspecto multilocular, que o envolviam. O nervo foi preservado nas lesões uniloculares (seis casos) em que o mesmo estava deslocado inferiormente.

Para Sachs (2006), parece não haver evidências de que o ameloblastoma se dissemine por infiltração perineural ou penetre dentro do nervo que atravessa a lesão. Quando o nervo é deslocado para a margem do tumor, ele deve ser removido do canal e examinado sob visão direta com magnificação. Quando ele atravessa o tumor, geralmente é ressecado. 
Gortzak et al. (2006) verificaram que em cinco peças cirúrgicas estudadas, o nervo alveolar inferior foi claramente demarcado do tumor, não havendo nenhuma infiltração tumoral.

\subsection{Tratamento}

\subsubsection{Terminologia}

Crawley e Levin (1978) comentaram que os métodos de tratamento raramente são definidos. Dificilmente consegue-se distinguir excisão, enucleação e curetagem; ressecção em bloco e mandibulectomia segmentar, sendo difícil julgar a efetividade do tratamento.

Gardner e Pecak (1980) reforçaram a imprecisão dos termos radical e conservador, a necessidade de uma terminologia precisa para descrição e extensão dos procedimentos, a fim de se permitir comparação. Outros exemplos de imprecisão são o uso de curetagem e enucleação como sinônimos, o termo não qualificado "excisão" e a falha em quantificar o osso aparentemente sadio removido nas ressecções parciais.

Os procedimentos podem ser assim definidos (GARDNER; PECAK, 1980; GOMES et al., 2002):

$\Rightarrow$ Enucleação: É a remoção de toda lesão sem fragmentação da cápsula e sem sacrifício das estruturas adjacentes. 
$\Rightarrow$ Curetagem: É a raspagem cirúrgica da parede da cavidade em tecido duro ou mole para remover seu conteúdo, preservando a continuidade óssea.

$\Rightarrow$ Descompressão / Marsupialização: Consiste na abertura de uma janela cirúrgica na parede do cisto, permitindo a drenagem do conteúdo da cavidade.

$\Rightarrow$ Ressecção Marginal (Mandibulectomia Marginal): É a remoção cirúrgica do tumor intacto com uma margem de segurança de osso sadio, porém sem perda de continuidade óssea.

$\Rightarrow$ Ressecção Segmentar da maxila ou mandíbula: É a remoção cirúrgica de um segmento da mandíbula ou maxila, havendo perda da continuidade óssea.

$\Rightarrow$ Hemissecção (Hemimandibulectomia, Hemimaxilectomia): É a remoção cirúrgica de um dos lados da maxila ou mandíbula.

Reichart, Phillipsen e Sonner (1995) comentaram sobre a dificuldade encontrada quanto a interpretação de termos radiográficos e histopatológicos em seu trabalho de revisão. O termo radiográfico unilocular foi freqüentemente confundido com o termo histopatológico unicístico. Como lesões multiloculares, podem ser histologicamente AU, a padronização dos termos é fundamental.

Salmassy e Pogrel (1995) sugeriram o abandono do termo enucleação em favor de curetagem. Alega a improbabilidade de se remover uma lesão intra-óssea sem violar sua integridade.

Para Farzard (2000), o tratamento conservador inclui a enucleação e a curetagem, enquanto o tratamento radical engloba a ressecção com ou sem a preservação da continuidade mandibular ou a maxilectomia parcial ou total. 


\subsubsection{Considerações}

O tratamento do ameloblastoma é um assunto controverso, explicado, em parte, por se tratar de um tumor relativamente raro, com poucos estudos terapêuticos de longo prazo e falha na definição do subtipo do tumor. Lesões uniloculares são, por vezes, tratadas sem diagnóstico prévio e o posterior tratamento adequado é adiado (GARDNER; PECAK, 1980; SAMPSON; POGREL, 1999). Os fatores que devem ser considerados na seleção do tratamento do ameloblastoma incluem o seu tipo clínico (ASM, AU, AP), localização, tamanho, idade do paciente e disponibilidade de acompanhamento (TORRES-LAGARES et al., 2005). Para Gardner e Pecak (1980), a curetagem deve ser evitada pelo seu alto índice de recidiva, ficando reservada para lesões pequenas, onde haja possibilidade de ressecção em caso de recidiva e em casos selecionados de pacientes idosos. O afilamento da cortical inferior da mandíbula ou o envolvimento do tecido mole adjacente indicam uma ressecção segmentar.

Para Olaitan, Adeola e Adekeye (1993), tratamento inicial conservador poderia ser indicado para pequenas lesões no corpo da mandíbula, sem envolvimento da borda inferior. Lesões no ramo, independentes do tamanho, deveriam ser ressecadas, pois recidivas não detectadas invariavelmente estendemse para estruturas paracranianas. Gardner (1996) estendeu a indicação da possibilidade de tratamento conservador para lesões de sínfise e região anterior de maxila, desde que se saiba da possibilidade de realização de várias intervenções para preservar estética e função e seja possível acompanhamento mínimo de 10 anos. 
Yokobaiashi et al. (1983) sugeriram que o ameloblastoma tem sido tratado radicalmente, por ampla ressecção, devido a um tratamento inicial inadequado, que leva freqüentemente à recorrência de uma lesão agressiva.

Muller e Slootweg (1985), baseados no comportamento do ameloblastoma em relação aos tecidos adjacentes, inferiram que no tratamento deste tumor, o osso esponjoso deve ser removido a uma distância de $1 \mathrm{~cm}$ das margens da lesão, o osso cortical deve ser ressecado economicamente e a mucosa de cobertura do processo alveolar em contato com o osso perfurado deve ser incluída na ressecção. Tanaka et al. (1999) ressaltaram que a preservação do periósteo é essencial para a regeneração óssea e deve ser priorizada quando não houver envolvimento do mesmo pelo tumor. Ferretti, Polakow e Coleman (2000) reforçaram que nos locais onde haja ruptura da cortical, a dissecção deve ser feita em plano supraperiostal. Entretanto, uma vez que o tumor tenha se disseminado para o tecido mole ou em locais anatômicos de difícil acesso (fossa infratemporal), erradicação completa é extremamente difícil. Esta é uma ocorrência rara.

Zane (1991) afirmou ser importante a distinção entre lesões uni e multiloculares, visto que aquelas têm crescimento mais lento e menos infiltrativo, podendo ser tratadas de forma mais conservadora.

O tratamento usualmente recomendado para o ameloblastoma é a ampla ressecção. Entretanto, cirurgia radical está associada com várias complicações, incluindo perda de dentes, alteração mastigatória e de movimentação mandibular, ainda após reconstrução adequada e deformidade facial, quando o paciente esteja em período de desenvolvimento (NAKAMURA et al., 1995). O ameloblastoma multicístico deve ser tratado de forma radical, mas há a possibilidade de danos estéticos e funcionais permanentes (FARZARD, 2000). 
Pela revisão de Reichart, Philipsen e Sonner (1995), os ameloblastomas mandibulares deveriam ser tratados radicalmente, exceção feita às lesões uniloculares, desde que todas as áreas do lúmen cístico sejam controladas intraoperatoriamente. No início do período revisado (década de 60), muitos casos foram tratados de forma conservadora, com diagnóstico inadequado de cisto e pela limitação das técnicas reconstrutivas da época. Com as altas taxas de recidiva observadas, a tendência para cirurgia radical prevaleceu. A idade é outro fator que influencia a escolha do tratamento. Pacientes com idade avançada não deveriam sofrer cirurgia radical, buscando relacionar expectativa de vida e tempo para o desenvolvimento de recidiva. Crianças com menos de 10 anos também não deveriam receber cirurgia radical.

Martins et al. (1999) recomendaram uma margem de segurança variando de 1,5 a $3 \mathrm{~cm}$ para os ameloblastomas do tipo folicular e plexiforme.

Farzard (2000) alertou que a efetividade do procedimento cirúrgico depende da acessibilidade ao tumor, da habilidade do operador e da completa remoção da doença.

Chapelle et al. (2004) sugeriram uma abordagem padronizada para as lesões císticas uniloculares dos maxilares. Lesões localizadas na maxila ou corpo da mandíbula devem ser enucleadas. Se o diagnóstico histológico for de queratocisto ou $A U$ grau 1 e 2, manter acompanhamento. Se for AU grau 3 ou ASM, realizar ressecção marginal ou segmentar e acompanhar. Nas lesões localizadas na região retromolar e ramo, indicam a enucleação com remoção da mucosa de cobertura e aplicação da solução de Carnoy ou crioterapia. Se o diagnóstico for de AU grau 3 ou ASM, deve-se ressecar. Nas lesões multiloculares com expansão, deve-se realizar 
biópsia, e quando não houver expansão, aspiração. Se não for conclusiva para queratocisto, indica-se biópsia.

Carlson e Marx (2006) recomendaram um protocolo de tratamento radical baseado nas barreiras anatômicas do tumor. Durante a ressecção, no mínimo uma barreira não envolvida deve ser mantida no espécime tumoral. A margem óssea linear deve ser de 1 a 1,5 cm de osso saudável. Para Gortzak et al. (2006), se o tumor estiver a menos de $1 \mathrm{~cm}$ da borda inferior da mandíbula, mandibulectomia segmentar é mandatória, mas o tecido mole perimandibular pode ser preservado.

Sachs (2006) comentou sobre as vantagens do tratamento do ameloblastoma através da excisão cirúrgica com ostectomia periférica, que permite excisão definitiva da lesão sem comprometer arbitrariamente as corticais não envolvidas, que podem promover estabilidade da mandíbula ou preservar a integridade maxilar.

A técnica preconiza a realização de um amplo acesso intrabucal, com dissecção supraperiostal onde houver ruptura da cortical óssea e remoção dos dentes em contato com a lesão. Acesso e visualização direta ao tumor é obtida através de uma ostectomia em direção látero-superior. A lesão é removida, na maioria das vezes, em uma peça única e todo leito ósseo deve ser cuidadosamente inspecionado. Após a remoção de todo tumor macroscópico, inicia-se a ostectomia periférica com broca esférica em uma profundidade de 2 a $3 \mathrm{~mm}$ de margem visível. A loja deve ser inspecionada ordenadamente e fotografada para auxiliar na interpretação do controle clínico e radiográfico pós-operatório. As principais indicações são para lesões de sínfise e corpo, onde é possível visibilidade e acesso direto ao tumor e presença de osso cortical contínuo não envolvido. 


\subsubsection{Crioterapia}

É uma modalidade terapêutica alternativa para o ameloblastoma e outras lesões ósseas odontogênicas localmente invasivas. O objetivo da crioterapia é eliminar a lesão óssea invasiva sem envolver, necessariamente, os problemas da cirurgia radical anatômica convencional. O congelamento extremo permite o tratamento do osso in situ por desvitalização e manutenção da matriz inorgânica, que serve como perfeito enxerto autógeno (BRADLEY, 1978; CURI; DIB; PINTO, 1997).

Há quatro métodos básicos para o uso da crioterapia na região maxilofacial: sonda, sonda e gel, serpentina com nitrogênio líquido e spray com nitrogênio líquido. O spray é um método de congelamento rápido e potente, que atinge temperatura de $-198^{\circ} \mathrm{C}$ em poucos minutos. Pode ser usado para tratar cavidades grandes e irregulares (BRADLEY; FISHER, 1975).

Wittaker (1984) propôs um mecanismo de necrose tecidual após a crioterapia, que é uma combinação da formação de cristais de gelo nos meios intra e extracelular, levando a uma lesão direta na célula, bem como um distúrbio osmótico e eletrolítico através da membrana celular.

Os efeitos da crioterapia no osso são divididos em três fases que se sobrepõe: fase necrótica, osteogênica e de remodelação. A fase inicial começa poucos dias após o tratamento e resulta em perda de células e necrose do tecido ósseo. A fase osteogênica inicia após várias semanas, havendo formação de novo osso subperiostal, substituindo o osso necrótico. A fase final ocorre após meses e consiste na remodelação do osso formado e substituição por osso lamelar vital (BRADLEY; FISHER, 1975). 
As vantagens da crioterapia incluem a margem de segurança após a curetagem, pela desvitalização da periferia do osso aparentemente normal, a possibilidade de congelamento e reimplantação do segmento afetado, como enxerto autógeno, entre outras. As desvantagens são o aumento da tendência de fratura do osso desvitalizado, a suscetibilidade à infecção, a formação de seqüestros ósseos, a deiscência e o edema (GARDNER; PECAK, 1980; WITTAKER, 1984).

Salmassy e Pogrel (1995) indicaram o uso de enxerto ósseo autógeno, após a crioterapia, em cavidades com mais de $4 \mathrm{~cm}$. Este procedimento visa diminuir os riscos de complicações pós-operatórias, como fratura patológica, e aumentar a porção de osso residual, facilitando a colocação de implantes osseointegrados.

Curi, Dib e Pinto (1997) relataram o tratamento de 36 pacientes através de curetagem e três ciclos de crioterapia. As complicações pós-operatórias foram divididas em menores e maiores. Recidiva local foi a mais severa, ocorrendo em 11 pacientes $(30,5 \%)$ em um período de 14 meses a 10 anos. Destes, cinco necessitaram de mandibulectomia. Fratura patológica ocorreu em quatro casos $(11,1 \%)$, mas sem deslocamento. O tratamento foi através de bloqueio intermaxilar. As complicações menores foram deiscência em 13 pacientes $(36,1 \%)$, infecção em dois $(5,5 \%)$ e parestesia do nervo alveolar inferior em dois $(5,5 \%)$. Os autores avaliam que o tratamento proposto reduziu a taxa de recidiva local, quando comparado com o tratamento conservador e resultou em menores seqüelas, quando comparado com o tratamento radical. Esta modalidade encorajou a realização de um tratamento cirúrgico inicial conservador, ainda se uma segunda ou terceira cirurgia tornar-se necessária.

Sampson e Pogrel (1999) também utilizaram a crioterapia (dois ciclos) como tratamento adjuvante em quatro casos de ameloblastoma, não havendo nenhuma 
recidiva. A tentativa em tratar extensão do tumor em tecido mole resultou em necrose e deiscência.

Schmidt e Pogrel (2004) avaliaram as alterações sensitivas relacionadas ao NAI em 16 pacientes tratados por enucleação e crioterapia. Todos pacientes tinham alteração de sensibilidade imediatamente após a crioterapia (dois anestesia e 14 parestesia). O tempo médio de recuperação foi de 91 dias (variando de dois a 235 dias). Ao fim do estudo, quatro pacientes tinham retorno total da sensibilidade e 12 tinham parestesia. Nenhum referiu limitações relacionadas à função neural alterada, concluindo que as alterações ocasionadas pela crioterapia ao nervo alveolar inferior são mínimas.

\subsubsection{Marsupialização / descompressão}

Consiste na abertura de uma janela cirúrgica na parede de uma lesão cística, permitindo a drenagem do conteúdo da cavidade patológica. O remanescente da cápsula cística é mantido, podendo-se fazer a sutura desta cápsula na mucosa bucal ou utilizar um dispositivo para manter o acesso entre a cavidade patológica e a boca. Após a diminuição da lesão em decorrência da eliminação da pressão hidrostática, executa-se a técnica cirúrgica que permita maior conservação das estruturas (NAKAMURA et al., 1995; PETERSON et al., 2000).

Yokobaiashi et al. (1983) relataram dois casos de ameloblastomas císticos submetidos à marsupialização, cujo procedimento auxiliou no diagnóstico diferencial entre ameloblastoma e cisto odontogênico. Com a liberação da pressão intracística, 
houve proliferação de uma massa sólida na loja monocística. Os autores afirmaram que este crescimento tumoral não está associado à destruição óssea. Desta forma, a marsupialização pode ser usada com segurança e por um período mínimo de seis meses antes da cirurgia definitiva de lesões com diagnóstico duvidoso.

Nakamura et al. (1995) realizaram a marsupialização de 24 ameloblastomas císticos, como tratamento pré-cirúrgico, em um período de 27 anos. O procedimento foi simultâneo à biópsia incisional, ampliando uma janela no rebordo alveolar. Os septos das lesões multicísticas foram removidos e um obturador acrílico foi utilizado. A marsupialização foi extremamente efetiva em cinco casos, efetiva em 11 e inefetiva em oito. O tempo variou de quatro meses a nove anos e seis meses, sendo mais efetiva em pacientes jovens. Macroscopicamente, o tumor desapareceu em três casos e proliferou, preenchendo a cavidade em cinco. Tratamento cirúrgico complementar foi executado em 21 casos, sendo enucleação e curetagem em 13, mandibulectomia marginal em um e segmentar em sete. Dos 13 casos curetados, nove recidivaram, sendo dois destes submetidos à ressecção. Houve mudança do padrão de crescimento histológico de expansivo para invasivo em oito casos.

Os autores consideraram a técnica útil para reduzir o tamanho do tumor e limitar a extensão da cirurgia em $2 / 3$ dos casos deste estudo. A efetividade da marsupialização depende principalmente do potencial de neoformação óssea, técnica empregada e características de crescimento do tumor. As lesões que não diminuem de tamanho ou tendem a crescer após a marsupialização devem ser removidas imediatamente.

Nakamura et al. (2001) demonstraram que em dois casos de ameloblastomas marsupializados houve neoformação de tecido ósseo saudável entre o osso residual e o tumor, permitindo a preservação do nervo. Ressaltaram melhoras na técnica de 
marsupialização, indicando o procedimento como primeira opção para o tratamento de grandes ameloblastomas císticos. Nakamura et al. (2002) declararam que na década de 90, nenhum de seus 12 pacientes com ameloblastoma sofreu cirurgia radical.

\subsubsection{Cauterização}

A cauterização da cavidade após a curetagem é potencialmente mais efetiva que a curetagem apenas (SMALL; WALDRON, 1955). Ela promove isquemia e necrose a alguma distância das margens da cavidade cirúrgica e poderia destruir tumor não identificado no osso esponjoso adjacente. Há pouca evidência na literatura que suporte sua efetividade (GARDNER, 1996). Apesar disto, é razoável dizer que a cauterização poderia ser usada como um tratamento auxiliar da curetagem. Entretanto, a curetagem com ou sem cauterização não são formas seguras para o tratamento do ameloblastoma, devendo ser evitada, se possível (GARDNER; PECAK, 1980).

\subsubsection{Radioterapia}

Segundo Gardner e Pecak (1980) e Reichart, Philipsen e Sonner (1995) parece haver consenso de que o ameloblastoma é radiorresistente e que, 
conseqüentemente, radioterapia não deveria ser usada em seu tratamento. Pelos riscos de desenvolvimento de sarcoma pós-radiação, carcinoma ameloblástico e osteorradionecrose, a radioterapia só deveria ser considerada em caso de tumores inoperáveis.

Alguns autores têm relatado tratamento paliativo de ameloblastoma com radioterapia. Doses variando de 45 a 60 Gy têm induzido a regressão ou controle da doença em cerca de metade dos casos (ZANE, 1991).

Gardner (1996) reconsiderou o ameloblastoma como sendo um tumor epitelial bem diferenciado e radiossensível, visto a efetividade com que componentes extraósseos de grandes ameloblastomas regrediam com a radioterapia, como relatado por Atkinson, Harwood e Cummings (1984). O tumor não pode ser tratado desta forma por ser uma lesão intra-óssea, o que a torna radiorresistente e pelos outros riscos já descritos.

\subsubsection{Resultados}

Sachs (1991) tratou nove pacientes de forma conservadora, utilizando ostectomia periférica. Não houve recidiva em um acompanhamento que variou de 2 a 15 anos.

Olaitan, Adeola e Adekeye (1993) trataram 296 pacientes com ameloblastoma. Mandibulectomia segmentar, incluindo $1 \mathrm{~cm}$ de osso aparentemente normal foi realizada em 199 casos (67,2\%), maxilectomia isolada ou estendida em 13 casos $(4,1 \%), 81$ pacientes $(27,4 \%)$ receberam tratamento conservador, sendo 61 
(20,6\%) mandibulectomias marginais, 19 (6,4\%) enucleações e uma $(0,3 \%)$ curetagem. Cirurgia reconstrutiva foi realizada em 31 pacientes, levando-se em consideração as condições financeiras, profissionais, higiene oral e classe social. De 199 pacientes mandibulectomizados, 19, receberam enxerto ósseo; 9 pacientes, prótese mandibular e três, retalho de tecido mole. Fez-se controle de 229 pacientes. Destes, 207 estavam livre de doença e 22 tinham recidivas, diagnosticadas entre dois e 18 anos após a cirurgia. Estas ocorreram em 5/13 maxilectomias, 1/61 mandibulectomias marginais, 7/19 (36,8\%) enucleações e 1/1 curetagem. Não houve morte associada à doença.

Reichart, Phillipsen e Sonner (1995) em sua revisão de relatos de caso, não mostraram diferença marcante entre a taxa de recidiva após cirurgia radical $-\mathrm{n}$ : 141 - $(17,7 \%)$ e cirurgia conservadora - n: 186 - (22,6\%). Mas ao associar os dados dos trabalhos de revisão, a taxa de recidiva do tratamento conservador - n: 622 - é de $34,7 \%$ e do tratamento radical - n: $484-17,3 \%$.

Chidzonga (1996) relatou o tratamento de 20 pacientes com idade menor ou igual a 18 anos, através de ressecção radical. Reconstrução foi realizada com fio de Kirschner ou placas de Sherman, havendo extrusão do material, com necessidade de remoção em 15 casos. Apenas três pacientes receberam reconstrução óssea secundária. Dificuldade na fala permaneceu em cinco pacientes.

Takahashi, Miyauchi e Sato (1998) trataram seis pacientes com menos de 16 anos. Curetagem com marsupialização foi feita em três casos, curetagem e fechamento primário em dois e marsupialização em um. Curetagem com marsupialização foi repetida no mínimo uma vez em cinco pacientes e ressecção marginal foi realizada em dois. Resultados satisfatórios foram obtidos em todos os casos. 
Sampson e Pogrel (1999) publicaram o tratamento de 26 casos de ameloblastoma (22 ASM e 4 AU), sendo 11 através de enucleação/curetagem (nove tratados previamente e dois pelos autores), quatro por mandibulectomia marginal ou curetagem associada à crioterapia e 12 por mandibulectomia segmentar com $1 \mathrm{~cm}$ de margem de segurança. Foram realizadas 27 cirurgias reconstrutivas em 17 pacientes, incluindo 18 reconstruções ósseas tardias, sendo três pacientes reabilitados com implantes. O acompanhamento variou de 6 a 100 meses (média de 37). Houve 11 recidivas nos 11 casos tratados por curetagem. Destas, cinco foram tratadas com crioterapia, com sucesso; seis tinham envolvimento de tecido mole e foram ressecadas. Recidiva secundária em tecido mole persistiu em dois pacientes, que sofreram múltiplos procedimentos para erradicar a doença, incluindo dissecção cervical e ressecção de base de crânio.

Farzard (2000) tratou sete casos de ASM, sendo quatro por enucleação ou curetagem, um por mandibulectomia marginal e dois por mandibulectomia segmentar. O acompanhamento variou de 2 a 21 meses. Recidiva ocorreu em 3/4 casos tratados por curetagem (3,4 e 6 anos após), 1/1 tratado por mandibulectomia marginal (21 anos após). O intervalo médio das recidivas foi de 7,2 anos.

Bataineh (2000) relatou 23 pacientes tratados através de um protocolo denominado radical conservador racional em um período de 10 anos, por um único cirurgião. O tratamento consistiu de uma mandibulectomia marginal por acesso intrabucal com preservação das bordas inferior e posterior do ramo e ostectomia periférica em profundidade de $1 \mathrm{~cm}$. Não houve recidiva em um acompanhamento médio de 6,5 anos (3 a 10). A única complicação observada foi parestesia transitória do nervo alveolar inferior. 
Hatada et al. (2001) revisaram os dados de tratamento de 185 pacientes com ameloblastoma. Ressecção parcial (segmentar ou marginal) foi realizada em 68 casos (36,8\%), enucleação em 66 (35,7\%), marsupialização e enucleação em 25 $(13,5 \%)$, hemimandibulectomia em $18(9,7 \%)$ e marsupialização em oito $(4,3 \%)$. Houve 17 recidivas (9\%) localizadas na mandíbula, principalmente na região alveolar de molares. Destas, 13 tinham sido tratadas por enucleação e quatro por marsupialização. O tempo médio de ocorrência da recidiva foi de 2 anos e 10 meses (7 meses a 9 anos). Apenas 44 pacientes $(23,2 \%)$ mantiveram o acompanhamento pós-operatório.

Kim e Jang (2001) publicaram 71 casos de ameloblastomas tratados conservadoramente (enucleação e/ou curetagem) ou radicalmente (ressecção parcial ou total), mas sem especificação sobre o número de pacientes em cada grupo. Houve 15 recidivas (21,1\%), sendo quatro, entre 1 e 3 anos, nove, entre 3 e 5 anos e duas após 5 anos.

Nakamura et al. (2002) avaliaram 78 casos de ameloblastoma tratados em um período de 35 anos. Marsupialização foi realizada em 31 pacientes (19 uniloculares e 12 multiloculares) com permanência de 3 meses a 91/2 anos. O tratamento de 42 pacientes foi através de cirurgia radical, enquanto que 36 foram tratados de forma conservadora. Recidiva ocorreu em 15 casos, sendo três tratados por ressecção segmentar, 10 por marsupialização e curetagem e dois por enucleação e curetagem. As taxas de recidiva após tratamento radical e conservador foram 7,1\% (3/42) e 33,3\% (12/36) respectivamente. A taxa de recorrência foi de 7,4\% no tipo unicístico, $52,4 \%$ no multicístico e $6,8 \%$ nos tumores sólidos, estando mais relacionada aos padrões folicular e plexiforme. Os autores estendem a indicação de tratamento 
conservador do ameloblastoma e ressaltam a importância de um tratamento mais eficiente nas lesões multicísticas.

Becelli et al. (2002) relataram o tratamento de 60 pacientes com ameloblastoma. Os AU (18 casos) foram tratados através de mandibulectomia marginal com margem de 1 a $2 \mathrm{~cm}$. De 42 casos de ASM, 27 sofreram ressecção marginal e 15 ressecção segmentar. O tempo mínimo de acompanhamento foi de 10 anos e não houve recidiva.

Gümgüm e Hosgören (2005) trataram quatro pacientes com ameloblastoma, sendo três por enucleação e curetagem e um por mandibulectomia segmentar, devido a afilamento da base da mandíbula. Não houve recidiva em um acompanhamento mínimo de 3 anos.

Torres-Lagares et al. (2005) apresentaram o tratamento de seis pacientes com ameloblastoma de mandíbula através de mandibulectomia marginal (dois casos), enucleação (um caso) e curetagem seguida de ostectomia periférica (três casos). O tempo médio de acompanhamento foi de 4 anos e 8 meses e não houve recidiva.

Sachs (2006) utilizou a técnica de excisão do tumor associada à ostectomia periférica da loja óssea no tratamento de 12 pacientes com ameloblastoma mandibular. Não houve recidiva em um acompanhamento mínimo de 10 anos.

Ghandhi et al. (2006) relataram a experiência terapêutica de 22 pacientes com ameloblastoma em Glasgow e 28 pacientes em San Francisco. Dos 22 casos tratados em Glasgow, cinco eram AU. Destes, quatro foram tratados por enucleação (três recidivas) e um por ressecção. Dos ASM, sete foram tratados radicalmente e 10 conservadoramente (oito recidivas). Dos 28 casos tratados em San Francisco, quatro eram $\mathrm{AU}$, tratados por enucleação (duas recidivas). Dos 24 ASM, 13 foram 
tratados radicalmente e 11 por enucleação (oito recidivas). Uma recidiva ocorreu após 19 anos.

Vayvada et al. (2006) trataram 11 pacientes com ameloblastoma mandibular através de mandibulectomia segmentar com margem de segurança de $1 \mathrm{~cm}$, seguida de reconstrução microcirúrgica com retalho de crista ilíaca ou fíbula. O tempo médio de hospitalização foi de 11 dias (8 a 16 dias). Não houve recidiva em um tempo médio de acompanhamento de 29,2 meses (17 a 38). Implantes osseointegrados foram instalados em três pacientes. Resultados estéticos e funcionais adequados foram obtidos em todos os casos.

Hong et al. (2007) realizaram o tratamento de 239 pacientes com ameloblastoma através de ressecção segmentar ou maxilectomia (22 casos), ressecção marginal (43 casos) e tratamento conservador - enucleação, precedida ou não por marsupialização e enucleação com curetagem - (174 casos). Houve 57 recidivas, sendo uma no grupo de ressecção segmentar (4,5\%), cinco no grupo de ressecção marginal $(11,6 \%)$ e 51 na terapia conservadora (29,3\%). Concluíram que a ressecção com margem de segurança é o tratamento ideal, reservando a terapia conservadora para pacientes na primeira década de vida, AU e padrão plexiforme.

\subsection{Ameloblastoma em maxila}

A maxila caracteriza-se por apresentar uma cortical óssea muito fina e uma exígua quantidade de osso entre o ápice dos dentes posteriores e o soalho do seio maxilar. Conseqüentemente, não há uma barreira anatômica efetiva contra a 
disseminação do tumor como ocorre com a cortical óssea mandibular. Há também uma íntima relação com outras estruturas anatômicas, como a fossa nasal, órbita, fossas pterigomandibular e infratemporal e base de crânio. A cirurgia deve visar remover o tumor inteiramente com margem de segurança na primeira tentativa (CRAWLEY; LEVIN, 1978; GARDNER, 1996; GARDNER; PECAK, 1980; SEHDEV et al., 1974; ZANE, 1991). O ameloblastoma pode levar a óbito por extensão intracraniana e a eliminação de recidivas pode ser impossível (GARDNER, 1996; SEHDEV et al., 1974). Crawley e Levin (1978) consideraram ser importante distinguir o acometimento da região anterior da maxila em relação à região posterior por ser tratar de uma área menos crítica. Gardner e Pecak (1980) ressaltaram que a grande maioria das lesões maxilares envolve a região posterior, sendo a maxila anterior acometida por menos de $2 \%$ destes tumores.

Pelo artigo de revisão de Reichart, Phillipsen e Sonner (1995), a maxila foi afetada em $16 \%$ dos casos. Destes, $49 \%$ envolviam a região de molares, $14 \%$ o seio maxilar e $5 \%$ a cavidade nasal. A média de idade dos pacientes acometidos foi de 47 anos. Recidivas podem representar um problema de diagnóstico, sendo que a tomografia computadorizada e ressonância magnética são fundamentais para o controle, que deve ser feito pela vida toda.

Olaitan, Adeola e Adekeye (1993) relataram 13 casos (4,1\%) de lesões maxilares em uma amostra de 315 ameloblastomas. Todos apresentavam expansão acentuada envolvendo ambas corticais. O tratamento consistiu de maxilectomia isolada em sete casos e associada à ressecção de outras estruturas em seis casos. Houve cinco recidivas.

Poon, Wu e So (1996) apresentaram oito (16\%) casos de ameloblastoma maxilares em um total de 50 casos. A região posterior foi afetada em cinco casos, a 
região anterior em dois e outro se estendeu para ambas. A idade média dos pacientes afetados foi de 44 anos.

Jackson, Callan e Forté (1996) apresentaram o tratamento de 11 pacientes com ameloblastomas maxilares em um período de sete anos. A idade variou de 35 a 60 anos (média de 53 anos), acometendo nove homens e duas mulheres. Os autores propuseram uma classificação e tratamento baseado nestes casos, conforme se segue:

Grupo 1: tumor confinado à maxila sem envolvimento do soalho de órbita (quatro casos)

Grupo 2: tumor envolvendo a maxila, o soalho de órbita, mas não a periórbita (dois casos)

Grupo 3: tumor envolvendo a maxila e o conteúdo orbital

Grupo 4: tumor envolvendo a maxila com extensão para a base do crânio (cinco casos)

Tratamento:

Grupo 1: maxilectomia parcial

Grupo 2: maxilectomia total

Grupo 3: maxilectomia total com exenteração

Grupo 4: maxilectomia total com exenteração e ressecção da base do crânio Curi, Dib e Pinto (1997) trataram dois pacientes com ameloblastoma de maxila por curetagem e crioterapia. Não houve recidiva em acompanhamento de 30 e 151 meses.

Zwahlen e Grätz (2002) analisaram 26 casos de ameloblastoma tratados em um período de 15 anos, dos quais, cinco $(19,2 \%)$ eram lesões maxilares. A idade dos pacientes variou de 26 a 73 anos (média 43,6 anos). Ressecção ampla com 
margem de segurança foi o tratamento de escolha. Houve uma recidiva com extensão para base de crânio.

\subsection{Recidivas}

Crawley e Levin (1978), Curi, Dib e Pinto (1997), Farzad (2000) e Yokobayashi et al. (1983) consideram que as recidivas de ameloblastomas são ocasionadas pela falha em se reconhecer a extensão da invasão medular pelo tumor, levando a remoção incompleta do mesmo. Apesar das altas taxas de recidiva relacionadas à curetagem, a extensão desta curetagem, tamanho inicial do tumor e da recidiva e tempo até a recorrência são raramente mencionados. Segundo Gardner e Pecak (1980), o tratamento inadequado pode resultar em múltiplas recidivas ou lesões muito extensas.

Para Waldron (1966) recidiva após curetagem não implica necessariamente em falha. A recorrência é freqüentemente limitada a uma pequena região, que pode ser tratada mais conservadoramente que a lesão inicial.

De acordo com Reichart, Phillipsen e Sonner (1995), diferentes taxas de recidiva têm sido relatadas. Nas lesões tratadas por enucleação ou curetagem, a taxa de recidiva varia de 20 a 90\%. Ameloblastomas unicísticos recorreram em 13,7\% (n: 73) dos casos, comparado aos não unicísticos com recorrência de 22,7\% (n: 278). O período de recidiva após tratamento conservador foi significativamente mais curto (4,8 anos) que após cirurgia radical (11,1 anos). 
$\mathrm{Na}$ avaliação de Poon, Wu e So (1996), os fatores que favoreceram a recidiva incluem tratamento inadequado, padrão histológico folicular, idade maior que 20 anos e presença de lesões multiloculares. Gümgüm e Hosgören (2005) acrescentaram a aparência clínico-radiográfica e o local anatômico.

Curi, Dib e Pinto (1997) relataram que as recidivas observadas em seus casos apresentavam padrão clínico e radiográfico peculiares. O aspecto era de uma imagem radiolúcida unilocular pequena e bem circunscrita localizada na cortical mandibular superior neoformada, que se tornou suficientemente espessa para suportar cirurgia radical.

Adekeye e Lavery (1986) e Bianchi et al. (1998) atribuíram as recidivas a uma combinação de tratamento cirúrgico inadequado e agressividade do tumor. As recidivas que ocorrem após ressecções radicais podem estar relacionadas à presença de ilhas de tecido neoplásico nas margens do osso esponjoso ou à implantação de células tumorais durante a remoção.

Segundo Farzad (2000), o ameloblastoma não invade estruturas vitais extraósseas, mesmo quando gigante, exceto se disseminado iatrogenicamente.

Ferretti, Polakow e Coleman (2000) relataram dois casos de recidiva sendo uma no músculo temporal, seis meses após o tratamento inicial e outra em um enxerto de crista ilíaca, 25 anos após o tratamento primário.

Daramola, Ajagbe e Oluwasanmi (1980) e Sá et al. (2004) alertaram que as recidivas do ameloblastoma tendem a ser mais agressivas e com maior potencial de invasão e destruição que a lesão original.

Becelli et al. (2002) consideraram que a ocorrência de recidiva foi a principal complicação da cirurgia inadequada de ameloblastoma. Nas cirurgias inadequadas, o tipo folicular recorre mais facilmente que o plexiforme e o ASM mais que o AU. 
Chapelle et al. (2004) relataram quatro casos de recidiva de ameloblastoma em dezenove pacientes tratados em 21 anos. Consideram que todos foram "subdiagnosticados e sub-tratados", pois se tratavam de lesões císticas submetidas à enucleação. Exame histopatológico mostrou ASM em todos os casos.

Martins e Fávaro (2004) relataram um caso de recidiva de ameloblastoma em enxerto ósseo de crista ilíaca dezesseis anos após a realização de mandibulectomia segmentar. Os cotos ósseos proximal e distal estavam livres de neoplasia no momento da ressecção, porém houve rompimento da cortical vestibular e invasão do periósteo com provável implantação de células no tecido mole. Choi et al. (2006) relataram um caso de recidiva em um enxerto após vinte anos, sugerindo que a via tenha sido a contaminação do enxerto no momento da cirurgia inicial.

Carlson e Marx (2006) questionaram a ocorrência de recidiva após tratamentos radicais, afirmando que as peças cirúrgicas deveriam ter seus limites analisados microscopicamente.

\subsection{Transformação maligna}

A transformação maligna de um ameloblastoma, caracterizada pela ocorrência de metástase é uma ocorrência muito rara. Pode representar extensão direta em um linfonodo ou aspiração do tumor. Pela raridade, não deve ser relevada para direcionar o método terapêutico (CRAWLEY; LEVIN, 1978; GARDNER; PECAK, 1980). 
Os locais de maior ocorrência de metástase são pulmão, pleura, linfonodos e osso. Algumas situações clínicas representam fatores de risco, tais como tumores de longa duração, múltiplas recidivas, doença local extensa, procedimentos cirúrgicos freqüentes e radioterapia. Ambas as lesões, primária e distante, são histologicamente benignas e o mecanismo de disseminação é incerto. As principais hipóteses são disseminação linfática ou hematogênica e a aspiração de células tumorais (CARLSON; MARX, 2006; ZANE, 1991).

Gardner (1996) distinguiu o ameloblastoma com evidências histológicas de malignidade - carcinoma ameloblástico - do ameloblastoma maligno, que é citologicamente benigno e, estranhamente, metastatiza.

Senra et al. (2008) relataram um caso de metástase pulmonar de ameloblastoma diagnosticado em exame radiográfico de rotina. A paciente tinha 27 anos e histórico de hemimandibulectomia realizada há sete anos para tratamento de ameloblastoma plexiforme. Não havia evidência de recidiva da lesão mandibular.

\subsection{Acompanhamento}

O acompanhamento clínico e radiográfico de longo prazo dos pacientes tratados por ameloblastoma, independente do tipo de tratamento, é muito importante (SAMPSON; POGREL, 1999).

Muller e Sllotweg (1985) questionaram a indicação de tratamento conservador para lesões unicísticas, alegando que estas crescem lentamente e não apresentam acompanhamento de longo prazo. 
Reichart, Phillipsen e Sonner (1995) demonstraram que 53\% das recidivas ocorreram nos primeiros cinco anos, portanto, um período maior de acompanhamento é fortemente recomendável.

Para Curi, Dib e Pinto (1997), o tratamento de ameloblastoma com curetagem e crioterapia é indicado apenas na possibilidade de realizar acompanhamento de longo prazo.

Hatada et al. (2001) mantiveram acompanhamento pós-operatório efetivo em $44(23,2 \%)$ de 190 pacientes tratados em um período de 29 anos. Isto pode prejudicar o diagnóstico e intervenção precoce em recidivas.

Chapelle et al. (2004) sugeriram acompanhamento anual nos primeiros cinco anos após a cirurgia, período em que ocorre a maioria das recidivas. Posteriormente, acompanhamento bianual por no mínimo 25 anos para controle de recidivas tardias.

Carlson e Marx (2006) consideraram que 20 anos de acompanhamento após tratamento conservador não é suficiente para comprovar a cura.

Ghandi et al. (2006) afirmaram que o acompanhamento mínimo deve ser de 10 anos. Em sua revisão, relatou uma recidiva após 19 anos do tratamento inicial. 


\section{PROPOSIÇÃO}

Os objetivos deste estudo foram:

1. Analisar retrospectivamente os dados demográficos, clínicos, radiográficos e histopatológicos de pacientes portadores de ameloblastoma tratados no Serviço de Cirurgia e Traumatologia Buco-Maxilo-Facial do Hospital das Clínicas da Faculdade de Medicina da Universidade de São Paulo (HCFMUSP).

2. Comparar os resultados obtidos entre duas modalidades terapêuticas diferentes: curetagem e curetagem associada à crioterapia. 


\section{CASUÍSTICA - MATERIAL E MÉTODOS}

\subsection{Casuística - material}

Foram avaliados de forma retrospectiva pacientes com diagnóstico de ameloblastoma atendidos no Serviço de Cirurgia e Traumatologia Buco-MaxiloFacial do HCFMUSP, entre setembro de 1997 e julho de 2006, operados por um mesmo cirurgião e que se submeteram a acompanhamento mínimo de dois anos. Os dados clínicos, incluindo idade, gênero e cor dos pacientes, tempo de queixa, sinais, sintomas e localização dos tumores, achados radiográficos, tratamento realizado, recidiva, complicações e situação clínica na última avaliação foram obtidos a partir dos prontuários localizados no Arquivo Médico do Instituto de Ortopedia e Traumatologia (IOT) do HCFMUSP e sumarizados em fichas clínicas padronizadas para o estudo (Apêndice A).

A avaliação radiográfica referente aos aspectos de uni ou multilocularidade, deslocamento e/ou envolvimento (presença de dente no interior da lesão) dental, reabsorção radicular e tamanho da lesão foi feita através da radiografia panorâmica. A análise do envolvimento das corticais ósseas vestibular, lingual e basal foi realizada pela $\mathrm{TC}$.

As lâminas, referente aos casos foram obtidas no Setor de Patologia do IOT e revisadas seguindo os critérios da OMS (GARDNER et al., 2005) por duas patologistas com experiência em patologia bucal para confirmar o diagnóstico de ameloblastoma e estabelecer a classificação histopatológica. 
Os pacientes foram, quando possível, convocados para controle clínico e radiográfico, orientação sobre o estudo e assinatura do termo de consentimento livre e esclarecido do mesmo se dispusessem.

Foram admitidos, no período do estudo, 73 pacientes com diagnóstico de ameloblastoma. Destes, 10 foram excluídos por não terem realizado acompanhamento mínimo de dois anos, um por não haver realizado o tratamento, um por óbito (por causa não relacionada ao tumor), um por alteração do diagnóstico durante a revisão da lâmina (diagnóstico alterado para carcinoma ameloblástico) e sete por terem sido tratados por outros cirurgiões. Desta forma, a amostra analisada totalizou 53 pacientes.

Este trabalho foi submetido e aprovado pelo Comitê de Ética em Pesquisa (Anexo A).

\subsection{Técnica cirúrgica}

Em todos os casos de tratamento conservador, o acesso cirúrgico foi realizado por via intraoral. A mucosa peritumoral ou em contato com a lesão em áreas de ruptura da cortical óssea foi removida. Retalho cirúrgico foi dissecado em nível subperiostal, onde havia integridade da cortical óssea e de forma supraperiostal nos locais de ruptura desta cortical, buscando atingir margens ósseas saudáveis em toda periferia da lesão. Procedeu-se a remoção dos dentes em contato com o tumor e ostectomia necessária para acesso e visualização direta da lesão. O tumor foi dissecado junto às margens ósseas, buscando removê-lo de forma mais intacta 
possível. Após remoção macroscópica de toda lesão, vigorosa e sistemática curetagem de toda loja óssea foi realizada com intuito de remover todo osso esponjoso peritumoral. Em locais onde irregularidades ósseas impediam acesso a efetiva curetagem, foi realizada ostectomia com broca de maneira localizada. Nos casos tratados por crioterapia, foram aplicados três ciclos de congelamento com nitrogênio líquido utilizando-se aparelho Cry $A c \circledR$ e pontas extensoras. O parâmetro foi o aspecto visual de congelamento ósseo, aguardando-se descongelamento espontâneo. Após regularização da loja cirúrgica, irrigação com soro fisiológico 0,9\% e hemostasia, realizou-se fechamento primário da mucosa sobre a cavidade cirúrgica.

\subsection{Métodos}

\subsubsection{Metodologia estatística}

Os dados foram resumidos através da freqüência absoluta e relativa no caso de variáveis categóricas e através da média, desvio padrão, valores mínimo e máximo e mediana no caso de variáveis numéricas. Inicialmente foram descritas as variáveis demográficas, depois alguns parâmetros próprios do estudo e as análises para verificar a associação entre variáveis. Também foi avaliado o tempo livre de doença, através de curva de sobrevida pelo método de Kaplan-Meier. 
A comparação entre os dados foi feita através do teste t ou ANOVA no caso de variáveis numéricas e através do teste exato de Fisher ou Qui-Quadrado no caso de variáveis categóricas.

Em alguns casos, principalmente para avaliar a associação entre variáveis categóricas, foi necessário excluir algumas categorias de forma que a avaliação fosse feita apenas nos casos mais freqüentes.

Significância estatística foi obtida para valores de $p<0,05$. Todas as análises foram obtidas através do programa estatístico Minitab, versão 15.0.

Quando os resultados não foram estatisticamente significantes, foi realizada apenas a análise descritiva dos achados clínicos, radiográficos, histopatológicos e terapêuticos. 
5 RESULTADOS

\section{Dados demográficos}

Dos 53 pacientes analisados, $25(47,2 \%)$ eram do gênero masculino e 28 $(52,8 \%)$ do gênero feminino. Quanto à etnia, a maioria era leucoderma $(50,9 \%)$, seguido por feoderma $(26,4 \%)$, melanoderma $(18,9 \%)$ e xantoderma $(3,8 \%)$.

O gráfico 5.1 e a tabela 5.1 mostram a distribuição dos pacientes por faixa etária e suas medidas resumo, respectivamente.

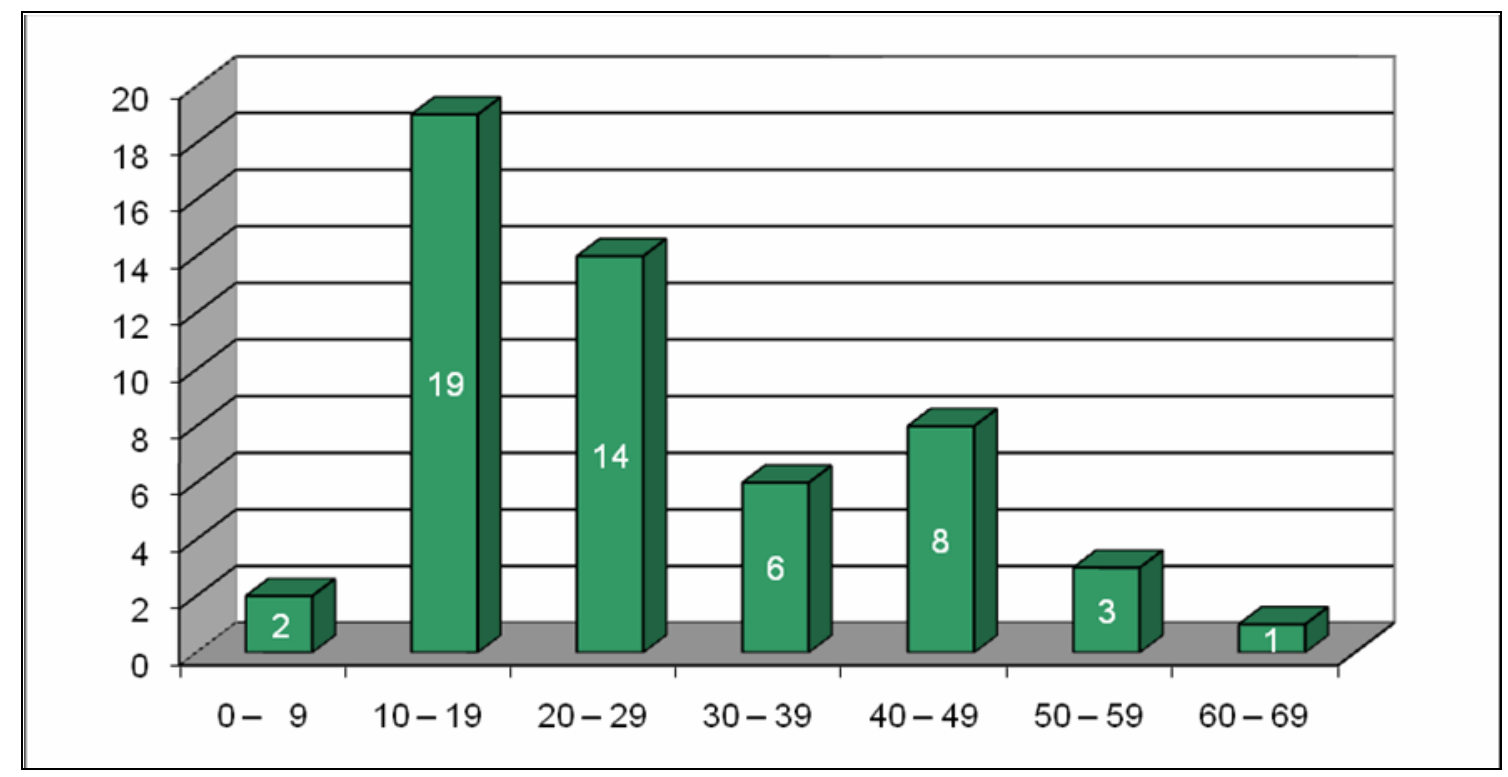

NOTA- valores expressos em anos

Gráfico 5.1- Distribuição do número de pacientes por faixa etária 
Tabela 5.1 - Medidas resumo para a idade dos pacientes

\begin{tabular}{c|c|c|c|c}
\hline \hline & Média & DP & Mínimo & Máximo \\
\hline $\begin{array}{c}\text { Idade } \\
\text { (anos) }\end{array}$ & 27,1 & 13,8 & 8 & 64 \\
\hline
\end{tabular}

A principal queixa que levou o paciente a procurar tratamento foi a presença de aumento volumétrico $(73,9 \%)$. No restante dos casos $(26,1 \%)$ a queixa foi dor e aumento volumétrico. O tempo de queixa variou de um até 120 meses (média \pm d.p. = $12,7 \pm 22,5$ meses). A tabela 5.2 mostra a distribuição detalhada quanto ao tipo e tempo de queixa. Nesta tabela os dados referem-se a 46 pacientes, pois em sete casos os pacientes foram assintomáticos e o diagnóstico foi feito por achado radiográfico.

Tabela 5.2 - Distribuição do número de pacientes por tipo e tempo de queixa

\begin{tabular}{l|c|c}
\hline \hline Queixa & $\boldsymbol{N}$ & $\%$ \\
\hline Tipo: tumor & 34 & 73,9 \\
\hline \multicolumn{1}{c|}{ dor e tumor } & 12 & 26,1 \\
\hline Tempo: média \pm d.p. & $12,7 \pm 22,5$ meses \\
\hline mínimo - máximo & $1-120$ meses \\
\hline \hline
\end{tabular}

A grande maioria dos pacientes (92,5\%) apresentou o tumor localizado na mandíbula. Em 40 casos (75,5\%), a lesão estava localizada na região posterior da mandíbula. Em quatro casos (7,6\%) ela envolvia apenas a região anterior e em cinco $(9,4 \%)$ acometia as regiões anterior e posterior. A maxila foi afetada em três casos $(5,7 \%)$ e em todos eles o tumor localizava-se na região posterior. Em um paciente 
$(1,9 \%)$ o ameloblastoma localizava-se apenas em partes moles de região mandibular previamente ressecada (Gráfico 5.2).

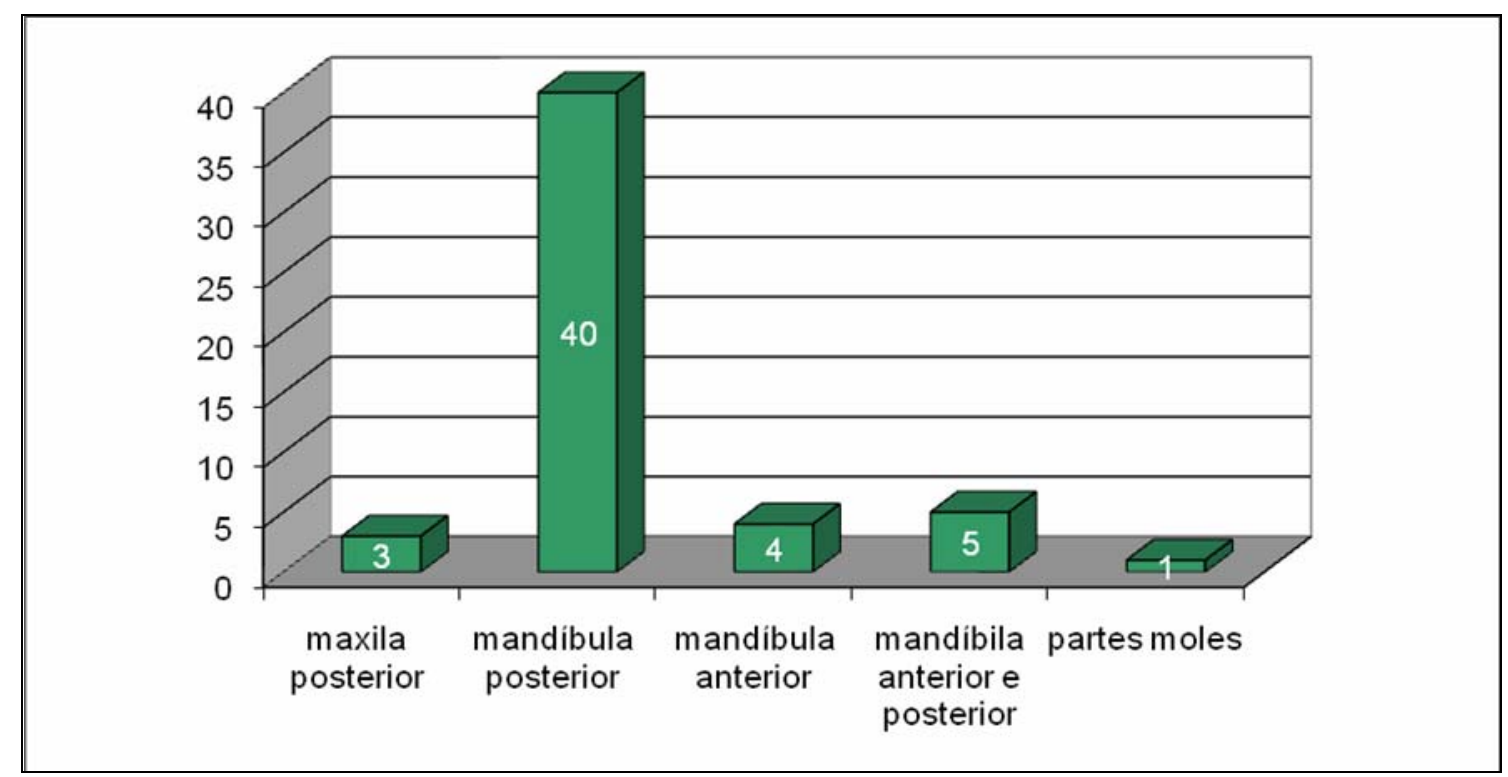

Gráfico 5.2 - Distribuição do número de pacientes por localização do tumor

\section{Aspectos radiográficos}

$\mathrm{Na}$ avaliação do aspecto radiográfico, um caso foi excluído por se tratar de uma lesão em tecido mole. Dos 52 casos, 35 (67,3\%) tinham aspecto multilocular e $17(32,7 \%)$ unilocular.

As corticais vestibular e/ou lingual foram expandidas e rompidas em 44 casos $(84,6 \%)$, somente expandidas em cinco (9,6\%), somente rompida em um $(1,9 \%)$ e preservadas nos outros dois casos (3,8\%). Quando avaliado o envolvimento da cortical basal da mandíbula, ela esteve expandida em 25 casos (51\%), expandida e perfurada em três $(6,1 \%)$ e preservada nos outros 21 casos $(42,8 \%)$.

Nos casos em que havia dentes associados ao tumor, 39 pacientes $(73,6 \%)$ apresentaram deslocamento dental e 36 (67,9\%) reabsorção radicular. Dente incluso envolvido pela lesão foi observado em 20 casos $(37,7 \%)$. 
Dos seis pacientes com ameloblastoma unicístico, um apresentou padrão radiográfico multilocular e os outros cinco padrão unilocular.

O tamanho radiográfico do tumor em sua maior extensão variou de 5 a 115 mm (média \pm d.p. $=62 \pm 25,8 \mathrm{~mm}$ )

$\mathrm{Na}$ correlação entre idade e padrão radiográfico, foi verificada uma relação estatisticamente significante ( $p=0,006$ teste t de Student), sendo que a idade média dos pacientes com padrão unilocular foi menor do que a idade média dos pacientes com padrão multilocular, 19,4 $\pm 12,5$ e 30,3 $\pm 13,0$ anos, respectivamente (Tabela 5.3).

Tabela 5.3 - Medidas resumo da idade de acordo com o padrão radiográfico

\begin{tabular}{l|c|c|c|c|c}
\hline \hline & Média & D.P. & Mínimo & Mediana & Máximo \\
\hline Unilocular & 19,4 & 12,5 & 8 & 16 & 55 \\
\hline Multilocular & 30,3 & 13 & 14 & 27 & 64 \\
\hline \hline
\end{tabular}

NOTA- valores expressos em anos

\section{Achados histopatológicos}

Os padrões folicular e plexiforme ocorreram com igual freqüência nesta amostra, com 17 casos $(32,1 \%)$ cada. O tipo misto, representado pela associação dos tipos folicular e plexiforme com ou sem a presença de outras variantes, foi observado em 11 casos (20,8\%). As variantes histológicas de células basais e acantomatoso foram identificadas em um caso (1,9\%) cada. O diagnóstico de ameloblastoma unicístico foi estabelecido pela associação dos dados clínicos radiográficos e histopatológicos, totalizando seis casos (11,3\%) (Gráfico 5.3). 


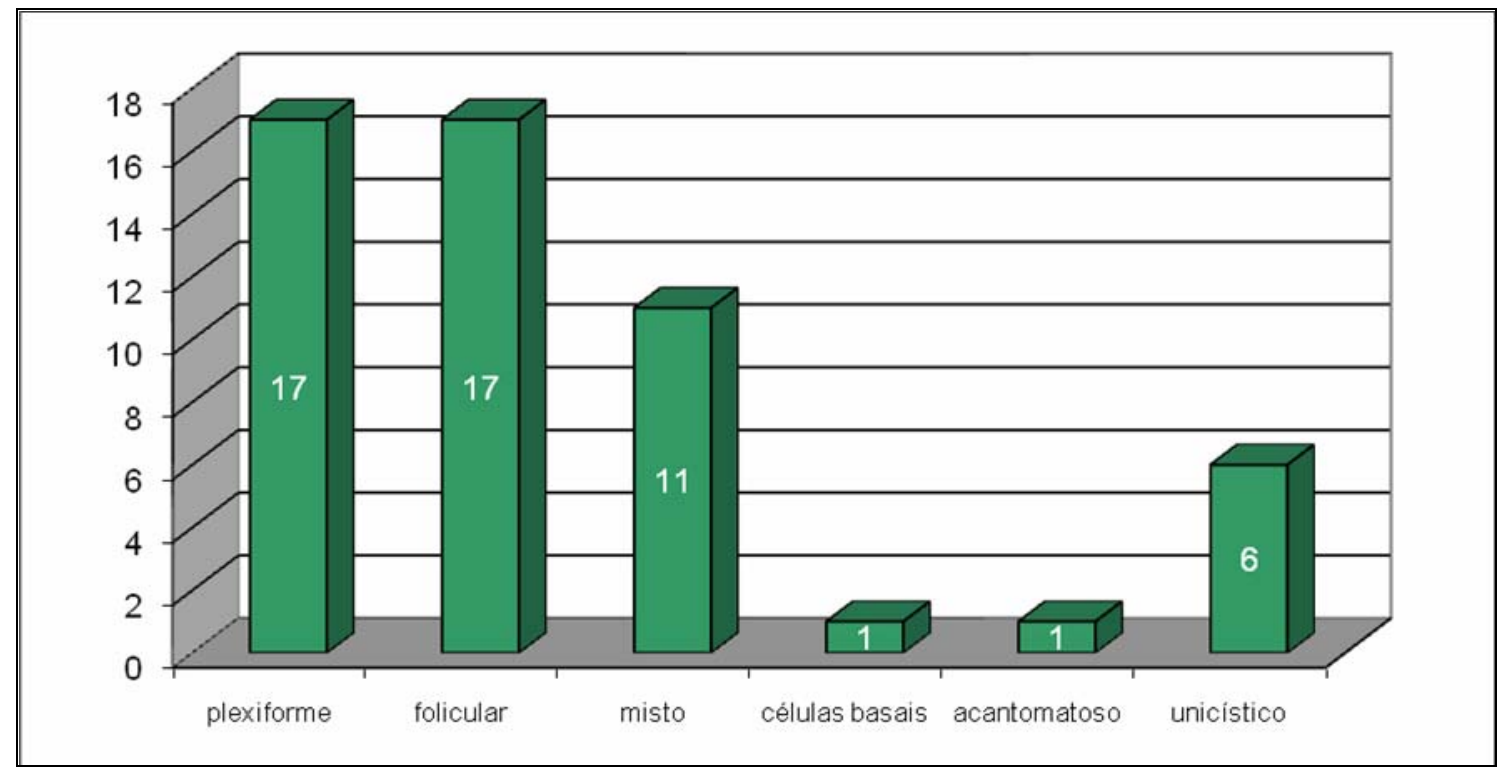

Gráfico 5.3 - Distribuição dos pacientes quanto ao tipo histológico

Quando relacionados apenas os três principais tipos histológicos (plexiforme, folicular e misto) com a idade média dos pacientes, não houve significância estatística $(p=0,876)$. A tabela 5.4 mostra detalhadamente as medidas resumo da idade de acordo com o tipo histológico.

Tabela 5.4 - Medidas resumo da idade de acordo com o tipo histológico

\begin{tabular}{l|c|c|c|c|c}
\hline \hline & Média & D.P. & Mínimo & Mediana & Máximo \\
\hline Plexiforme & 26,7 & 15,0 & 8 & 20 & 64 \\
\hline Folicular & 28,8 & 13,1 & 12 & 27 & 56 \\
\hline Misto & 29,1 & 13,3 & 16 & 24 & 56 \\
\hline Células Basais & 55,0 & - & 55 & 55 & 55 \\
\hline Acantomatoso & 24,0 & - & 24 & 24 & 24 \\
\hline Unicístico & 15,3 & 4,9 & 9 & 16,5 & 21 \\
\hline
\end{tabular}

NOTA- valores expressos em anos 


\section{Tratamento prévio}

A maioria dos pacientes não havia sido submetida a nenhum tratamento prévio (36 casos - 67,9\%). Dos que foram tratados previamente, a curetagem foi realizada na maior parte dos casos (18,9\%). A distribuição detalhada quanto ao tipo de tratamento prévio está expressa na tabela 5.5.

Tabela 5.5 - Distribuição dos pacientes de acordo com o tratamento prévio

\begin{tabular}{l|c|c}
\hline \hline & $N$ & $\%$ \\
\hline Ressecção & 2 & 3,8 \\
\hline Marsupialização & 2 & 3,8 \\
\hline Curetagem & 10 & 18,9 \\
\hline Crioterapia & 3 & 5,7 \\
\hline \hline
\end{tabular}

\section{Tratamento realizado}

O tratamento por curetagem seguido de crioterapia foi realizado em 30 pacientes (56,6\%), curetagem isolada em 18 (33,9\%), mandibulectomia segmentar em quatro $(7,6 \%)$ e ressecção de partes moles em um $(1,9 \%)$ (Tabela 5.6).

Tabela 5.6 - Distribuição dos pacientes de acordo com o tipo de tratamento realizado

\begin{tabular}{|c|c|c|}
\hline & $N$ & $\%$ \\
\hline $\begin{array}{l}\text { mandibulectomia } \\
\text { segmentar }\end{array}$ & 4 & 7,6 \\
\hline $\begin{array}{ll}\text { Curetagem } & \text { e } \\
\text { crioterapia } & \end{array}$ & 30 & 56,6 \\
\hline Curetagem & 18 & 33,9 \\
\hline $\begin{array}{l}\text { Ressecção de } \\
\text { partes moles }\end{array}$ & 1 & 1,9 \\
\hline
\end{tabular}


Desta casuística, seis pacientes apresentaram ameloblastoma unicístico, sendo quatro tratados por curetagem seguida de crioterapia e dois por curetagem.

\section{Complicações}

As complicações referentes aos tratamentos realizados são apresentadas detalhadamente na tabela 5.7 .

Tabela 5.7 - Complicações de acordo com tipo de tratamento realizado

\begin{tabular}{c|c|c|c|c|c|c|c}
\cline { 2 - 8 } & deiscência & infecção & $\begin{array}{c}\text { parestesia } \\
\text { transitória }\end{array}$ & $\begin{array}{c}\text { parestesia } \\
\text { permanente }\end{array}$ & $\begin{array}{c}\text { fratura } \\
\text { patológica }\end{array}$ & $\begin{array}{c}\text { sequestro } \\
\text { ósseo }\end{array}$ & $N$ total \\
\hline $\begin{array}{c}\text { ressecção } \\
\text { segmentar }\end{array}$ & - & - & - & $4(100 \%)$ & - & - & 4 \\
\hline $\begin{array}{c}\text { curetagem e } \\
\text { crioterapia }\end{array}$ & $26(86,7 \%)$ & $5(16,7 \%)$ & $17(56,7 \%)$ & $10(33,3 \%)$ & $6(20 \%)$ & $12(40 \%)$ & 30 \\
\hline $\begin{array}{c}\text { curetagem } \\
\text { ressecção de } \\
\text { partes moles }\end{array}$ & $16(88,9 \%)$ & $1(5,6 \%)$ & $10(55,6 \%)$ & $4(22,2 \%)$ & - & $1(5,6 \%)$ & 18 \\
\hline $\mathbf{p}^{*}$ & 0,999 & 0,388 & 0,999 & 0,52 & 0,071 & 0,017 & \\
\hline
\end{tabular}

Ao comparar os dois principais tipos de tratamento realizados (curetagem isolada e curetagem associada à crioterapia), não houve relação estatística significante entre o tipo de tratamento com a ocorrência de deiscência $(p=0,999)$, infecção $(p=0,388)$, parestesia transitória $(p=0,999)$, parestesia permanente $(p=0,520)$ e fratura patológica $(p=0,071)$. Entretanto, a presença de seqüestro ósseo foi significativamente maior nos pacientes que foram submetidos à curetagem 
seguida de crioterapia do que nos pacientes tratados apenas por curetagem $(p=0,017)$.

\section{Alteração do contorno facial}

Alteração do contorno facial foi notada em três pacientes (30\%) tratados por curetagem seguida de crioterapia, em dois $(11,1 \%)$ tratados por curetagem e em quatro (100\%) tratados por ressecção (Tabela 5.8). Associação entre tratamento realizado e contorno facial não foi significante $(p=0,999)$.

Tabela 5.8 - Alteração do contorno facial de acordo com o tipo de tratamento realizado

\begin{tabular}{l|c|c|l}
\hline \hline & N total & $\begin{array}{l}\text { N com alteração } \\
\text { do contorno } \\
\text { facial }\end{array}$ & $\begin{array}{l}\text { com } \\
\text { alteração do } \\
\text { contorno } \\
\text { facial }\end{array}$ \\
\hline ressecção segmentar & 4 & 4 & 100 \\
\hline curetagem e crioterapia & 30 & 3 & 10 \\
\hline curetagem partes & 1 & 2 & 11,1 \\
\hline $\begin{array}{l}\text { ressecção de } \\
\text { moles }\end{array}$ & 18 & 1 & 100 \\
\hline \hline
\end{tabular}

\section{Tempo de acompanhamento}

O tempo de acompanhamento variou de 24,4 até 128,9 meses (média \pm d.p. = $65,8 \pm 28,4$ meses), distribuídos da seguinte forma de acordo com o tipo de tratamento realizado (Tabela 5.9). 
Tabela 5.9 - Tempo de acompanhamento de acordo com o tipo de tratamento realizado

\begin{tabular}{c|c|c|c|c|c|c}
\hline \hline & N total & $\begin{array}{c}\text { média } \\
\star\end{array}$ & d.p.* & mínimo* & mediana* & máximo* \\
\hline ressecção segmentar & 4 & 74,2 & 34,2 & 37,5 & 69,5 & 120,2 \\
\hline curetagem e crioterapia & 30 & 69,69 & 27,56 & 27,63 & 65,15 & 128,97 \\
\hline curetagem & 18 & 55,54 & 26,87 & 24,43 & 47,5 & 115,8 \\
\hline ressecção de partes moles & 1 & 104,77 & & 104,77 & 104,77 & 104,77 \\
\hline \hline
\end{tabular}

NOTA- * valores expressos em meses

\section{Ocorrência de recidiva e correlações}

Cinco dos 53 pacientes estudados apresentaram recidiva após o tratamento do tumor, representando um índice de recidiva global de 9,4\%. Três pacientes (10\%) que apresentaram recidiva haviam sido tratados por curetagem seguida de crioterapia, um $(5,6 \%)$ havia sido tratado por curetagem e em outro o tratamento foi a ressecção de partes moles (Tabela 5.10). Esse último paciente apresentou dois episódios de recidiva. Não houve associação estatisticamente significante entre o tipo de tratamento realizado (curetagem e curetagem seguida de crioterapia) e a ocorrência de recidiva: $(p=0,999)$ 
Tabela 5.10 - Distribuição dos casos em relação à recidiva por tipo de tratamento

\begin{tabular}{l|c|c|l}
\hline \hline & $\begin{array}{l}N \\
\text { total }\end{array}$ & $\begin{array}{l}\text { com } \\
\text { recidiva }\end{array}$ & $\begin{array}{l}\% \\
\text { recidiva }\end{array}$ \\
\hline ressecção segmentar & 4 & 0 & 0 \\
\hline curetagem e crioterapia & 30 & 3 & 10 \\
\hline curetagem & 18 & 1 & 5,6 \\
\hline ressecção de partes moles & 1 & 1 & 100 \\
\hline \hline
\end{tabular}

O tempo transcorrido do tratamento realizado até o diagnóstico das recidivas variou de 10,1 a 101,8 meses (média \pm d.p. $=59,1 \pm 34,4$ meses).

A idade média dos cinco pacientes que apresentaram recidiva foi de 26,6 $\pm 12,1$ anos, enquanto que a idade média dos pacientes sem recidiva foi de 27,1 $\pm 14,1$ (Tabela 5.11)

Tabela 5.11 -Medidas resumo da idade de acordo com a ocorrência de recidiva

\begin{tabular}{l|c|c|c|c|c}
\hline \hline & média & d.p. & mínimo & mediana & máximo \\
\hline Sem recidiva & 27,1 & 14,1 & 8 & 23 & 64 \\
\hline Com recidiva & 26,6 & 12,1 & 17 & 23 & 46 \\
\hline \hline
\end{tabular}

NOTA- valores expressos em anos 
Dos cinco pacientes que apresentaram recidiva, quatro tinham tumor localizado na mandíbula posterior e um em tecido mole adjacente à ressecção prévia. Não houve associação significativa entre a localização do tumor (mandíbula posterior) e a ocorrência de recidiva ( $p=0,999$ teste exato de Fisher). (Tabela 5.12)

Tabela 5.12 - Distribuição dos casos em relação à recidiva, por localização do tumor

\begin{tabular}{l|c|c|c}
\hline \hline & N total & $\begin{array}{l}\text { N } \\
\text { com recidiva }\end{array}$ & $\begin{array}{l}\% \\
\text { recidiva }\end{array}$ \\
\hline Maxila posterior & 3 & 0 & 0 \\
\hline Mandíbula posterior & 40 & 4 & 10 \\
\hline Mandíbula anterior & 4 & 0 & 0 \\
\hline Mandíbula posterior e anterior & 5 & 0 & 0 \\
\hline Extra-ósseo & 1 & 1 & 100 \\
\hline \hline
\end{tabular}

Dos cinco pacientes com recidiva, três haviam sido tratados previamente (um por ressecção, um por marsupialização e um por crioterapia). Não houve associação significante entre tratamento prévio e ocorrência de recidiva $(p=0,312$ teste exato de Fisher) (Tabela 5.13).

Tabela 5.13 - Recidiva de acordo com tratamento prévio

\begin{tabular}{l|c|c}
\hline \hline & $\begin{array}{l}\text { sem } \\
\text { recidiva }\end{array}$ & $\begin{array}{l}\text { com } \\
\text { recidiva }\end{array}$ \\
\hline sem tratamento prévio & 34 & 2 \\
\hline com tratamento prévio & 14 & 3 \\
\hline \hline
\end{tabular}


Dos cinco pacientes que apresentaram recidivas, um não foi avaliado quanto ao padrão radiográfico, por apresentar tumor extra-ósseo. Dos quatro casos avaliados, todos apresentaram padrão radiográfico multilocular. Esta associação não apresentou diferença estatística significante ( $p=0,147$ teste exato de Fisher) (Tabela 5.14).

Tabela 5.14 - Recidiva de acordo com o
aspecto radiográfico

\begin{tabular}{l|c|c|c}
\hline \hline & $\begin{array}{l}\mathrm{N} \\
\text { total }\end{array}$ & $\begin{array}{l}\mathrm{N} \mathrm{cl} \\
\text { recidiva }\end{array}$ & \multicolumn{2}{l}{$\%$} \\
\hline aspecto unilocular & 17 & 0 & 0 \\
\hline aspecto multilocular & 35 & 4 & 11,5 \\
\hline \hline
\end{tabular}

Todos os pacientes que apresentaram recidiva tiveram as corticais ósseas vestibular e/ou lingual da mandíbula expandidas e rompidas, três apresentaram expansão da cortical basal mandibular e em um esta cortical mantinha-se preservada.

$\mathrm{Na}$ correlação entre tamanho do tumor e a ocorrência de recidiva, as lesões que recidivaram eram significativamente menores que as que não recidivaram, com $47 \pm 9$ e 63,6 $\pm 126,6 \mathrm{~mm}$ respectivamente ( $p=0,011$ teste t de Student) (Tabela 5.15). 
Tabela 5.15 - Correlação entre tamanho da lesão inicial e recidiva

\begin{tabular}{lcccccc}
\hline Recidiva & $\mathrm{N}$ & média & d.p. & mínimo & mediana & máximo \\
\hline Não & 48 & 63,6 & 26,6 & 5 & 60 & 115 \\
Sim & 5 & 47,0 & 9,1 & 35 & 50 & 55 \\
\hline
\end{tabular}

Comparação entre tamanho e recidiva: $p=0,011$ (teste t)

O padrão histológico dos cinco pacientes com recidiva está detalhado na tabela 5.16.
Tabela 5.16 - Recidiva de acordo com o tipo histológico

\begin{tabular}{l|c|c|c|}
\hline \hline & $\begin{array}{l}\mathrm{N} \\
\text { total }\end{array}$ & $\begin{array}{l}\text { com } \\
\text { recidiva }\end{array}$ & $\begin{array}{l}\% \\
\text { recidiva }\end{array}$ \\
\hline Plexiforme & 17 & 1 & 5,9 \\
\hline Folicular & 17 & 2 & 11,8 \\
\hline Misto & 11 & 2 & 18,2 \\
\hline Células Basais & 1 & - & 0 \\
\hline Acantomatoso & 1 & - & 0 \\
\hline Unicístico & 6 & - & 0 \\
\hline \hline
\end{tabular}

\section{Análise da sobrevida livre da doença}

Considerando apenas a última informação dos pacientes, todos encontram-se vivos. Um paciente está com doença.

O gráfico 5.4 mostra a curva de sobrevida livre de doença, calculada pelo método de Kaplan-Meier. 


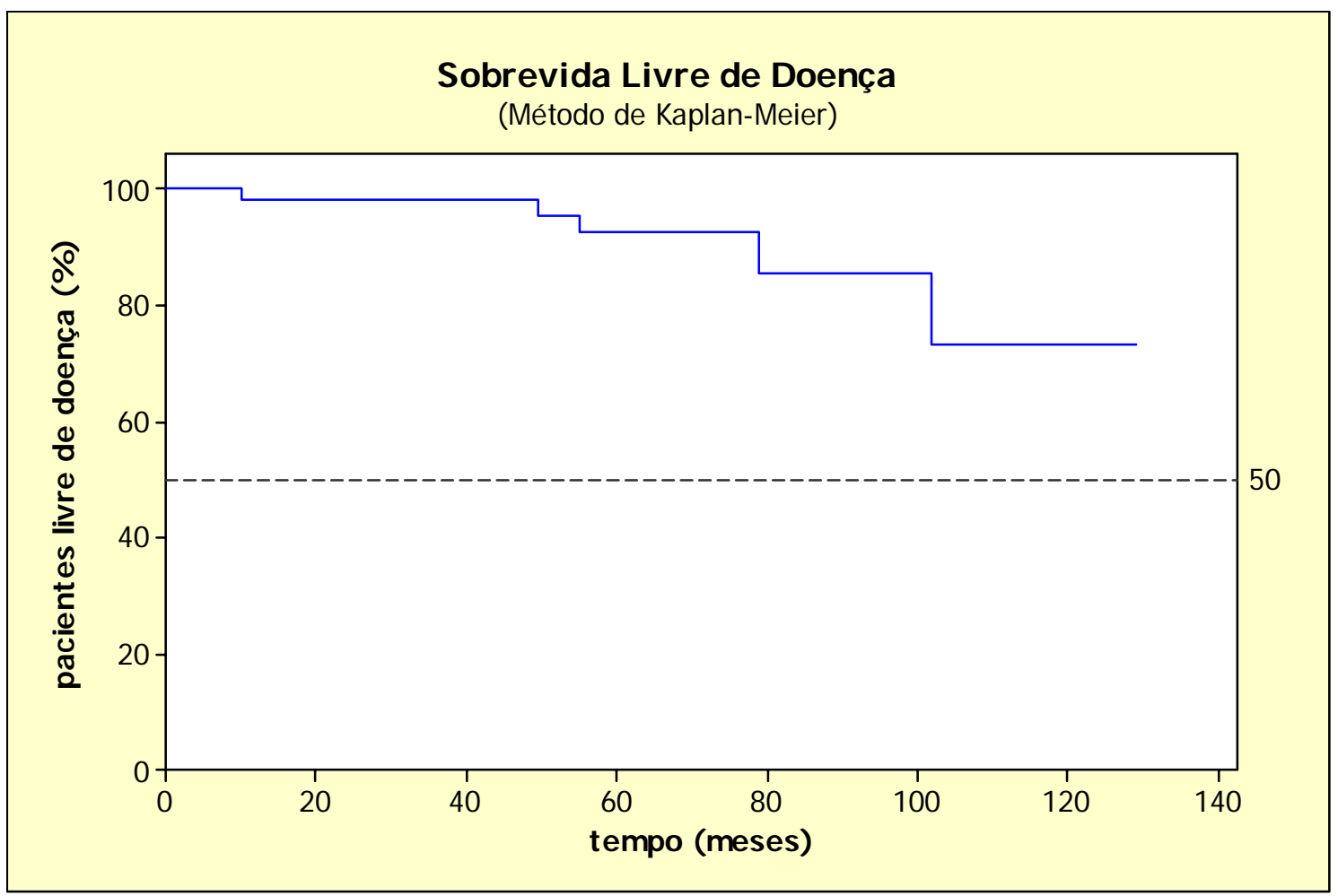

Gráfico 5.4 - Sobrevida livre de doença 


\section{DISCUSSÃO}

O ameloblastoma é a neoplasia odontogênica de maior significado clínico devido a sua prevalência, comportamento clínico e controvérsias relacionadas ao seu tratamento.

Sua etiologia permanece incerta, porém seu padrão de comportamento invasivo e padrão histológico sugerem uma provável origem de remanescentes da lâmina dental (CURI; DIB; PINTO, 1997; POON; WU; SO, 1996; SANTOS et al., 2006).

O tumor apresenta crescimento lento e progressivo, normalmente assintomático, podendo ocasionar deformidade facial acentuada (Apêndice B). Embora o tempo exato do início do desenvolvimento da lesão seja difícil de ser definido, a alteração facial ocorre somente após o envolvimento da medular óssea e da expansão avançada das corticais (AL KHATEEB; ABABNEB, 2003) (Apêndice C). Neste estudo, 86,8\% (46/53) dos pacientes tinham queixa, sendo o aumento de volume presente em $73,9 \%$ dos casos e aumento de volume associado à dor em 26,1\%. Achados estes semelhantes aos de Zane (1991), mas mais freqüentes que os relatados por Olaitam, Adeola e Adekeye (1993) com 42,9\% de expansão e 14,6\% de expansão e dor e que os observados por Becelli et al. (2002) e Kim e Jang (2001), ambos com 38\% de expansão. Já Farzard (2000), Ghandhi et al. (2006) e Vayvada et al. (2006) relataram a presença de expansão em todos os seus casos. Parestesia também foi um achado relatado por alguns autores (BECELLI et al., 2002; GHANDHI et al., 2006; VAYVADA et al., 2006), mas que não não foi encontrada nos pacientes estudados. Diagnóstico feito a partir de exame 
radiográfico de rotina ocorreu em sete pacientes $(13,2 \%)$ assintomáticos. Já Becelli et al. (2002) relataram diagnóstico feito de forma semelhante em $35 \%$ dos seus casos.

O tempo de evolução referido pelos 46 pacientes com queixa variou de 1 até 120 meses (média \pm d.p. $=12,7 \pm 22,5$ meses). Reichart, Phillipsen e Sonner (1995), analisando a literatura, encontraram um tempo de evolução médio de 27 meses, sendo 32,6 meses em países em desenvolvimento e 24,5 meses em países desenvolvidos. No trabalho de Chidzonga (1996), o tempo de queixa variou de 2 a 6 anos. Pode-se considerar este dado um tanto quanto subjetivo, pois não necessariamente uma alteração é notada em seu início por se tratar de um processo indolor. Alguns pacientes também percorreram outros serviços antes de serem encaminhados para o tratamento definitivo, o que aumenta o tempo entre o aparecimento do primeiro sinal e/ou sintoma e o diagnóstico. Apesar disto, o tempo médio de queixa de 12,7 meses encontrado neste trabalho encontra-se abaixo da maioria de outros relatos.

A literatura é unânime ao afirmar que a localização de maior incidência do ameloblastoma é a mandíbula, principalmente na região posterior. Fazem exceção a esta regra os relatos de Chidzonga (1996), que descreveu a sínfise como principal localização afetada em crianças africanas e Adebiyi et al. (2004) que encontraram 70,1\% de acometimento na região de pré-molares e molares. Neste trabalho, a mandíbula foi afetada em 49 casos (92,5\%), sendo 40 (75,5\%) na região posterior, quatro $(7,6 \%)$ na mandíbula anterior e cinco $(9,4 \%)$ envolvendo a mandíbula posterior e anterior. Somente três $(5,7 \%)$ pacientes apresentavam tumor na maxila posterior e um (1,9\%) tinha envolvimento de partes moles, como recidiva de ressecção prévia. Estes achados coincidem com os relatados por Adebiyi et al. 
(2004), Curi, Dib e Pinto (1997), Hatada (2001), Olaitam, Adeola e Adekeye (1993) e Poon, Wu e So (1996).

Os tumores localizados na mandíbula posterior (40 casos) foram tratados principalmente por curetagem seguida de crioterapia (26 casos) e curetagem (12 casos). Dos cinco pacientes que apresentaram recidiva, quatro tinham tumor localizado na mandíbula posterior, e um em tecido mole adjacente à ressecção prévia. Desta forma, não foi identificada associação estatística entre a localização do tumor (mandíbula posterior) com o tipo de tratamento realizado nem com a ocorrência de recidiva, assim como no trabalho de Hong et al. (2007).

Os gêneros masculinos e femininos tendem a ser afetados de maneira semelhante (CHIDZONGA, 1996; CURI; DIB; PINTO, 1997; MARTINS et al., 1999; REICHART; PHILIPSEN; SONNER, 1995). Ocorrência esta também observada neste estudo, com 25 (47,2\%) pacientes do gênero masculino e 28 (52,8\%) do gênero feminino. Outros trabalhos demonstraram maior prevalência no gênero masculino, como os de Adebiyi et al. (2004) e Hatada et al. (2001) com 75\% e Becelli et al. (2002) com 65\%. Já Hong et al. (2007) relataram predominância em mulheres (58\%) em uma amostra de 239 pacientes.

Os pacientes portadores de ameloblastoma apresentam um espectro de idade bastante variado, sendo raro na primeira década de vida e com pico na terceira e quarta décadas. Neste estudo a idade variou de oito até 64 anos (média \pm d.p. = $27,1 \pm 13,8$ anos), sendo os pacientes na segunda década de vida os mais afetados (35,8\% dos casos). Este dado coincide com o relatado por Reichart, Philipsen e Sonner (1995) para pacientes de países em desenvolvimento (média de 27,7 anos), que são envolvidos em idade mais precoce em comparação com pacientes de países desenvolvidos (média de 39 anos). Segundo o autor, o processo de 
desenvolvimento do tumor pode ser acelerado pela desnutrição e cuidados mais precários com a saúde. A idade média deste estudo também se equipara com a relatada por Betaineh (2000) e está pouco acima da encontrada por Vayvada et al. (2006), que foi de 25,4 anos. Porém fica abaixo da maioria das outras séries, que tiveram a média de idade variando entre 30 e 49,5 anos (CURI; DIB; PINTO, 1997; FARZARD, 2000; HATADA et al., 2001; HONG et al., 2007; POON; WU; SO, 1996; SAMPSON; POGREL, 1999; SANTOS et al., 2001).

A classificação dos pacientes por etnia é sempre uma tarefa complexa em vista da ampla miscigenação de raças presentes no Brasil. De qualquer maneira, neste estudo houve predominância de pacientes leucodermas $(50,9 \%)$, seguidos por feodermas $(26,4)$, melanodermas $(18,9 \%)$ e xantodermas $(3,8 \%)$. Há referências sobre possível prevalência da lesão em melanodermas, porém as grandes séries relatadas em países africanos podem estar relacionadas a grandes concentrações de pacientes desta etnia em poucos centros de referência. Chidzonga (1996) comenta que o Serviço de Cirurgia Maxilo-Facial do Zimbábue é o único centro de atendimento em cirurgia buco-maxilo-facial para uma população de 10,5 milhões de habitantes.

Radiograficamente, o ameloblastoma apresenta-se como lesão radiolúcida uni ou multilocular, de caráter expansivo e com freqüente perfuração de corticais ósseas. Os dentes envolvidos são normalmente deslocados e mostram reabsorção radicular de forma mais rotineira que as outras lesões que afetam os maxilares. Os aspectos radiográficos dos pacientes deste estudo foram avaliados através de radiografia panorâmica e TC. A maioria das lesões (35 casos - 67,3\%) apresentava aspecto multilocular e $17(32,7 \%)$ eram do tipo unilocular. Mesma proporção foi relatada por Bataineh (2000) e Gandhi et al. (2006). A literatura confirma a 
predominância do padrão multilocular em relação ao unilocular, com uma variação entre 50\% (REICHART; PHILIPSEN; SONNER, 1995) a 90,4\% (OLAITAM; ADEOLA; ADEKEYE, 1993) de lesões multiloculares. A idade média dos pacientes com padrão unilocular foi menor do que a idade média dos pacientes com padrão multilocular com relação estatisticamente significante $(p=0,006)$. Outros autores tiveram achados semelhantes, com predomínio do aspecto unilocular em pacientes jovens (CHIDZONGA, 1996; KIM; JANG, 2001; TAKAHASHI; MIYAUCHI; SATO, 1998). Referem também que estas lesões seriam menos agressivas. Dentre os quatro casos de recidiva deste estudo que puderam ser avaliados radiograficamente, todos tinham padrão multilocular e causavam expansão e perfuração das corticais vestibular e palatina e três mostravam envolvimento da cortical basal.

Quando o tumor envolvia os dentes, as principais alterações encontradas foram deslocamento dental (39 casos - 73,6\%) e reabsorção radicular (36 casos 67,9\%). Dentes inclusos associados à lesão foram observados em 20 casos (37,7\%). Ogunzalu et al. (2006) observaram dentes inclusos e reabsorção radicular em 32\% dos casos, enquanto Poon, Wu e So, 1996 encontraram reabsorção radicular em apenas 7,1\% de 42 casos de ASM e inclusão dental em 11,9\%.

A TC foi realizada em todos os casos, sendo de extrema utilidade na avaliação da lesão com as estruturas anatômicas adjacentes, especialmente corticais ósseas e nervo alveolar inferior (cortes coronais). Este exame foi essencial, especialmente para o planejamento cirúrgico dos pacientes, como ressaltado por Gümgüm e Hosgören (2005), Sachs (2006) e Sampson e Pogrel (1999).

Poucos estudos mensuraram o tamanho das lesões, referindo-se, normalmente, apenas à localização anatômica acometida. A TC é o exame ideal para se realizar uma medição precisa, porém pela indisponibilidade dos filmes de 
todos os pacientes no arquivo, o tamanho radiográfico das lesões foi medido na radiografia panorâmica. Por motivo de análise estatística, foi considerada apenas a medida da maior extensão da lesão (ântero-posterior). O tamanho dos tumores variou de 5 a $115 \mathrm{~mm}$ com média de $62 \mathrm{~mm}$, sendo pouco maior que o tamanho médio (50 mm) de 26 casos relatados por Sampson e Pogrel (1999). Interessantemente, o tamanho médio dos cinco tumores que recidivaram $(47 \mathrm{~mm})$ foi significativamente menor que o tamanho dos 48 casos que não recidivaram $(63,6$ $\mathrm{mm}$ ). Isto sugere que outras características locais, que não apenas a extensão, estão relacionadas com maior risco de recidiva. Por vezes, lesões localmente infiltrativas são tecnicamente mais difíceis de serem tratadas do que lesões extensas, mas com limites bem definidos cirurgicamente.

Outro parâmetro que evidencia a extensão e a agressividade do ameloblastoma é sua relação com as corticais ósseas. Neste estudo, dos 52 casos avaliados (por meio de TC), apenas dois apresentavam as corticais vestibular e lingual preservadas. Na maioria das vezes (44 casos), houve expansão e ruptura destas corticais, em cinco casos apenas expansão e em um, ruptura sem expansão. O envolvimento da cortical basal foi avaliado em 49 casos de lesões mandibulares, estando esta envolvida em 28 casos (expansão em 25 e expansão associada à ruptura em três) e preservada em 21. Nos quatro casos que recidivaram, todos tinham expansão associada à ruptura das corticais vestibular e lingual. Três casos apresentaram expansão da cortical basal e um preservação desta.

As características histopatológicas do ameloblastoma são bem descritas na literatura, assim como suas variantes. Os principais subtipos histopatológicos observados são o folicular, plexiforme e a associação de ambos (misto). Há um consenso entre a maioria dos autores de que o tipo histológico do tumor não tem 
relação com seu comportamento clínico (FERRETTI; POLAKOW; COLEMAN, 2000; GARDNER, 1996; GARDNER; PECAK 1980; GHANDHI et al., 2006; KRAMER, 1963). Martins et al. (1999) baseiam sua opção terapêutica de acordo com o subtipo histológico associado a outras variáveis. Não faz parte de nossa prática clínica, e conseqüentemente, dos casos avaliados nesta pesquisa, a subclassificação histológica do tumor, principalmente nas biópsias incisionais.

Os padrões folicular e plexiforme ocorreram com igual freqüência nesta amostra, com 17 casos $(32,1 \%)$ cada. O tipo misto, representado pela associação de ambos com ou sem a presença de outras variantes, foi observado em 11 casos (20,8\%). Achados semelhantes foram relatados por Kim e Jang (2001), Nakamura et al. (2002), Poon, Wu e So (1996) e Reichart, Philipsen e Sonner (1995). Bataineh (2000) relatou a predominância do subtipo plexiforme (47,8\%), enquanto Adebiyi, Odukoya e Talwo (2004) apresentaram $62,6 \%$ dos casos como do subtipo folicular. Os pacientes que apresentavam lesão do tipo plexiforme não tinham idade média menor como observado por Kim e Jang (2001) e Takahashi, Miyauchi e Sato (1998).

Hong et al. (2007), Poon, Wu e So (1996) e Reichart, Philipsen e Sonner (1995), relataram maior índice de recidiva em tumores do tipo folicular; Kim e Jang (2001), em lesões plexiformes e Nakamura et al. (2002) em lesões mistas, demonstrando ausência de consenso. O padrão histológico dos cinco pacientes com recidiva deste trabalho foi: plexiforme (um caso), folicular (dois casos) e misto (dois casos).

O AU é classicamente considerado como uma entidade independente por apresentar características peculiares descritas desde 1977 por Robinson e Martinez. Uma destas características é o acometimento de indivíduos mais jovens, entre a segunda e terceira décadas de vida. Neste estudo, a idade média dos pacientes com 
AU foi de 15 anos, menor que as observadas por Poon, Wu e So (1996), Reichart, Philipsen e Sonner (1995) e Rosenstein et al. (2001), que foi de 22, 22 e 35 anos respectivamente. A região posterior da mandíbula é a área de maior acometimento. Neste estudo, todos os casos ocorreram na região posterior da mandíbula. 0 aspecto radiográfico é predominantemente unilocular, assemelhando-se a uma lesão cística, por vezes associada à inclusão dental. Neste estudo, metade dos casos (3 em 6) tinha dente incluso associado à lesão, sendo que outro havia sido tratado previamente, tornando difícil a avaliação desta ocorrência. Vários autores relataram lesões com aspecto radiográfico multilocular, como Al-khateeb e Ababneb (2003) (1/6), Nakamura et al. (1995) (9/24 casos - 37,5\%); Rosenstein et al. (2001) (6/21 29\%); e Torres-Lagares et al. (2005) (2/3). Neste trabalho, um caso de AU também mostrou imagem multilocular. O aspecto multilocular associado ao AU está relacionado principalmente com a persistência de traves ósseas de resistência da mandíbula visualizadas na radiografia panorâmica. A avaliação destes casos por TC mostraria, provavelmente, que esta "multilocularidade" não é real, pois as loculações se intercomunicam. Esta avaliação é importante, pois autores como Gardner (1996) colocam como critério para o diagnóstico de $\mathrm{AU}$, aspecto radiográfico unilocular.

A incidência do AU dentre os ameloblastomas varia de 6\% (REICHART; PHILIPSEN; SONNER, 1995) a 16\% (POON; WU; SO, 1996). Neste estudo, esta variante representou 11,3\% da amostra (6 em 53), estando dentro da média descrita na literatura. Outro aspecto importante é a subclassificação do AU em suas variantes luminal, intraluminal e mural, visto que esta última representaria maior risco de recidiva (GARDNER; PECAK, 1980; REICHART; PHILIPSEN; SONNER, 1995). Esta informação é confirmada apenas com a avaliação histopatológica feita após a remoção de toda peça cirúrgica, o que torna sua aplicabilidade limitada antes da 
cirurgia definitiva. Concordamos com a orientação de Ferretti, Polakow e Coleman (2000), indicando que todo AU seja tratado como portador de infiltração capsular por ilhas tumorais. Na casuística de Poon, Wu e So (1996), todos os casos (oito) apresentavam infiltração da cápsula. Nesta série, dois casos apresentavam infiltração tumoral na cápsula cística. Portanto, julgamos que a simples enucleação não se justifique como tratamento destas lesões, devendo-se realizar, no mínimo, uma curetagem vigorosa da loja cirúrgica após a enucleação da lesão.

Vários autores consideram o AU como uma variante de comportamento menos agressivo que o ASM (CURI; DIB; PINTO, 1997; GARDNER, 1984; NAKAMURA et al., 1995; POON; WU; SO, 1996; ROBINSON; MARTINEZ 1977). Na revisão de Reichart, Philipsen e Sonner (1995), houve 13,7\% de recidivas; AlKhateebi e Ababneb (2003) não relataram nenhuma recidiva em seus casos tratados por curetagem e ostectomia periférica. Opiniões diferentes são apresentadas por outros autores, que consideram esta variante agressiva e com índices de recidiva elevados (GHANDHI et al., 2006; ROSENSTEIN et al., 2001). Estes preconizam tratamento radical, por meio de ressecção, mesmo para o AU. Nesta pesquisa, dois casos de AU foram tratados por curetagem e quatro casos por curetagem associada à crioterapia, não sendo observada a ocorrência de recidiva.

O AP é considerado como uma variante extra-óssea do ameloblastoma, de ocorrência gengival e com pouco significado clínico. Não houve caso de AP na amostra estudada.

Também não houve nenhum caso de $A D$ nesta casuística. $O A D$, anteriormente considerado uma variante histológica, representa agora um subtipo específico do ameloblastoma (GARDNER et al., 2005). A lesão apresenta características peculiares, como predomínio de ocorrência na região anterior dos 
maxilares, aspecto radiográfico misto e colagenização acentuada do estroma tumoral. O reflexo destes achados no comportamento clínico da lesão ainda é pouco conhecido, com alguns autores o considerando menos agressivo (HONG et al., 2007; NAKAMURA et al., 2002), outros o considerando de comportamento semelhante ao ASM (GARDNER, 1996; KAWAl et al., 1999) e outros sugerindo que a variante apresenta comportamento mais agressivo, devido a dificuldade de diferenciação entre lesão e osso normal, o que dificulta o tratamento cirúrgico (WALDRON; eL MOFTY, 1987).

Outro tópico de especial interesse, especialmente em relação ao tratamento cirúrgico conservador do ameloblastoma, é a forma com que a lesão se comporta em relação às estruturas anatômicas adjacentes. Esta avaliação é feita principalmente através de espécimes cirúrgicos ressecados e serve como um parâmetro teórico que embasa o tratamento conservador. É consenso que o potencial infiltrativo da lesão ocorre basicamente em osso medular, onde ilhas tumorais penetram numa distância de 1 a 14 mm além da lesão macroscópica, sendo a média de 5 mm Barbachan ${ }^{3}$ (1999, apud GOMES et al., 2002) e Carlson ${ }^{4}$ (2000, apud CARLSON; MARX, 2006). Já o osso cortical pode ser expandido e erodido com a evolução do tumor, mas não apresenta tendência a invasão (GARDNER, 1980; MULLER; SLOOTWEG, 1985). Apenas Gortzak et al. (2006) encontraram infiltração tumoral nos canais harvesianos do osso cortical de grandes tumores, mas o periósteo permaneceu como barreira contra a disseminação tumoral. Achado este também relatado por Muller e Slootweg (1985), que não identificaram barreira quando o tumor está contíguo à mucosa bucal. Nos pacientes deste estudo,

\footnotetext{
${ }^{3}$ Barbachan JJD, et al. Estudo comparativo entre os limites radiográfico e histológico em ameloblastomas. Rev Fac Odontol Porto Alegre 1999;40(1):49-54.

${ }^{4}$ Carlson ER. Ameloblastoma. In: Symposium on Odontogenic tumors, AAOMS $82^{\text {nd }}$ Annual Meeting and Scientific Sessions, San Franscisco, CA, September 23; 2000.
} 
a mucosa bucal em contato com a lesão foi removida, as corticais remanescentes (após acesso cirúrgico) não papiráceas foram preservadas, visando manter a continuidade mandibular e favorecer a reparação óssea, enquanto o osso medular peritumoral foi vigorosamente curetado, buscando atingir a cortical.

A relação entre o ameloblastoma e o nervo alveolar inferior também é bastante freqüente pela alta incidência do tumor na região posterior da mandíbula. Os estudos mostram haver delimitação entre estas estruturas e que a bainha neural e o nervo não são infiltrados pelo tumor (GORTZAK et al., 2006; NAKAMURA et al., 2001; SACHS, 2006). No presente trabalho, houve a tentativa de preservar o nervo alveolar inferior em todos os casos de tratamento conservador (Apêndice D), porém em um paciente ocorreu a neurotmese iatrogênica do mesmo.

O tratamento do ameloblastoma é o aspecto mais discutido e controverso na literatura. Há duas correntes principais que ditam a abordagem terapêutica desta lesão. O tratamento radical, que preconiza a remoção do tumor em bloco com margem de segurança, de forma que não haja exposição das células tumorais ao campo cirúrgico, ocasionando ou não defeito de continuidade mandibular e o tratamento conservador, que se baseia na remoção do tumor, com preservação do osso adjacente. Esta técnica pode ou não ser associada a terapias adjuvantes.

Os autores se dividem na indicação destas abordagens, defendendo, cada qual, os benefícios de sua opção. De uma maneira geral, o tratamento radical é o que fornece maior índice de cura, mas trata-se de um procedimento mais invasivo, que freqüentemente deve ser associado a cirurgias reconstrutivas. Ao se considerar a recidiva da doença como único critério de sucesso do tratamento, esta abordagem é sempre a que oferece melhores resultados. O tratamento conservador baseia-se 
em uma abordagem cirúrgica de menor morbidade. Entretanto, o índice de recidiva tende a ser maior neste grupo de pacientes.

O presente estudo reflete uma forte tendência de adoção do tratamento conservador do ameloblastoma. Dos 53 pacientes avaliados, 48 (90,6\%) foram tratados por curetagem ou curetagem associada à crioterapia e cinco $(9,4 \%)$ por ressecção (uma de partes moles). O pequeno número de casos deste grupo (ressecção) fez com que optássemos por realizar a análise estatística para comparação de algumas variáveis somente entre os dois grupos de tratamento conservador.

A crioterapia é uma modalidade terapêutica coadjuvante preconizada por alguns autores no tratamento do ameloblastoma, que visa, basicamente, diminuir a taxa de recidiva do tratamento conservador, evitando ou reduzindo a indicação da cirurgia radical. Estes objetivos foram atingidos por Curi, Dib, Pinto (1997), Salmassy e Pogrel, (1995) e Sampson e Pogrel (1999). O tratamento por curetagem associada à crioterapia foi inicialmente empregado nos pacientes desta série, com realização de três ciclos de congelamento (Apêndice E). Por ter sido a modalidade inicial de tratamento, o tempo de acompanhamento médio destes pacientes (69,6 meses) foi maior que do grupo de curetagem (55,5 meses). Durante o acompanhamento destes pacientes, foi observado que, apesar de um aparente índice de recidiva baixo, muitas complicações locais, provavelmente associadas à crioterapia, estavam ocorrendo. Dentre estas, destacaram-se a formação de seqüestro ósseo, fratura patológica da mandíbula e um caso de osteomielite supurativa crônica.

A formação de seqüestro ósseo ocorre pela incapacidade de revascularização de segmentos, principalmente corticais, que se desvitalizam após o congelamento. A conseqüência clínica é a perda de uma porção óssea, que normalmente leva a uma 
diminuição da altura óssea mandibular após a remodelação, além de uma redução da resistência mandibular (Apêndice F). Nesta análise, houve significância estatística na ocorrência de seqüestro ósseo nos pacientes que fizeram curetagem associada à crioterapia $(p=0,017)$ em relação aos pacientes tratados por curetagem apenas. Esta complicação ocorreu em 40\% dos casos (12/30) daquele grupo.

Fratura patológica também foi uma complicação presente nos pacientes tratados por curetagem associada à crioterapia, ocorrendo em seis casos (20\%). Incidência maior que a relatada por Curi, Dib e Pinto (1997), que a encontraram em $11,1 \%$ e igual à de Salmassy e Pogrel (1995), que tiveram duas fraturas em 10 pacientes tratados sem associação com enxerto ósseo. Estes autores preconizam a realização de enxerto ósseo imediato para reduzir esta complicação. Das seis fraturas diagnosticadas nos pacientes deste estudo, uma ocorreu no transoperatório, sendo tratada com fixação interna rígida com placa reconstrutiva (Apêndice $G$ ). As restantes foram diagnosticadas entre o segundo e terceiro mês de controle pósoperatório, corroborando com os estudos de resistência óssea após crioterapia realizado por Fisher, Williams e Bradley (1978), que mostraram que o período de maior risco é por volta da oitava semana de pós-operatório. Em apenas um caso houve deslocamento dos cotos ósseos, mesmo com o paciente sob bloqueio intermaxilar, sendo necessária reintervenção cirúrgica (Apêndice H). Nos outros quatro casos, fez-se orientação de dieta e restrição de movimentos mandibulares, observando boa evolução com consolidação óssea. Em quatro casos relatados por Curi, Dib e Pinto (1997), não houve deslocamento dos cotos fraturados. Não houve nenhum caso de fratura patológica nos pacientes tratados por curetagem apenas. Apesar de não ter sido constatada significância estatística nesta análise, o valor de $p=0,071$ reforça a associação entre crioterapia e o maior risco de fratura patológica 
mandibular. A não significância estatística se deve ao baixo número de casos analisados.

Outra complicação observada em uma paciente tratada por curetagem e crioterapia, foi a evolução para osteomielite supurativa crônica de mandíbula, que agudizou após nove meses de pós-operatório, quando foi então tratada por limpeza cirúrgica. A paciente evoluiu bem, não apresentando outras complicações (Apêndice I).

O nervo alveolar inferior parece ser uma estrutura resistente ao congelamento, havendo regeneração após um período de três a quatro meses como demonstrado por Bradley (1978). Nesta série, a parestesia transitória foi semelhante nos dois grupos avaliados em decorrência da própria manipulação do nervo durante a cirurgia. Porém a parestesia permanente foi maior nos pacientes submetidos à crioterapia $(33,3 \%)$ em relação aos tratados por curetagem $(22,2 \%)$. Ocorrência significativamente maior que a de Curi, Dib e Pinto (1997) que foi de 5,5\%. A avaliação desta complicação foi feita apenas em base subjetiva, questionando o paciente sobre a sensibilidade da região inervada. $\mathrm{O}$ emprego de testes específicos para avaliação da parestesia pode oferecer resultados mais fiéis, porém a análise retrospectiva dos casos impossibilitou esta realização. Apesar do alto índice de parestesia residual observada em ambos os grupos, esta alteração não parece ser limitante para os pacientes, como também observado por Schmidt e Pogrel (2004).

Infecção da ferida cirúrgica, caracterizada pela presença de exsudato purulento com drenagem intra-oral também foi mais prevalente no grupo de curetage associada à crioterapia $(16,7 \%)$ que no grupo de curetagem $(5,5 \%)$. Curi, Dib e Pinto (1997) relataram 5,5\% dos casos com infecção após crioterapia. O fato de haver uma via aberta de drenagem para o meio bucal torna esta complicação menos 
mórbida e tratada, normalmente, por cuidados locais como irrigação com soro fisiológico 0,9\%. Em um caso, a infecção foi acompanhada por celulite e posterior fratura patológica, sendo o tratamento feito por antibioticoterapia e cuidados locais. Outro evoluiu para osteomielite. Esta associação não foi encontrada na literatura, mas a necrose óssea secundária à crioterapia pode justificá-la.

Deiscência da ferida cirúrgica foi a ocorrência mais freqüente no pósoperatório em ambos os grupos, ocorrendo em $86,6 \%$ dos casos tratados por curetagem associada à crioterapia e em $88,8 \%$ dos casos tratados por curetagem. Este achado se justifica pelo fato da sutura ser feita em mucosa sem apoio de tecido ósseo e sobre um grande defeito cirúrgico. Como conseqüência, ocorre uma fenestração na incisão de menor ou maior extensão entre a primeira e terceira semana de pós-operatório, comunicando o defeito cirúrgico com o meio bucal (Apêndice J). Isto leva ao acúmulo de resíduos alimentares e necessidade de irrigações freqüentes com solução salina. Houve fechamento espontâneo em todos os casos entre dois e três meses de pós-operatório. Interessantemente, Curi, Dib e Pinto (1997) relataram apenas 36,1\% de deiscência em seus casos. Chima, Seldin e Dodson (2006) também sugerem o fechamento primário das lojas cirúrgicas após remoção de lesões intra-ósseas. Este procedimento proporciona menor número de visitas pós-operatórias sem aumentar as complicações inflamatórias.

É difícil estabelecer a profundidade do dano ósseo ocasionada pela crioterapia. Variáveis como o tempo de congelamento, número de ciclos, tipo de osso (cortical ou esponjoso), espessura do osso residual e principalmente, o diâmetro da ponta do aparelho que ejeta o nitrogênio não são bem estabelecidas na literatura. Estas variações fazem diferença na ocorrência e na intensidade das complicações. A crioterapia pode ser considerada como um complemento da 
curetagem, que visa eliminar células neoplásicas não removidas por esta. O índice de complicações, especialmente no grupo de crioterapia deste estudo, pode ser considerado elevado, de maneira que com o aprimoramento da curva de aprendizado cirúrgico, lesões extensas, que afilavam a borda inferior da mandíbula passaram a ser tratadas apenas por curetagem para diminuir o risco de fratura mandibular. Curiosamente, após a adoção desta conduta, foi observada menos complicações pós-operatórias sem aumento no índice de recidiva.

Outro tratamento adjuvante pré-operatório realizado em três casos (25, 34 e 35) foi a marsupialização de tumores císticos extensos, que ocasionavam grande comprometimento das corticais ósseas, inviabilizando tratamento inicial conservador. Em um dos casos, já havia fratura patológica da mandíbula (Apêndice $K$ ), sendo classificado como ASM de padrão histológico misto; os outros dois eram AU. O tempo de descompressão pré-operatória variou de cinco a onze meses, período no qual ocorreu redução do volume inicial da lesão e espessamento ósseo significativo das corticais adjacentes, viabilizando tratamento cirúrgico definitivo, que consistiu de curetagem associada à crioterapia em um caso (ASM) e curetagem em outros dois (AU). Esta abordagem é defendida por Huang et al. (2007), Nakamura et al. (1995, 2002) e Takahasi, Miyauchi e Sato (1998), o qual comentaram sobre a neoformação óssea que tende individualizar o nervo alveolar inferior do tumor a medida que a lesão regride. Este fato foi observado nos três pacientes desta série, sendo que dois tiveram parestesia transitória e nenhum parestesia permanente.

Yokobaiashi et al. (1983) apontaram a possibilidade de ameloblastomas submetidos à descompressão serem estimulados e se tornarem mais agressivos. Bernabé (2005) investigaram a efetividade da descompressão no tratamento inicial de oito ameloblastomas e os efeitos desse tipo de tratamento conservador nas 
características histopatológicas e de proliferação celular do tumor. A técnica mostrou ser efetiva para redução do tamanho do tumor e aumento do suporte ósseo, reduzindo a necessidade da realização de mandibulectomia e prevenindo suas complicações. A redução do tumor pela descompressão parece estar associada a uma modificação benéfica do epitélio tumoral sem indícios de aumento da proliferação celular.

Al Khatebb e Ababneb (2003) e Takahashi, Miyauchi e Sato (1998) ressaltaram a importância de se evitar ressecções mandibulares em crianças em vista das eventuais alterações estéticas, funcionais e psicológicas resultantes. A ressecção conservadora, precedida ou não por descompressão, deve ser o tratamento de escolha, sempre que houver possibilidade de acompanhamento. No mínimo, este procedimento permite ganhar tempo até o término do crescimento facial. Neste estudo, 11 pacientes (20,7\%) tinham idade menor ou igual a 16 anos, estando, portanto, em fase de crescimento. Nenhum apresentou alteração do desenvolvimento facial, diferente dos resultados de Huang et al. (2007), que relataram deformidade facial em quatro pacientes em idade de desenvolvimento submetidos a mandibulectomia e reconstrução com enxerto ósseo.

Outro parâmetro avaliado neste estudo foi a preservação ou não do contorno facial após o tratamento. Esta variável é importante, pois pode interferir diretamente na reintegração do paciente às suas atividades normais, especialmente por se tratar de uma população jovem (66\% com menos de 30 anos) com idade média de 27 anos, na qual o fator estético desempenha um papel muito relevante. Alteração do contorno facial foi observada em 10\% (3 em 30) dos pacientes tratados por curetagem e crioterapia. Em dois casos, a assimetria foi secundária a lesões extensas, que ocasionavam severa distorção da madíbula no pré-operatório e que, 
após remodelação óssea, permanenceram com abaulamento na base da mandíbula. Outro caso evoluiu com fratura patológica e deslocamento, necessitando de cirurgia reconstrutiva, permanecendo com discreta assimetria facial. No grupo tratado por curetagem, 11,1\% (2 em 18) evoluíram com assimetria, porém uma paciente havia sofrido ressecção prévia e reconstrução mandibular com enxertia de costela, o que justifica a assimetria. Em outro caso, também houve permanência de abaulamento da cortical inferior da mandíbula. As expansões das corticais vestibular e lingual, especialmente do ramo mandibular evoluíram com remodelação completa, mesmo quando apresentavam deformações acentuadas, provavelmente pela ação da musculatura matigatória inserida nestas regiões. Sachs (2006) e Takahashi, Miyauchi e Sato (1998) também relataram resultados estéticos muito satisfatórios com o tratamento conservador.

O comprometimento da borda inferior da mandíbula por expansão, afilamento e/ou erosão não foi um fator limitante da indicação do tratamento conservador nesta série, visto que $57,1 \%$ (28/49) das lesões mandibulares tratadas apresentavam algum tipo de envolvimento desta cortical. Não foi utilizado material de síntese, tais como placas reconstrutivas, para prevenir a ocorrência de fratura mandibular. Ao que parece, a expansão das corticais aumenta a área de superfície da mandíbula que permanece inserida no periósteo e na musculatura em toda porção inferior. Com a realização de acesso intra-oral, esta condição permite a manutenção da continuidade mandibular durante o período de reparação óssea (Apêndice L). Outros autores consideram que o envolvimento da cortical basal pelo tumor é um fator decisivo para indicação de ressecção mandibular (BECELLI et al., 2002; GARDNER; PECAK, 1980; GORTZAK et al., 2006; GÜMGÜM; HOSGÖREN, 2005; SAMPSON; POGREL, 1999). As corticais vestibular e lingual também foram preservadas sempre 
que possível, restringindo-se à remoção necessária para adequado acesso cirúrgico, como preconizado por Crawley e Levin (1978) e contestado por Gardner e Pecak (1980). Esta conduta é de grande valia na preservação da altura mandibular após o processo de remodelação óssea, favorecendo a reabilitação protética (Apêndice M).

Um aspecto importante relacionado à curetagem é o fato de tratar-se de uma técnica muito sensível ao operador e difícil de ser reproduzida de modo padronizado. Sua eficácia está na dependência da experiência do cirurgião, do adequado manejo transoperatório, da qualidade do instrumental utilizado, de características específicas de cada lesão, entre outros fatores. Estas variáveis talvez justifiquem a diversidade de resultados observada na literatura com o emprego de uma mesma técnica.

A ostectomia periférica representa uma interessante técnica complementar à curetagem, visto que permite a obtenção de margem de segurança em osso esponjoso de maneira mais previsível, sendo descrita detalhadamente por Sachs (2006). É contestada por Carlson e Marx (2006), que consideram a possibilidade de disseminação de células tumorais no leito cirúrgico. Neste trabalho, a ostectomia foi realizada nas lesões com aspecto radiográfico de favos de mel, visto que as pequenas loculações formadas por infiltração tumoral em espessos remanescentes ósseos, impedem o acesso a uma curetagem efetiva. Esta técnica permite uma melhora efetiva da curetagem com maior previsão de viabilidade do osso residual. Sachs (2006) e Torres-Lagares et al. (2005) não relataram recidivas em suas séries com o emprego desta técnica.

O ameloblastoma localizado na maxila é relatado como tendo características especiais pela proximidade com regiões anatômicas nobres. Estes fatores associados aos altos índices de recidiva publicados na literatura (OLAITAM; ADEOLA; ADEKEYE, 1993; SEHDEV et al., 1974) tornam a ressecção com margem 
de segurança, o tratamento de escolha pela maioria dos autores (CRAWLEY; LEVIN, 1978; GARDNER; PECAK, 1980; ZANE, 1991). Curi, Dib e Pinto (1997) trataram dois pacientes com curetagem e crioterapia com bons resultados. Nesta série, três pacientes (5,6\%) apresentavam lesões maxilares, sendo dois tratados por curetagem e um por curetagem associada à crioterapia. Não houve recidiva em acompanhamento clínico e tomográfico de 37, 48 e 66 meses pós-operatório (Apêndice N).

O tratamento de escolha para o ameloblastoma, usualmente recomendado por vários autores ainda é a ressecção mandibular, especialmente em lesões que causam destruição de corticais ósseas e envolvem o ramo mandibular (CARLSON; MARX, 2006; HATADA et al., 2001; OLAITAM; ADEOLA; ADEKEYE, 1993; REICHART; PHILIPSEN; SONNER, 1995; VAYVADA et al., 2006). A margem de segurança preconizada varia de 1 a $3 \mathrm{~cm}$ de osso normal (MARTINS et al., 1999; OLAITAM; ADEOLA; ADEKEYE, 1993). Sachs (2006) considera que para se obter esta margem, apenas lesões pequenas poderiam ser tratadas sem ocasionar descontinuidade mandibular e que a presença de cortical parece ser um fator mais importante em termos de barreira anatômica do que a distância em si. Para Nakamura et al. (1995), esta abordagem é usualmente indicada, mas está associada a seqüelas funcionais e estéticas importantes, especialmente em crianças. De outra forma, Vayvada et al. (2006) obteve resultados estéticos e funcionais adequados em 11 pacientes tratados por ressecção e reconstrução com retalho microcirúrgico, associado a implantes osseointegrados em três casos. Carlson e Marx (2006) também consideram que a reconstrução imediata promove bons resultados. Ferretti, Polakow e Coleman (2000) julgam que a morbidade associada a ressecções, mesmo envolvendo a linha média, é menor que a observada para múltiplas 
curetagens para tratamento de recidivas. Olaitam, Adeola e Adekeye (1993) realizaram mandibulectomia segmentar em 215 pacientes, mas apenas 31 tiveram cirurgia reconstrutiva, enquanto 184 permaneceram sem reconstrução. Chidzonga (1996) tratou 20 pacientes com menos de 18 anos por ressecção, sendo que três tiveram reconstrução óssea. Hatada et al. (2001) defenderam reconstrução óssea e neural após ressecções para minimizar seqüelas, mas de 86 pacientes tratados, 77 receberam enxerto ósseo e 31 reconstrução neural.

Nesta série, quatro pacientes $(7,5 \%)$ foram tratados por mandibulectomia segmentar com margem de $1,5 \mathrm{~cm}$ e desarticulação em dois casos, perfazendo um tempo de acompanhamento médio de 74,2 meses sem evidência de recidiva. A indicação principal foi a extensão das lesões, que comprometia de forma acentuada todas as corticais ósseas adjacentes. Reconstrução imediata do defeito ósseo foi realizada com retalho microcirúrgico de fíbula em três casos e placa reconstrutiva com côndilo de acrílico em outro. As principais complicações foram alteração do contorno facial em todos os casos, sendo discreta em dois e evidente em dois por posicionamento inadequado da fíbula (Apêndice O); anestesia permanente da região inervada pelo nervo alveolar inferior; presença da ilha cutânea em região alveolar, dificultando a reabilitação e desvio mandibular durante abertura bucal. No paciente reconstruído com placa reconstrutiva, houve fratura da mesma após nove anos, sendo necessária remoção e reconstrução com retalho microcirúrgico de fíbula (Apêndice P). Nenhum destes pacientes recebeu reabilitação dental. Ferretti, Polakow, Coleman (2000) e Sampson e Pogrel (1999) também comentaram o baixo índice de pacientes reabilitados com implantes osseointegrados, provavelmente para evitar outras intervenções cirúrgicas e por causas financeiras. Em vista do porte cirúrgico, tempo de internação, morbidade da área doadora, necessidade de 
participação de outras equipes, custos hospitalares e expectativa de resultados, este procedimento, em nossa opinião, deve ser indicado para casos extremos, onde outras terapias não possam ser realizadas por causas locais (extensão da lesão) ou relacionadas ao paciente (opção pessoal).

Enxerto ósseo tardio foi realizado em cinco pacientes, sendo dois em casos de fratura patológica, com finalidade de restabelecer a continuidade mandibular e três com objetivo de viabilizar a instalação de implantes osseointegrados (Apêndice Q). Houve sucesso em todos os casos. Esta conduta está em concordância com Ferretti, Polakow e Coleman (2000) e Schimmele (2001), que defendem a reconstrução óssea tardia de defeitos de continuidade mandibular, quando for utilizado enxerto ósseo livre. Esta abordagem reduz drasticamente a taxa de complicações associada com reconstrução óssea imediata. Estas complicações se devem, provavelmente, à ampla comunicação entre o leito cirúrgico e o meio intrabucal, normalmente presente nestas cirurgias. Esta comunicação tende a contaminar e comprometer total ou parcialmente o enxerto ósseo.

Tumores que envolvem o tecido mole após cirurgia de ressecção têm, sabidamente, comportamento agressivo e sua erradicação completa é muito difícil, mesmo com tratamentos mais agressivos como relatado por Ferretti, Polakow e Coleman (2000) e Sampson e Pogrel (1999). Neste trabalho, houve um caso de uma paciente tratada por ressecção em outro serviço, que evoluiu com lesão nos tecidos moles adjacentes, sendo operada três vezes por recidivas. Este comportamento se deve à perda das barreiras anatômicas, especialmente do periósteo e implantação de lesão nos tecidos adjacentes (Apêndice R). Farzard (2000) reforça que esta evolução está sempre associada à disseminação iatrogênica do tumor. 
Um dos principais tópicos discutidos a respeito do ameloblastoma, e fator determinante para escolha do tratamento, é a taxa de recidiva. Há praticamente uma unanimidade na literatura de que as cirurgias radicais proporcionam uma menor taxa de recidiva. Entretanto, as complicações implícitas à cirurgia reconstrutiva, especialmente envolvendo crianças, região sinfisária e articulação têmporomandibular tendem a ser mais relevantes. Outro fator importante a ser considerado refere-se à diferenciação entre recidiva e lesão residual. Na maior parte das vezes, as "recidivas" parecem representar tumor, que não foi totalmente removido por tratamento inicial inadequado, tornando-se clínica e radiograficamente evidente após um período de tempo. Vários autores concordam com esta teoria (BECELLI et al., 2002; CARLSON; MARX, 2006; GARDNER; PECAK, 1980; POON; WU; SO, 1996; YOKOBAYASHI et al., 1985). O comportamento infiltrativo do ameloblastoma, sua extensão, normalmente ampla, e localização, freqüentemente envolvendo região posterior, tornam a cirurgia - especialmente a conservadora - tecnicamente difícil. Esta opinião contrasta com a de Carlson e Marx (2006), que consideraram a cirurgia conservadora mais simples de ser executada, sendo realizada por acesso intra-oral e sem necessidade de reconstrução óssea. Isto estimularia cirurgiões menos experientes a optar pela técnica e interpretar permanência do tumor como recidiva, não reconhecendo sua falha em selecionar e executar a cirurgia inicial. Alguns relatos reforçam estas divergências. Ferretti, Polakow e Coleman (2000) descreveram uma mandibulectomia de um ameloblastoma com extensão para fossa infra-temporal, removido incompletamente por dificuldades cirúrgicas. Após seis meses, observou-se lesão em região temporal, interpretada como tumor recidivante. Pizer, Page e Svirsky (2002) também relataram recidiva de um ameloblastoma tratado conservadoramente, porém nem os dentes envolvidos pelo tumor foram 
removidos na cirurgia inicial (Anexo B). Estas ocorrências refletem a dificuldade de se avaliar e interpretar resultados de abordagens não padronizadas descritas com mesma nomenclatura.

Os resultados deste estudo mostraram uma baixa taxa de recidiva associada ao tratamento conservador (8,3\%). A taxa de recidiva associada ao tratamento por curetagem foi de 5,6\% (1 em 18 casos) em um tempo de acompanhamento médio de 55,5 meses, enquanto a taxa de recidiva associada à curetagem seguida de crioterapia foi de 10\% (3 em 30) em um tempo de acompanhamento médio de 69,7 meses. Se considerarmos apenas o casos de ASM (4 em 42), a taxa de recidiva foi de 9,5\%. Olaitan, Adeola e Adekeye (1993) relataram sete recidivas (36,8\%) em 19 pacientes tratados de ameloblastoma por enucleação e uma recidiva em um paciente tratado por curetagem. Reichart, Phillipsen e Sonner (1995) revendo 622 casos tratados de forma conservadora, sem especificação do tipo de tratamento, encontraram uma taxa de recidiva de 34,7\%. Curi, Dib e Pinto (1997) obtiveram $30,5 \%$ de recidiva em 36 casos tratados por curetagem e crioterapia com tempo de acompanhamento variando de 14 meses a 10 anos. Salmassy e Pogrel (1999) não tiveram recidiva em quatro casos de ameloblastoma tratados por curetagem e crioterapia. Farzard (2000) tratou quatro casos de ameloblastoma por curetagem, havendo três recidivas entre três e seis anos de controle pós-operatório. Hatada et al. (2001) encontraram 13 recidivas $(19,7 \%)$ em 66 casos tratados por enucleação, nenhuma recidiva em 25 casos tratados por marsupialização e enucleação e quatro recidivas (50\%) em oito casos tratados por marsupialização em um período de sete meses a nove anos. Nakamura et al. (2002) trataram 36 pacientes de forma conservadora, sendo 31 destes por meio de descompressão isolada ou associada à curetagem, havendo 12 casos de recidiva $(33,3 \%)$ em um período de 
acompanhamento de 35 anos. Gümgüm e Hosgören (2005) não relataram recidiva em três pacientes tratados por enucleação e curetagem acompanhados por três anos. Hong et al. (2007) trataram 174 pacientes com ameloblastoma por enucleação com ou sem marsupialização prévia e enucleação seguida de curetagem, ocorrendo 51 recidivas $(29,3 \%)$.

Acreditamos que a baixa taxa de recidiva observada neste trabalho está relacionada a uma cuidadosa técnica cirúrgica, que envolve abordagem criteriosa do tecido mole, especialmente com a remoção da mucosa peritumoral, extração dos dentes em contato com a lesão, acesso cirúrgico adequado, remoção macroscópica do tumor e, principalmente, uma minuciosa curetagem da loja cirúrgica com inspeção de toda sua extensão e irregularidades. Esta curetagem da loja cirúrgica realizada após o tumor ter sido removido macroscopicamente consome a maior parte do tempo cirúrgico, sendo o principal responsável pela maior probabilidade de cura. A pressa na remoção do tumor e na curetagem do osso remanescente nem sempre são sinônimos de cirurgia bem feita, podendo levar a remoção incompleta do epitélio tumoral e a longo prazo ser determinante para a ocorrência da recidiva.

Há divergências em se considerar que uma recidiva implica em insucesso do tratamento. Alguns autores (BIANCHI et al., 1998; DARAMOLA; AJAGBE; OLUWASANMI, 1980; SÁ et al., 2004) defendem que as recidivas são representadas por lesões mais agressivas e invasivas, dificultando cirurgia de resgate. Carlson e Marx (2006) afirmam que o reaparecimento de um processo benigno já define a falha do tratamento. De outra forma, muitos (CURI; DIB; PINTO, 1997; HUANG et al., 2007; NAKAMURA et al., 2002; PIZER; PAGE; SVIRSKY, 2002; SACHS, 2006; TAKAHASHI; MIYAUCHI; SATO, 1998; WALDRON, 1966) entendem que a recidiva ocorre de forma localizada, permitindo reintervenção 
conservadora e controle da doença sem a necessidade de procedimentos extensos. Ao que nos parece, ambas as situações podem ocorrer, em qualquer tipo de tratamento, dependendo do volume e localização da lesão residual e momento em que o diagnóstico é realizado. Dos quatro casos de recidiva intra-óssea desta série, três foram diagnosticados em tempo oportuno e tratados de maneira simples (Apêndice S), enquanto outro teve evolução desfavorável por perda de adesão ao tratamento (Apêndice T).

Há casos de recidiva envolvendo o enxerto ósseo realizado após ressecções mandibulares (CHOI et al. 2006; FERRETTI; POLAKOW; COLEMAN, 2000). Martins e Fávaro (2004) consideram como origem do problema a presença de tumor residual nos cotos ósseos, no tecido mole adjacente ou por contaminação intra-operatória. Um dos casos desta série mostrava envolvimento tumoral extenso, acometendo o coto distal da ressecção, tecidos moles e sobrepondo-se à costela utilizada na reconstrução, mas sem infiltrá-la, provavelmente pela sua característica cortical (Apêndice U).

A possibilidade de realizar acompanhamento pós-operatório dos pacientes é um fator fundamental de sucesso. Apesar de a maioria das recidivas ocorrerem nos primeiros cinco anos de pós-operatório (HATADA et al., 2001; REICHART; PHILIPSEN; SONNER, 1995; TAKAHASHI; MIYAUCHI; SATO, 1998), vários autores relatam recidivas tardias (GHANDHI et al., 2006; OLAITAM; ADEOLA; ADEKEYE, 1993). O acompanhamento periódico permite a detecção precoce de eventuais recidivas e tratamento adequado das mesmas. Não há um protocolo definido para realização deste controle, mas sugere-se que seja feito de forma semestral nos primeiros dois anos de pós-operatório, anual até o décimo ano e bianual a partir deste, sem alta definitiva. 
Nesta série, o tempo médio de acompanhamento foi de cinco anos e meio. Concordarmos que o tempo mínimo de controle de dois anos adotado como critério de inclusão é baixo, mas cremos tratar-se de tempo suficiente para haver completa remodelação mandibular e avaliar presença de lesão residual evidente, que se manifestaria neste período de tempo. Pacientes que se encontram bem controlados nesta fase, têm ótimas possibilidades de controle da doença, desde que mantenham o acompanhamento adequado, mesmo apresentando eventuais recidivas. $\mathrm{Na}$ amostra, o tempo médio de diagnóstico de recidiva foi de 59 meses, sendo que em dois casos, estes diagnósticos foram tardios.

É muito difícil avaliar se o paciente irá aderir ao acompanhamento necessário ao qual é orientado inicialmente. Com a presença da lesão, as preocupações e promessas de assumir compromissos estão sempre presentes. Com o passar do tempo, principalmente aliado a uma boa evolução, há uma tendência de acomodação e desistência. Da amostra inicial de 73 pacientes, 10 (13,7\%) foram excluídos por não terem mantido tempo mínimo de controle de dois anos; seis pacientes $(11,32 \%)$ que participaram do estudo estão com o tempo de controle defasado, o que pode levar a uma subestimativa da taxa real de recidiva. Hatada et al. (2001) manteve acompanhamento pós-operatório de 23,2\% dos pacientes de sua amostra. Isto alerta para a necessidade de um empenho adicional em se obter a adesão do paciente, buscando meios que viabilizem os retornos de forma menos burocrática, minimizando o número de consultas necessárias para cada controle e atualizando dados cadastrais, especialmente em pacientes da rede pública.

Este trabalho abrange um número razoável de pacientes tratados de ameloblastoma em uma mesma instituição e com a participação de um mesmo profissional, o que segundo Bataineh (2000) minimiza uma variável importante da 
amostra que é a participação de vários cirurgiões. Houve uma nítida preferência pelo tratamento conservador, inclusive ampliando as indicações formais desta modalidade terapêutica, especialmente em lesões extensas que envolvem a borda inferior da mandíbula. Esta abordagem terapêutica pode contribuir para evitar a realização de ressecções extensas, que mesmo acompanhadas por cirurgias reconstrutivas adequadas, apresentam grande morbidade. Cuidadosa técnica cirúrgica e curva de aprendizado diferenciada são essenciais para o tratamento destes pacientes. Aumento do tempo de acompanhamento e aprimoramento dos métodos de controle dos pacientes são fundamentais para comprovar os resultados por hora relatados. 


\section{CONCLUSÕES}

1. O ameloblastoma foi mais comum na segunda década de vida, o aumento volumétrico foi a queixa mais freqüente, a região posterior da mandíbula a mais afetada e houve predomínio do aspecto multilocular e dos padrões histopatológicos folicular e plexiforme.

2. A taxa de recidiva do ameloblastoma tratado por curetagem $(5,5 \%)$ e curetagem seguida de crioterapia (10\%) foi baixa em comparação com a maioria dos estudos da literatura.

3. O tratamento por meio de curetagem mostrou menos complicações em relação à curetagem seguida de crioterapia, especialmente em relação à formação de seqüestro ósseo e ocorrência de fratura patológica da mandíbula.

4. O afilamento da cortical basal da mandíbula não representou uma contraindicação para realização do tratamento conservador.

5. A recidiva do tumor não implicou necessariamente em insucesso do tratamento, quando diagnosticada e tratada em tempo oportuno. 


\section{REFERÊNCIAS 5}

Ackermann GL, Altini M, Shear M. The unicystic ameloblastoma: a clinicopathologic study of 57 cases. J Oral Pathol 1988;17(9-10):541-6.

Adebiyi KE, Odukoya O, Taiwo EO. Ectodermal odontogenic tumours: analysis of 197 Nigerian cases. Int J Oral Maxillofac Surg 2004;33(8):766-70.

Adebiyi KE, Ugboko VI, Omoniyi-Esan GO, Ndukwe KC, Oginni FO. Clinicopathological analysis of histological variants of ameloblastoma in a suburban Nigerian population. Head Face Med 2006;2:42.

Adekeye EO. Ameloblastoma of the jaws: a survey of 109 Nigerian patients. J Oral Surg 1980;38(1):36-41.

Adekeye EO, Lavery KM. Recurrent ameloblastoma of the maxillo-facial region. Clinical features and treatment. J Maxillofacial Surg 1986;14(3):153-7.

Al-Khateeb T, Ababneh KT. Ameloblastoma in young Jordanians: A review of the clinicopathologic features and treatment of 10 cases. J Maxillofacial Surg 2003;61(1):13-8.

Artés-Martinez MJ, Prieto-Rodríguez M, Navarro-Hervás $M$, Penãs-Pardo L, Camañas-Sanz A, Vaquero de la Hermosa MC, et al. Ameloblastoma. Diagnosis by means of FNAB. Report of two cases. Med Oral Patol Oral Cir Bucal 2005;10(3):205-9.

Atkinson $\mathrm{CH}$, Harwood AR, Cummings BJ. Ameloblastoma of the jaw. A reappraisal of the role of megavoltage irradiation. Cancer 1984;53(4):869-73.

\footnotetext{
${ }^{5}$ De acordo com Estilo Vancouver. Abreviatura de periódicos segundo base de dados MEDLINE.
} 
Bataineh AB. Effect of preservation of the inferior and posterior borders on recurrence of ameloblastomas of the mandible. Oral Surg Oral Med Oral Pathol Oral Radiol Endod 2000;90(2):155-63.

Becelli R, Carboni A, Cerulli G, Perugini M, lannetti G. Mandibular ameloblastoma: analysis of surgical treatment carried out in 60 patients between 1977 and 1998. J Craniofac Surg 2002;13(3):395-400.

Bernabé DG. Estudo clínico, imaginológico, histopatológico e imunohistoquímico de ameloblastomas submetidos à descompressão [Dissertação de Mestrado]. Faculdade de Odontologia da UNESP Araçatuba; 2005.

Bianchi SD, Tarello F, Polastri F, Valente G. Ameloblastoma of the mandible involving an autogenous bone graft. J Oral Maxillofac Surg 1998;56(10):1187-91.

Bradley, PF. Modern trends in cryosurgery of bone in the maxillo-facial region. Int $\mathrm{J}$ Oral Surg 1978;7(4):405-15.

Bradley PF, Fisher AD. The cryosurgery of bone. An experimental and clinical assessment. Br J Oral Surg 1975;13:111-27.

Carlson ER, Marx RE. The ameloblastoma: primary, curative surgical management. J Oral Maxillofac Surg 2006;64(3):484-94.

Chapelle KAOM, Stoelinga PJW, Wilde PCM, Brouns JJA, Voorsmit RACA. Rational approach to diagnosos and treatment of ameloblastomas and odontogenic keratocysts. Br J Oral Maxillofac Surg 2004;42(5):381-90.

Chidzonga MM. Ameloblastoma in children. Oral Surg Oral Med Oral Pathol Oral Radiol Endod 1996;81(2):168-70. 
Chima KK, Seldin EB, Dodson TB. Comparison of wound management methods after removal of maxillofacial osseous lesions. J Oral Maxillofac Surg. 2006;64(9):1398403.

Choi YS, Asaumi J, Yanagi Y, Hisatomi M, Konouchi H, Kishi K. A case of recurrent ameloblastoma developing in an autogenous iliac bone graft 20 years after the initial treatment. Dentomaxillofac Radiol 2006;35(1):43-6.

Crawley W, Levin S. Treatment of the ameloblastoma. A controversy Cancer 1978;42:357-63.

Curi MM, Dib LL, Pinto DS. Management of solid ameloblastoma of the jaws with liquid nitrogen spray cryosurgery. Oral Surg Oral Med Oral Pathol Oral Radiol Endod 1997;84(4):339-44.

Daramola JO, Ajagbe HA, Oluwasanmi JO. Recurrent ameloblastoma of the jaws: A rewiev of 22 cases. Plast Reconstr Surg 1980;65(5):577-9.

Eversole LR, Leider AS, Hansen LS. Ameloblastomas with pronounced desmoplasia. J Oral Maxillofac Surg 1984;42(11):735-40.

Farzad P. Ameloblastoma of the jaws. Huddinge: Institute of Odontology, Karolinska Instituted; 2000. p. 305-313.

Feinberg SE, Steinberg B: Surgical management of ameloblastoma. Current status of the literature. Oral Surg Oral Med Oral Pathol Oral Radiol Endod 1996;81:383.

Ferretti C, Polakow R, Coleman H. Recurrent ameloblastoma: report of 2 cases. J Oral Maxillofac Surg 2000;58:800-4. 
Fisher AD, Williams DF, Bradley PF. The effect of cryosurgery on the strength of bone. Br J Oral Surg 1978;15(3):215-22.

Gardner DG. A pathologist's approach to the treatment of ameloblastoma. J Oral Maxillofac Surg 1984;42(3):161.

Gardner DG. Some current concepts on the pathology of ameloblastomas. Oral Surg Oral Med Oral Pathol Oral Radiol Endod 1996;82(6):660-9.

Gardner DG, Heikinheimo K, Shear M, Philipsen HP, Coleman H. Ameloblastomas. In: Barnes L, Eveson JW, Reichart P, Sidransky D. Pathology and genetics of head and neck tumours. Lyon: IARC; 2005. (World Health Organization Classification of Tumours; 9).

Gardner DV, Pecak AMJ. The treatment of ameloblastoma based on pathologic and anatomic principles. Cancer 1980;46(1):2514-9.

Ghandhi D, Ayoub AF, Pogrel MA, MacDonald G, Brocklebank LM, Moos KF. Ameloblastoma: a surgeon's dilemma. J Oral Maxillofac Surg 2006;64(7):1010-4.

Gomes AAA, Dias E, Gomes DO, Paraíso DP, Nascimento GJF, Cabral RAA. Rev Cir Traumat Buco-Maxilo-Facial 2002;2(2):17-24.

Gortzak RATh, Latiel BS, Lekkas C, Slootweg PJ. Growth characteristics of large mandibular ameloblastomas: report of 5 cases with implications for the approach to surgery. Int J Oral Maxillofac Surg 2006;35(8):691-5.

Gümgüm S, Hosgören B. Clinical and radiologic behavior of ameloblastoma in 4 cases. J Can Dent Assoc 2005;71(7):481-4. 
Hatada K-I, Noma H, Katakura A, Yama M, Takano M, Ide Y, et al. Clinicostatistical study of ameloblastoma treatment. Bull Tokyo Dent Coll 2001;42(2):87-95.

Hollows P, Fasanmade A, Hayter JP. Ameloblastoma - a diagnostic problem. $\mathrm{Br}$ Dent J 2000;188(5):243-4.

Hong J, Yun PY, Chung IH, Myoung H, Suh JD, Seo BM, et al. Long-term follow up on recurrence of 305 ameloblastoma cases. Int J Oral Maxillofac Surg 2007;36(4):283-8.

Huang IY, Lai ST, Chen CH, Chen CM, Wu CW, Shen YH.Surgical management of ameloblastoma in children. Oral Surg Oral Med Oral Pathol Oral Radiol Endod 2007;104(4):478-85

Jackson IT, Callan PP, Forté RA. An anatomical classification of maxillary ameloblastoma as an aid to surgical treatment. J Craniomaxillofac Surg 1996;24(4):230-6.

Kahn MA. Ameloblastoma in young persons: A clinicopathologic analysis and etiologic investigations. Oral Surg Oral Med Oral Pathol 1989;67(6):706-15.

Kawai T, Kishino M, Hiranuma H, Sassai T, Ishida T. A unique case of desmoplastic ameloblastoma of the mandible: report of case and brief review of the English language literature. Oral Surg Oral Med Oral Pathol Oral Radiol Endod 1999;87(2):258-63.

Kim SG, Jang HS. Ameloblastoma: a clinical, radiographic, and histopathologic analysis of 71 cases. Oral Surg Oral Med Oral Pathol Oral Radiol Endod 2001;91:649-53. 
Kramer IRH. Ameloblastoma: a clinicopathological appraisal. $\mathrm{Br} \mathrm{J}$ Oral Surg 1963;1:13-28.

Lau SL, Samman N. Recurrence related to treatment modalities of unicystic ameloblastoma: a systematic review. Int J Oral Maxillofac Surg 2006;35(8):681-90.

Larsson A, Almeren H. Ameloblastoma of the jaws. Acta Pathol Microbiol Scand 1978;86 (5):337-49.

Leider AS, Eversole LR, Barkin ME. Cystic ameloblastoma. A clinicopathologic analysis. Oral Surg Oral Med Oral Pathol 1985;60(6):624-30.

Maia Campos G. Ameloblastoma a behvioral and histologic paradox (A philosophical approach). Braz Dent J 1990;1(1):5-15.

Martins RH, Sobrinho JA, Rapoport A, Rosa MP. Histopathologic features and management of ameloblastoma: study of 20 cases. São Paulo Med J $1999 ; 117(4): 171-4$.

Martins WD, Favaro DM. Recurrence of an ameloblastoma in an autogenous iliac bone graft. Oral Surg Oral Med Oral Pathol Oral Radiol Endod 2004;98(6):657-9.

Marx RE, Smith BH, Smith BR, Fridrich KL. Swelling of the retromolar region and cheek associated with limited opening. J Oral Maxillofac Surg 1993;51:304-9.

Mintz S, Velez I. Desmoplastic variant of ameloblastoma: report of two cases and review of the literature. J Am Dent Assoc 2002;133(8):1072-5.

Muller $\mathrm{H}$, Slootweg PJ. The growth characteristics of multilocular ameloblastomas: A histological investigation with some inferences with regard to operative procedures. J Maxillofac Surg 1985;13:224. 
Nakamura N, Higuchi Y, Mitsuyasu T, Sandra F, Ohishi M. Comparison of long-term results between different approaches to ameloblastoma. Oral Surg Oral Med Oral Pathol Oral Radiol Endod 2002;93(1):13-20.

Nakamura N, Higuchi Y, Mitsuyasu T, Sandra F, Ohishi M. Marsupialization of cystic ameloblastoma: A clinical and histopathologic study of the growth characteristics before and after marsupialization. J Oral Maxillofac Surg 1995;53(7):748-54.

Nakamura N, Mitsuyasu T, Higuchi Y, Sandra F, Ohishi M. Growth characteristics of ameloblastoma involving the inferior alveolar nerve: A clinical and histopathologic study. Oral Surg Oral Med Oral Pathol Oral Radiol Endod 2001;91(5):557-62.

Neville BW, Damm DD, Allen CM, Bouquot JE. Cistos e tumores odontogênicos. Rio de Janeiro: Guanabara Koogan; 2004. cap. 15, p. 566-616.

Ogunzalu C, Daisley H, Henry K, Bedayse S, White K, Jagdeo B, et al. A new radiological classification for ameloblastoma based on analysis of 19 cases. West Indian Med J. 2006;55(6):434-9.

Olaitan AA, Adeola DS, Adekeye EO. Ameloblastoma: clinical features and management of 315 cases from Kaduna, Nigeria. J Craniomaxillofac Surg 1993;21(8):351-5.

Peterson LJ, Ellis III E, Hupp JR, Trcker MR. Cirurgia Oral e Maxilofacial Contemporânea. Tratamento Cirúrgico das Lesões Patológicas Orais. $3^{a}$ ed. Rio de Janeiro: Guanabara Koogan; 2000.

Philipsen HP, Reichart PA. Unicystic ameloblastoma: A review of 193 cases from the literature. Oral Oncol 1998;34:317. 
Pinheiro JJV. Estudo Imuno-Histoquímico e zimográfico das metaloproteinases da matriz 1, 2 e 9 no ameloblastoma [Dissertação de Mestrado]. Faculdade de Odontologia da USP; 2002.

Pizer ME, Page DG, Svirsky JA.Thirteen-year follow-up of large recurrent unicystic ameloblastoma of the mandible in a 15-year-old boy. J Oral Maxillofac Surg 2002;60(2):211-5.

Poon CSP, Wu PC, So MKP. Ameloblastoma in Hong Kong Chinese. HKMJ $1996 ; 2(2): 172-6$.

Reichart PA, Philipsen HP, Sonner S. Ameloblastoma: biological profile of 3677 cases. Eur J Cancer B Oral Oncol1995;31b(2):86-99.

Robinson L, Martinez MG. Unicystic ameloblastoma: A prognostically distinct entity. Cancer 1977;40:2278.

Rosenstein T, Pogrel A, Smith RA, Regezi JA. Cystic ameloblastoma-Behavior and treatment of 21 cases. J Oral Maxillofac Surg 2001;59(11):1311-6.

Sá ACD, Zardo M, Paes Júnior AJO, Souza RP, Neme MP, Sabedotti I, et al. Ameloblastoma da mandíbula: relato de dois casos. Radiol Bras 2004;37(6):465-68.

Sachs SA. Surgical excision with peripheral ostectomy. A definitive yet conservative approach to the surgical management of ameloblastoma. Oral Maxillofac Surg Clin North Am 1991;3:99.

Sachs SA. Surgical excision with peripheral ostectomy. A definitive yet conservative approach to the surgical management of ameloblastoma. J Oral Maxillofac Surg 2006;64(3):476-83. 
Salmassy DA, Pogrel MA. Liquid nitrogen cryosurgery and immediate bone grafting in the management of aggressive primary jaw lesions. J Oral Maxillofac Surg 1995;53(7):784-90.

Sampson DE, Pogrel MA. Management of mandibular ameloblastoma: The clinical basis for a treatment algoritm. J Oral Maxillofac Surg 1999;57(9):1074-7.

Santos JN, Pereira Pinto L, Figueiredo CRLV, Souza LB. Odontogenic tumours: analysis of 127 cases. Pesq Odontol Bras 2001;15(4):308-13.

Santos JN, Souza VF, Azevedo RA, Sarmento VA, Souza LB. Caracterização imunohistoquímica de lesão híbrida de ameloblastoma desmoplásico e convencional. Rev Bras Otorrinolaringol 2006;72(5):709-13.

Sauk JJ. Basement membrane confinement of epithelial tumor island in benign and ameloblastomas. J Oral Pathol 1985;14(4):307-14.

Schimmele SR. Delayed reconstruction of continuity defects of the mandible after tumor surgery. J Oral Maxillofac Surg 2001;59(11)1340-4.

Schmidt BL, Pogrel MA. Neurosensory changes after liquid nitrogen cryotherapy. J Oral Maxillofac Surg. 2004;62(10):1183-7.

Sehdev MK, Huvos AG, Strong EW, Gerold FP, Willis GV. Ameloblastoma of maxilla and mandible. Cancer 1974;33(2):324-33.

Senra GS, Pereira AC, Murilo dos Santos L, Carvalho YR, Brandão AA Malignant ameloblastoma metastasis to the lung: a case report. Oral Surg Oral Med Oral Pathol Oral Radiol Endod. 2008;105(2):e42-6 
Small IA, Waldron CA. Ameloblastomas of the jaws. Oral Surg Oral Med Oral Pathol 1955;8(3):281-97.

Takahashi K, Miyauchi K, Sato K. Treatment of ameloblastoma in children. Br J Oral Maxillofac Surg 1998;36(6):453-6.

Tanaka N, Murata A, Yamaguchi A, Kohama G. Clinical features and management of oral and maxillofacial tumors in children. Oral Surg Oral Med Oral Pathol Oral Radiol Endod 1999;88(1):11-5.

Torres-Lagares D, Infante-Cossío P, Hernandez-Guisado JM, Gutierrez-Pérez JLH. Mandibular ameloblastoma. A review of the literature and presentation of six cases. Med Oral Patol Oral Cir Bucal 2005;10(3):231-8.

Vayvada H, Mola F, Menderes A, Yilmaz M. Surgical management of ameloblastoma in the mandible: segmental mandibulectomy and immediate reconstruction with free fibula or deep circumflex iliac artery flap (evaluation of the long-term esthetic and functional results. J Oral Maxillofac Surg 2006;64(10):1532-9.

Vickers RA, Gorlin RJ. Ameloblastoma: Delineation of early histopathologic features of neoplasia. Cancer 1970;26:699.

Waldron CA. Ameloblastoma in perspective. J Oral Surg 1966;24(4):331-33.

Waldron CA, el-Mofty SK. A histopathologic study of 116 ameloblastomas with special reference to the desmoplastic variant. Oral Surg Oral Med Oral Pathol 1987;63(4):441-51.

Whittaker DK. Mechanisms of tissue destruction following cryosurgery. Ann R Coll Surg Engl 1984;66:313-8. 
Williams TP. Management of ameloblastoma: a changing perspective. J Oral Maxillofac Surg 1993;51(10):1064-70.

Yokobayashi Y, Yokobayashi T, Nakajima T, Oyama T, Fukushima M, Ishiki T. Marsupialization as a possible diagnostic aid in cystic ameloblastoma. J max-fac Surg 1983;11(3):137-41.

Zane RS. Maxillary Ameloblastoma: documento/ conferência. Disponível em URL: http://www.bcm.edu/oto/grand/81091.html [1991 Fev. 28].

Zwahlen RA, Grätz KW. Maxillary ameloblastomas: a review of the literature and of a 15-year database. J Craniomaxillofac Surg 2002;(30):273-9. 


\section{APÊNDICES}


APÊNDICE A - Ficha padrão para coleta das informações nos prontuários

1. ID

2. RGHC

3. Idade (anos)

4. Etnia (1) Melanoderma (2) Leucoderma (3) Feoderma (4) xantoderma.

5. Sexo (1) masculino 2 (feminino)

6. Tempo de queixa (meses. (0) ND

7. Tipo de queixa (1) Dor (2) Tumor (3) Parestesia (4) Trismo (5) Outros

8. Tamanho radiográfico do tumor $(\mathrm{cm})$ (0) ND

9. Localização do tumor

(1) Maxila Posterior (2) Maxila Anterior (3) Mandíbula Posterior (4) Mandíbula anterior (5) Extra-ósseo 10. Infiltra mucosa bucal : (1) Sim (0) Não

11. Tratamento prévio

(1) Nenhum (2) Ressecção (3) Marsupialização (4) Curetagem (5) Crioterapia

12. Tipo histopatológico: (1) Plexiforme (2) Folicular (3) Misto (4) Células Basais (5) Células Granulares (6) Acantomatoso (7) Unicístico (8) Desmoplásico

13. Tipo de tratamento realizado.

(1) Ressecção marginal (2) Ressecção segmentar (3) Curetagem + crioterapia (4) Curetagem

(5) Marsupialização (6) Outros:

14. Data da cirurgia -

15. Recidiva (1) Sim (0) Não

16. Recidiva (1) Intra-óssea (2)Extra-óssea

17. Data da recidiva 1

18. Data da última informação . 1

19 Situação da ultima informação

(1) Vivo sem doença (2) Vivo com doença (3) Morto pela doença (4) Morto por outras causas (5) Perdido de vista

20. Padrão radiográfico (1) Unilocular (2) Multilocular (0) ND

21. Envolvimento da cortical V e L(P) (1) Preserva (2) Expande (3) Rompe (0) ND.

22. Envolvimento da cortical basilar (1) Preserva (2) Expande (3) Rompe (0) ND

23. Associação com elementos dentais.

(1) Deslocamento dental (2) Envolvimento tumoral (3) Reabsorção radicular (4) Nenhum (0) ND.

24. Complicações pós-operatórias

(1) Deiscência (2) Infecção (3) Seqüestro ósseo (4) Parestesia Transitória (5) Parestesia Permanente (5) Fratura Patológica

25. Contorno Facial .

(1) Preservado (2) Alterado 
APÊNDICE B - Paciente com ameloblastoma apresentando deformidade facial por aumento de volume acentuado em região mandibular esquerda após 4 anos de evolução do tumor

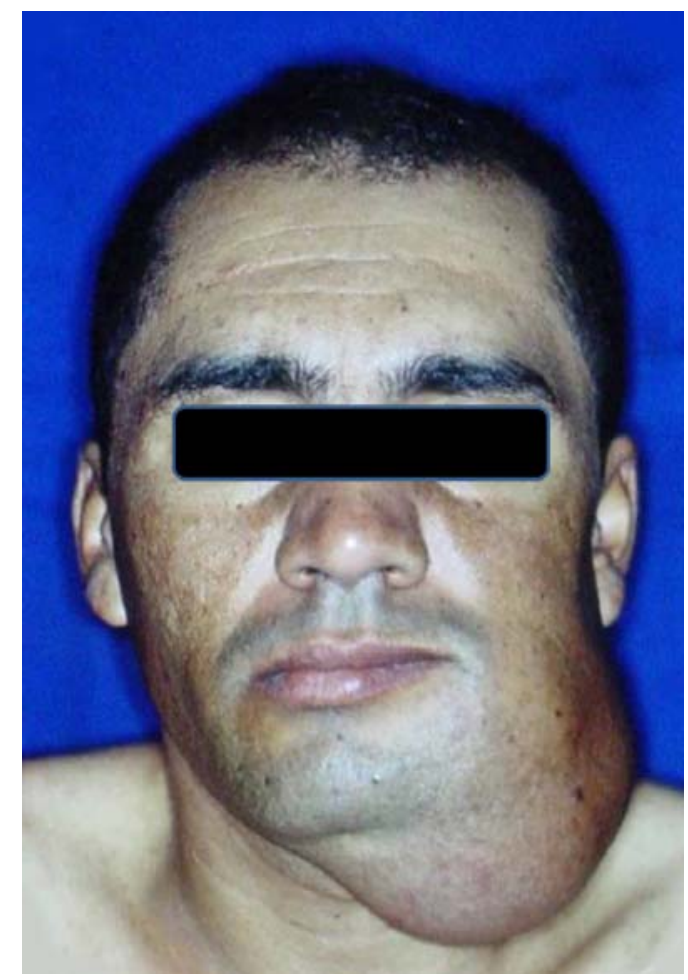

APÊNDICE C - 1. Imagem radiolúcida unilocular e de limites bem definidos em região retromolar. Achado radiográfico desprezado à época; 2. Imagem radiolúcida multilocular envolvendo região posterior de corpo e ramo mandibular 5 anos após a imagem anterior

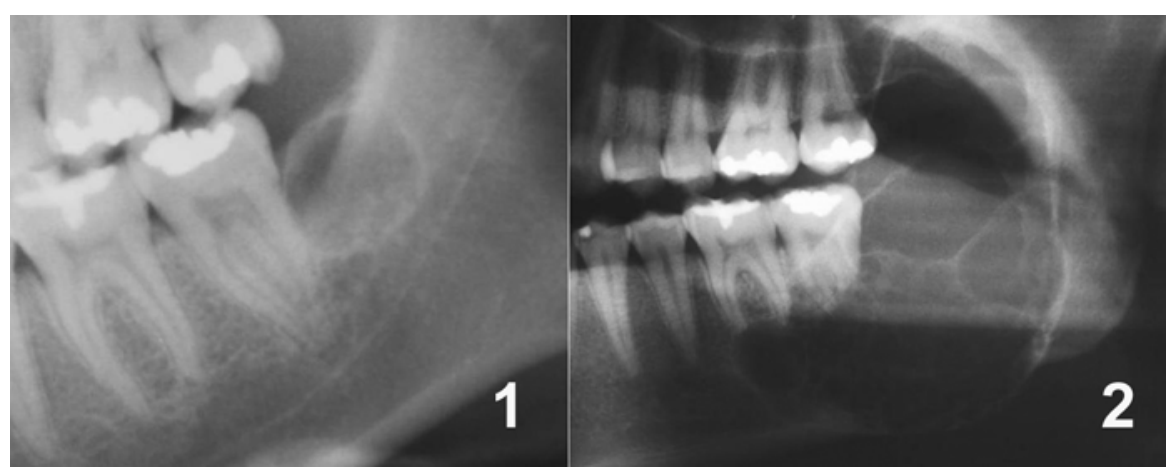


APÊNDICE D - 1. Aspecto intraoperatório mostrando nítida separação entre o NAI e a lesão; 2 . Foto cirúrgica mostrando preservação do NAI após remoção de ameloblastoma

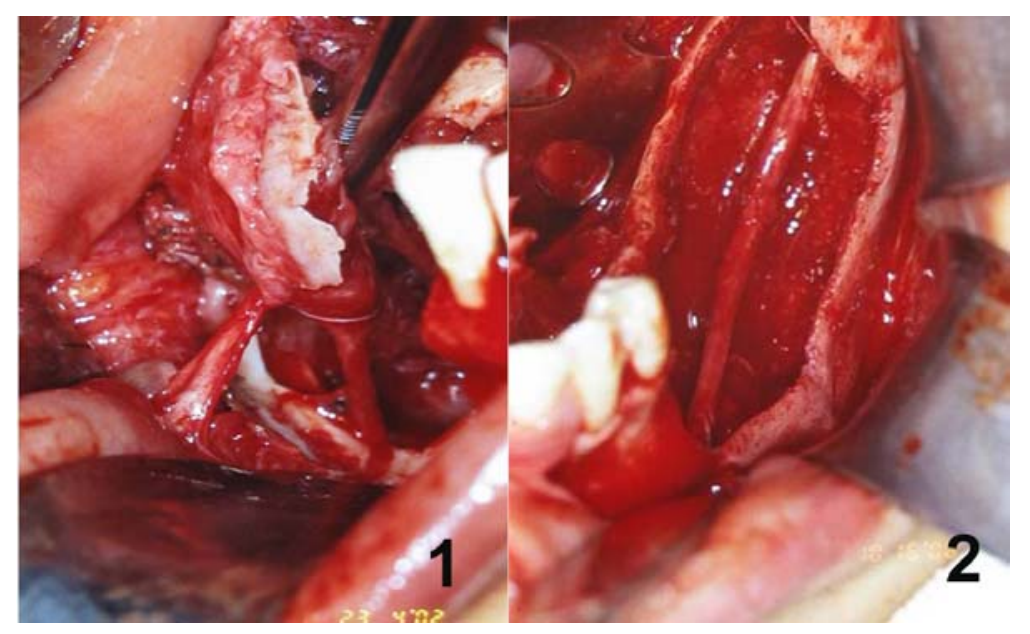

APÊNDICE E - Aspecto do leito cirúrgico após realização da crioterapia com nitrogênio líquido

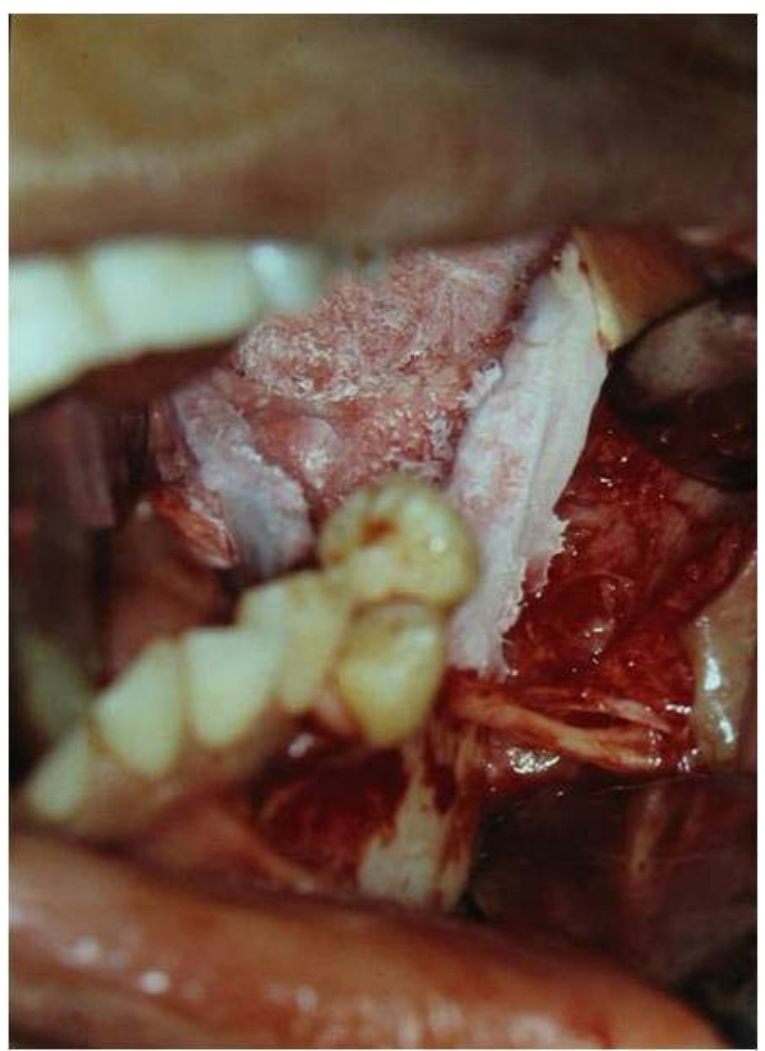


APÊNDICE F - 1. Presença de cortical óssea lingual exposta e necrótica após realização de crioterapia; 2. Aspecto do seqüestro ósseo removido cirurgicamente

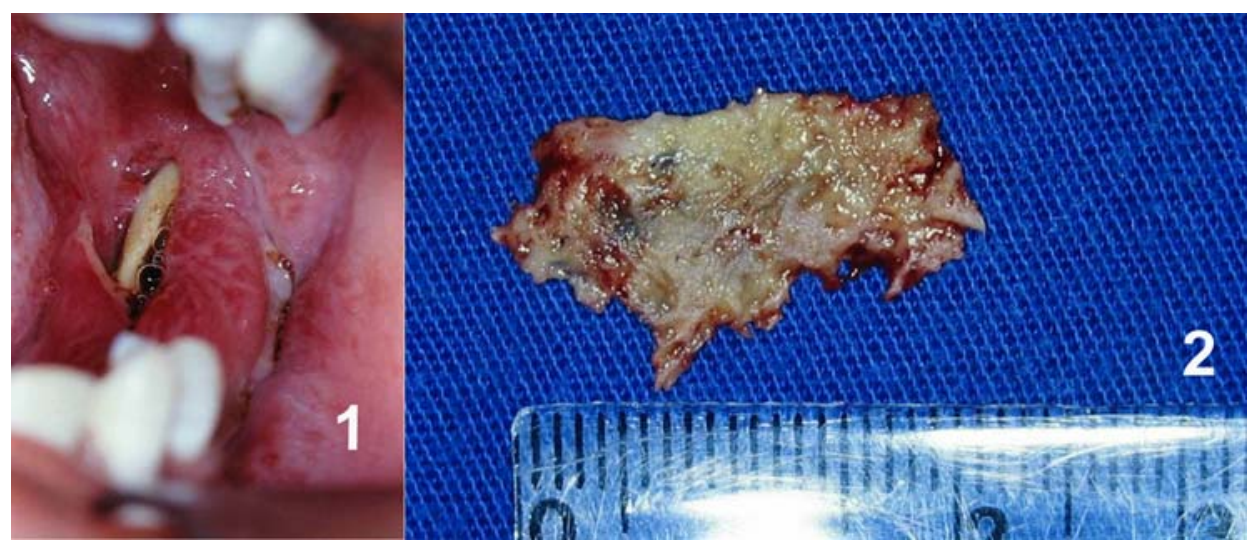

APÊNDICE G - Fixação de fratura mandibular ocorrida no transoperatório com placa reconstrutiva de $2,7 \mathrm{~mm}$

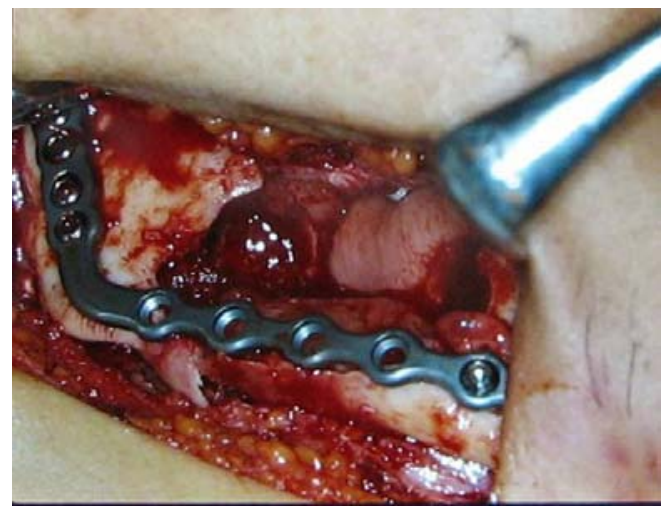

APÊNDICE H - Fratura patológica de corpo mandibular direito ocorrida após 2 meses do tratamento com crioterapia

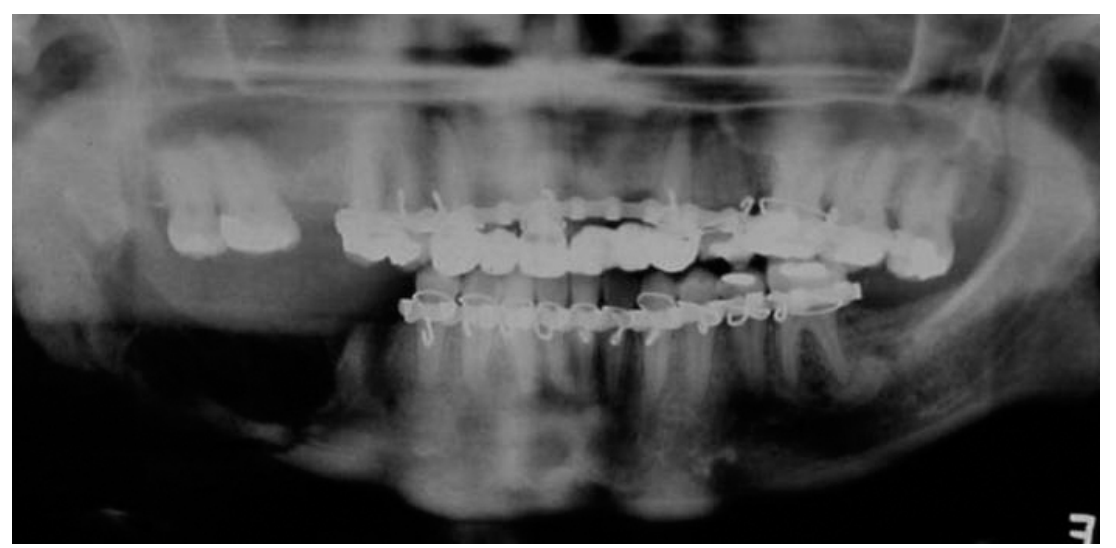


APÊNDICE I - 1. Drenagem de exsudato purulento em região posterior direita de mandíbula, 9 meses após o tratamento por crioterapia; 2. Aspecto radiográfico de desorganização do trabeculado ósseo mandibular da área operada, sugerindo o diagnóstico de osteomielite supurativa crônica; 3. Controle pós-operatório de 10 anos, evidenciando aspecto ósseo de normalidade

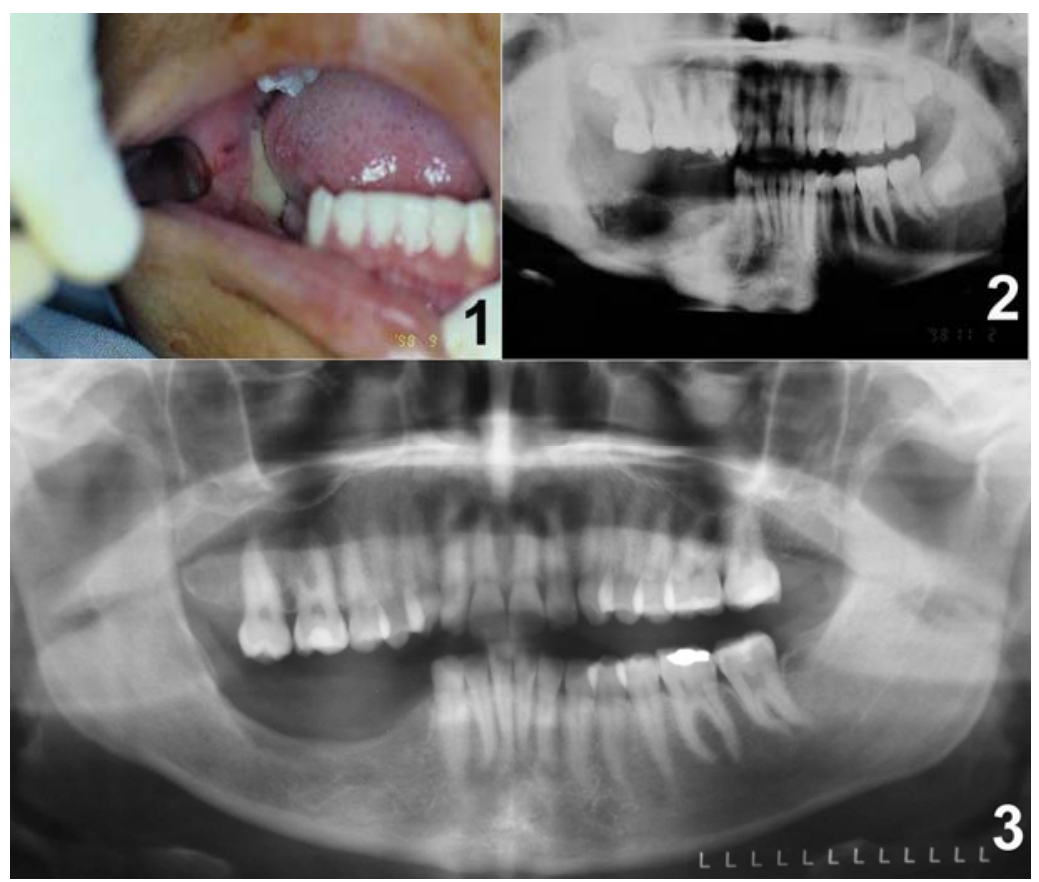

APÊNDICE J- Segunda semana de pós-operatório de ameloblastoma tratado por curetagem associada à crioterapia. Observa-se deiscência de sutura e exposição da loja cirúrgica

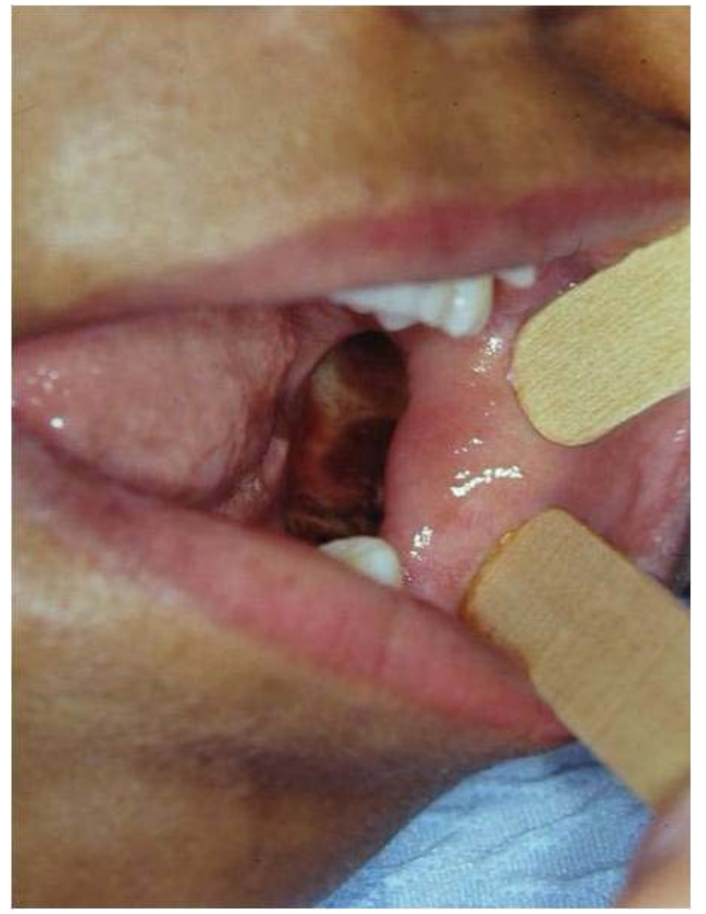


APÊNDICE K - 1. Radiografia panorâmica mostra imagem mutilocular com extensa loja radiolúcida e fratura patológica (seta) na base da mandíbula; 2 . Tomografia computadorizada (corte coronal-janela óssea) confirmando presença da fratura (seta); 3. Radiografia panorâmica após 11 meses da descompressão evidencia consolidação da fratura patológica e diminuição do tumor intra-ósseo; 4. TC comprovando achados de 3

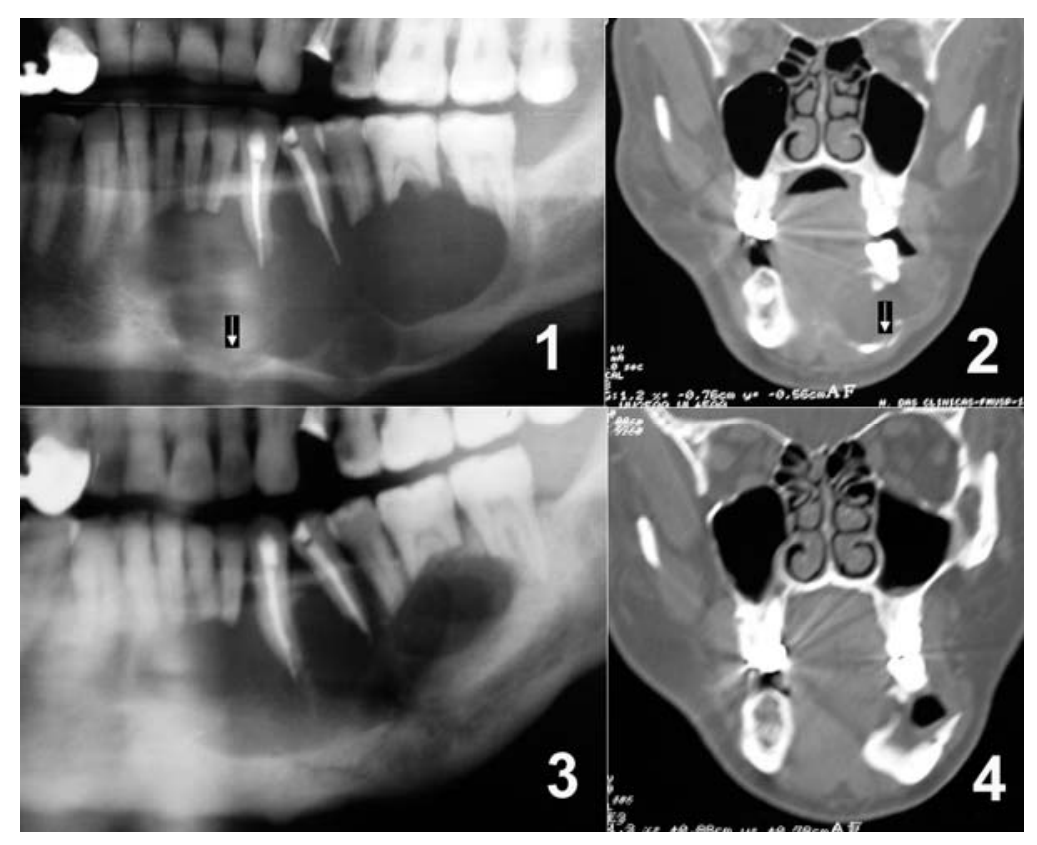

APÊNDICE L - 1. Ameloblastoma ocasionando expansão e afilamento da cortical basal da mandíbula; 2. Aspecto radiográfico, seis anos após o tratamento por curetagem, mostrando continuidade mandibular preservada, apesar da redução da altura óssea; 3. Aspecto clínica da reabilitação com prótese removível inferior.

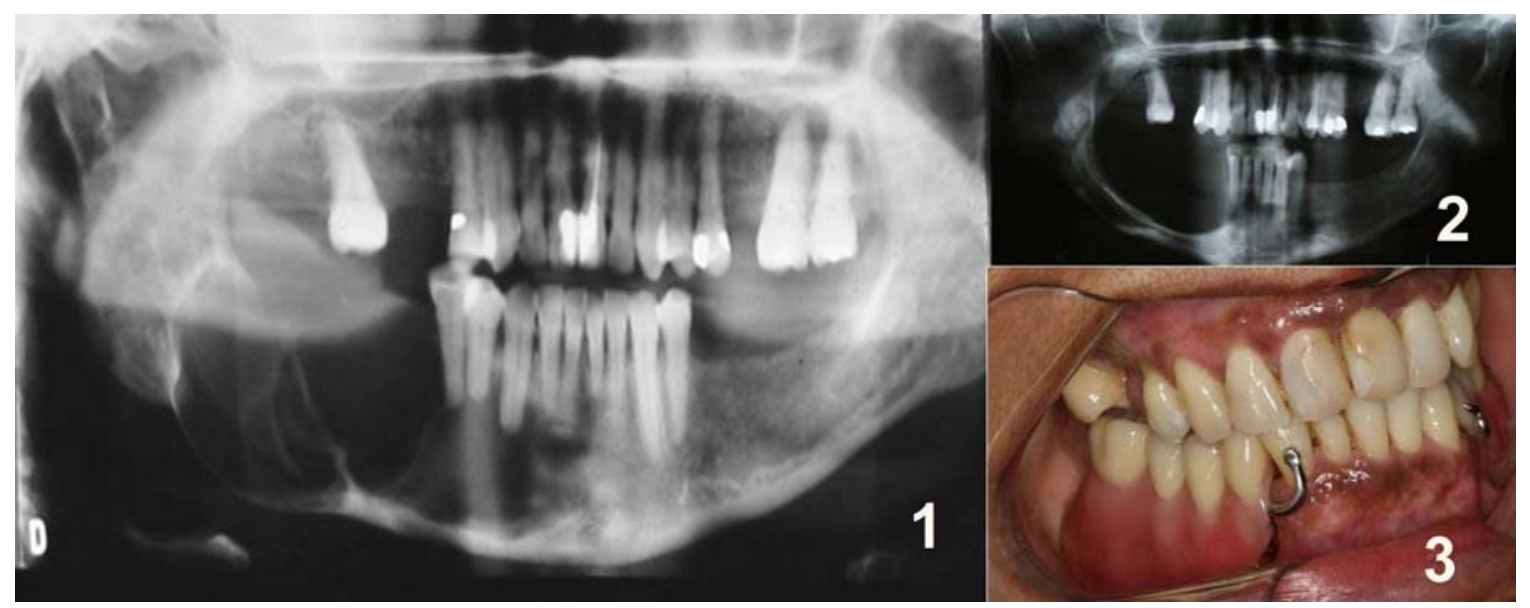


APÊNDICE M - 1. Radiografia panorâmica evidencia imagem radiolúcida unilocular envolvendo a região posterior de corpo esquerdo de mandíbula; 2. Tomografia computadorizada em corte coronal mostrando afilamento das corticais ósseas com área de destruição da cortical vestibular; 3. Radiografia panorâmica mostrando remodelação mandibular completa seis anos após remoção de ameloblastoma com preservação das corticais ósseas

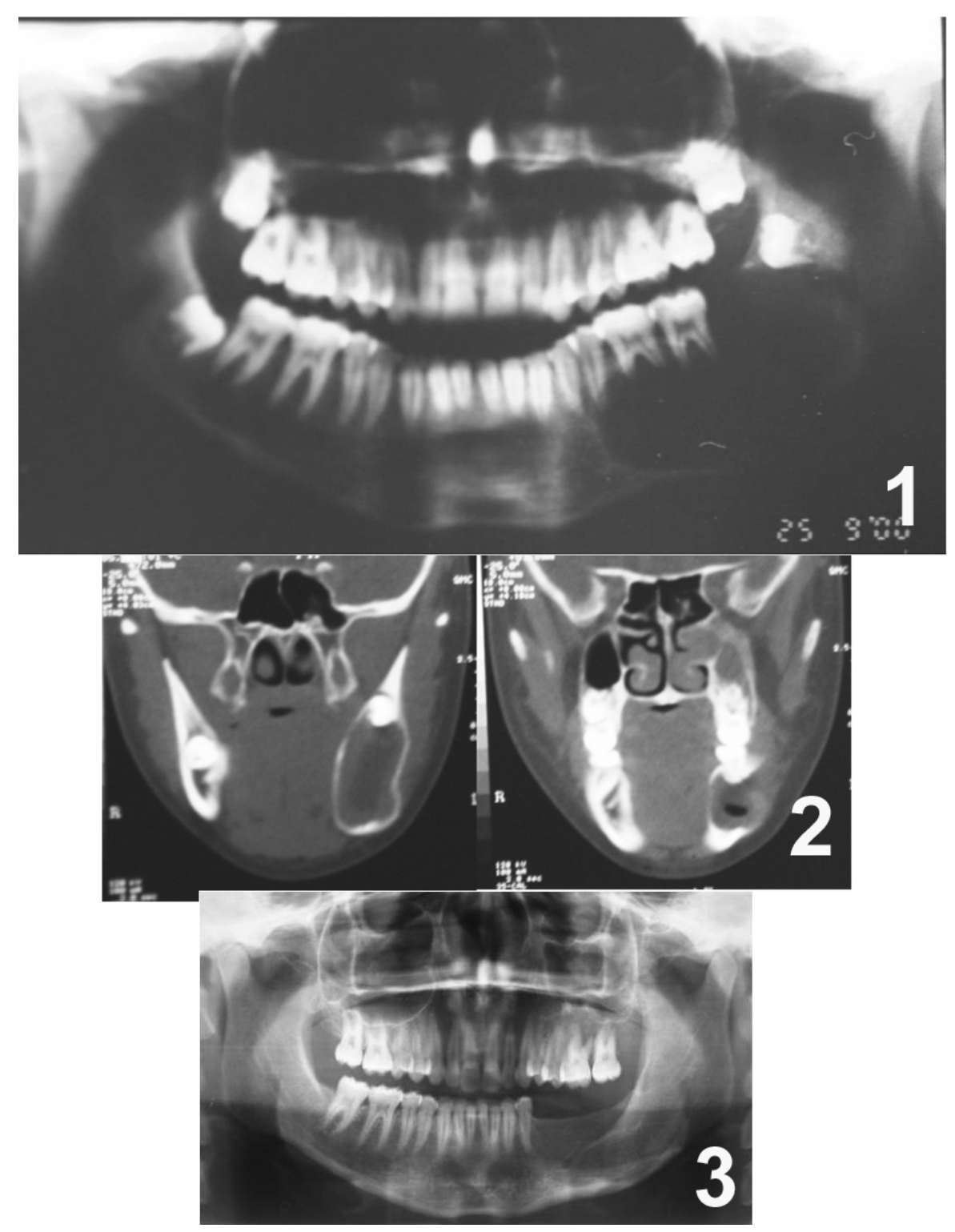


APÊNDICE N - 1. Tomografia computadorizada em corte axial, evidenciando lesão de atenuação mista, ocupando o seio maxilar direito e erodindo a cortical lateral do nariz; 2. Controle tomográfico pós-operatório de quatro anos sem sinais de recidiva

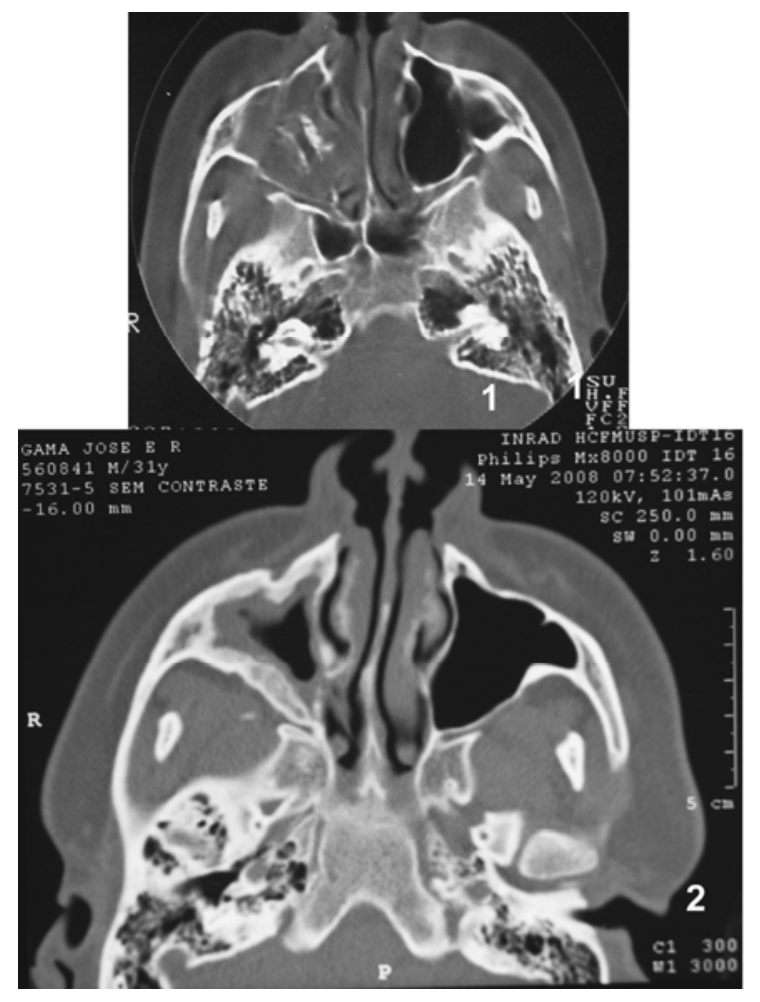

APÊNDICE O - 1 e 2. Vista frontal e inferior mostrando alteração do contorno facial após ressecção mandibular e reconstrução com retalho microcirúrgico de fíbula

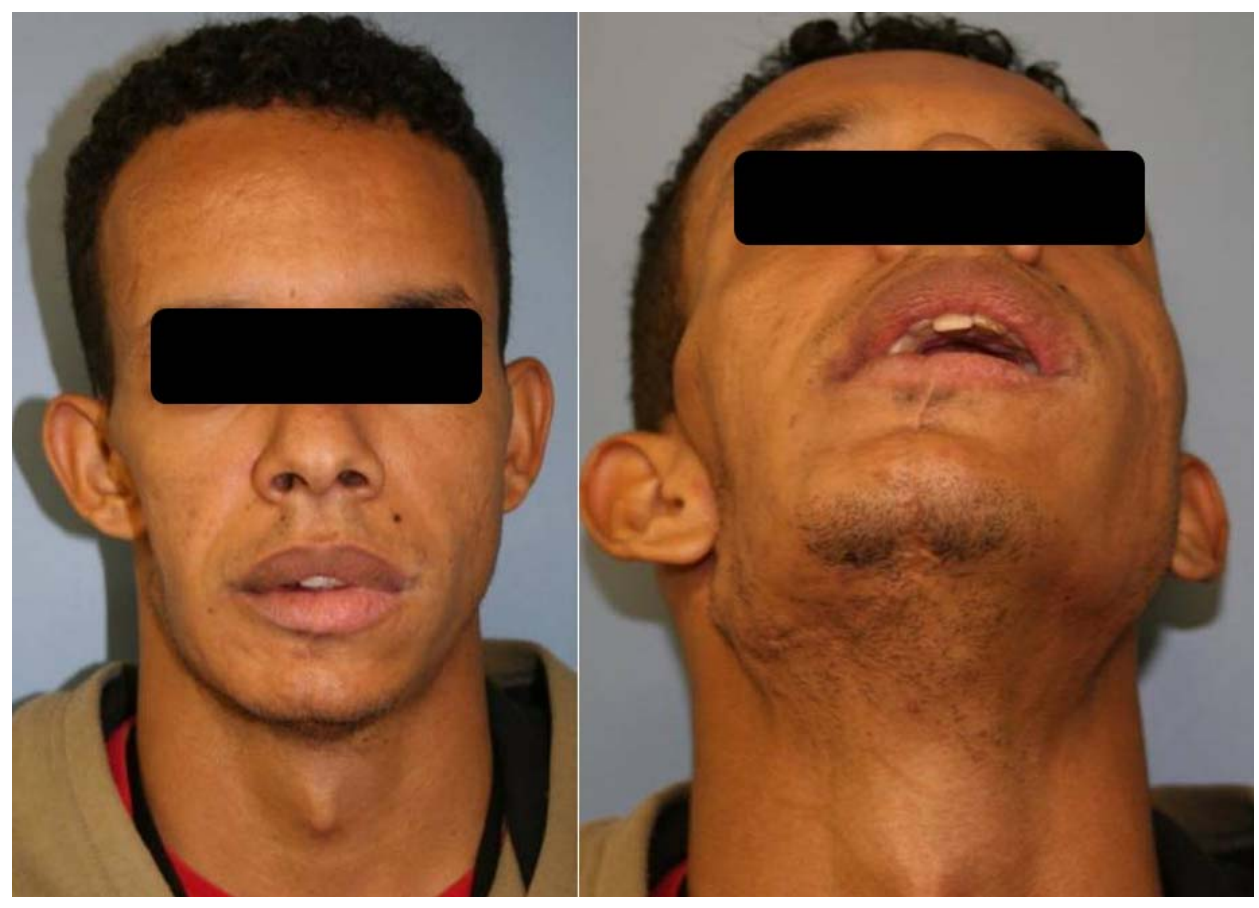


APÊNDICE P - Fratura de placa reconstrutiva junto ao coto distal da ressecção nove anos após o tratamento inicial

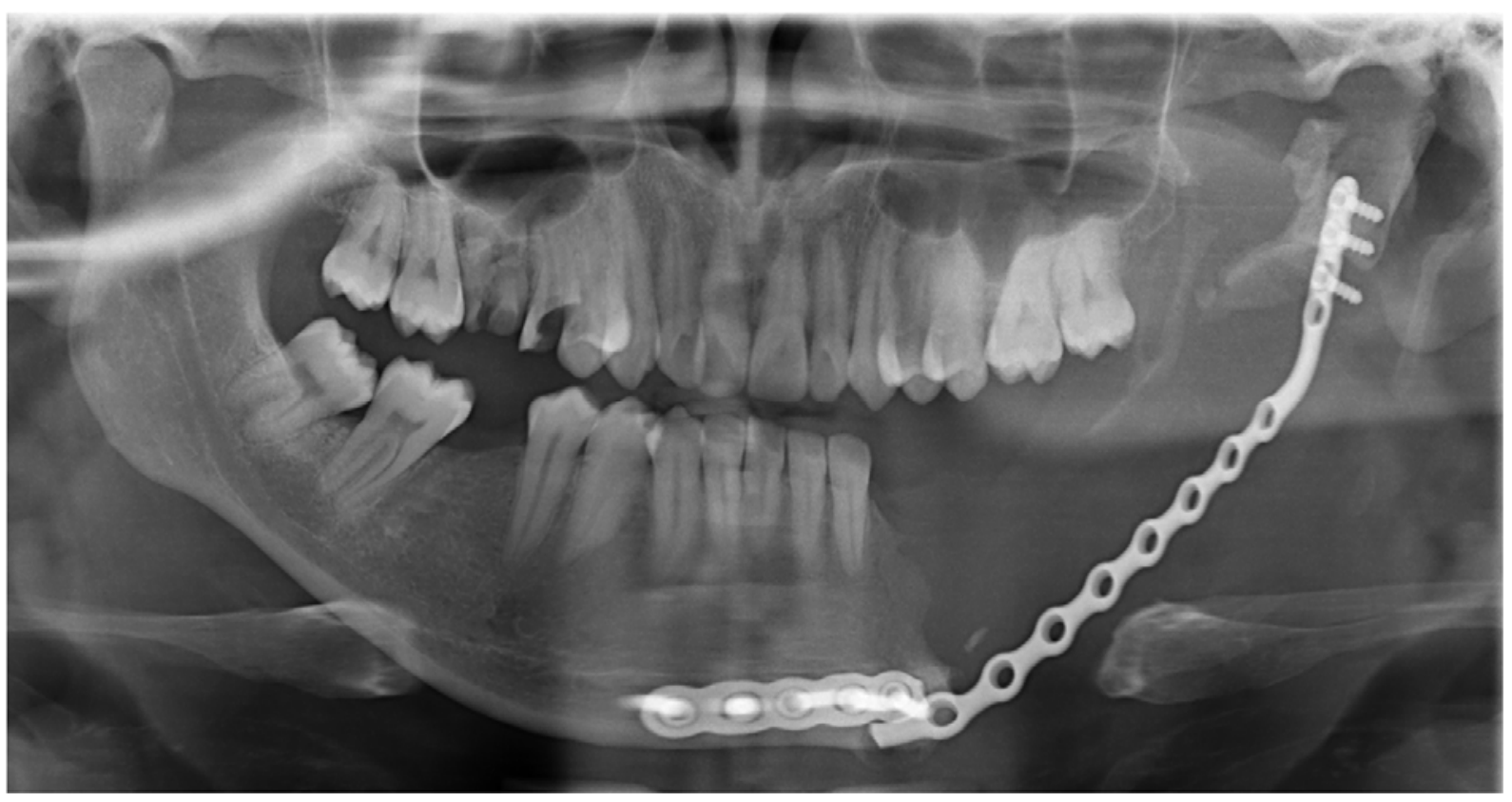


APÊNDICE Q - 1. Aspecto radiográfico de extenso ameloblastoma, envolvendo sínfise e corpo mandibular bilateralmente; 2 . Radiografia panorâmica após enxerto ósseo de crista ilíaca realizado em segundo tempo cirúrgico para viabilizar instalação de implantes osseointegrados; 3 . Aspecto clínico da reabilitação protética com prótese total superior e prótese sobre implantes inferior

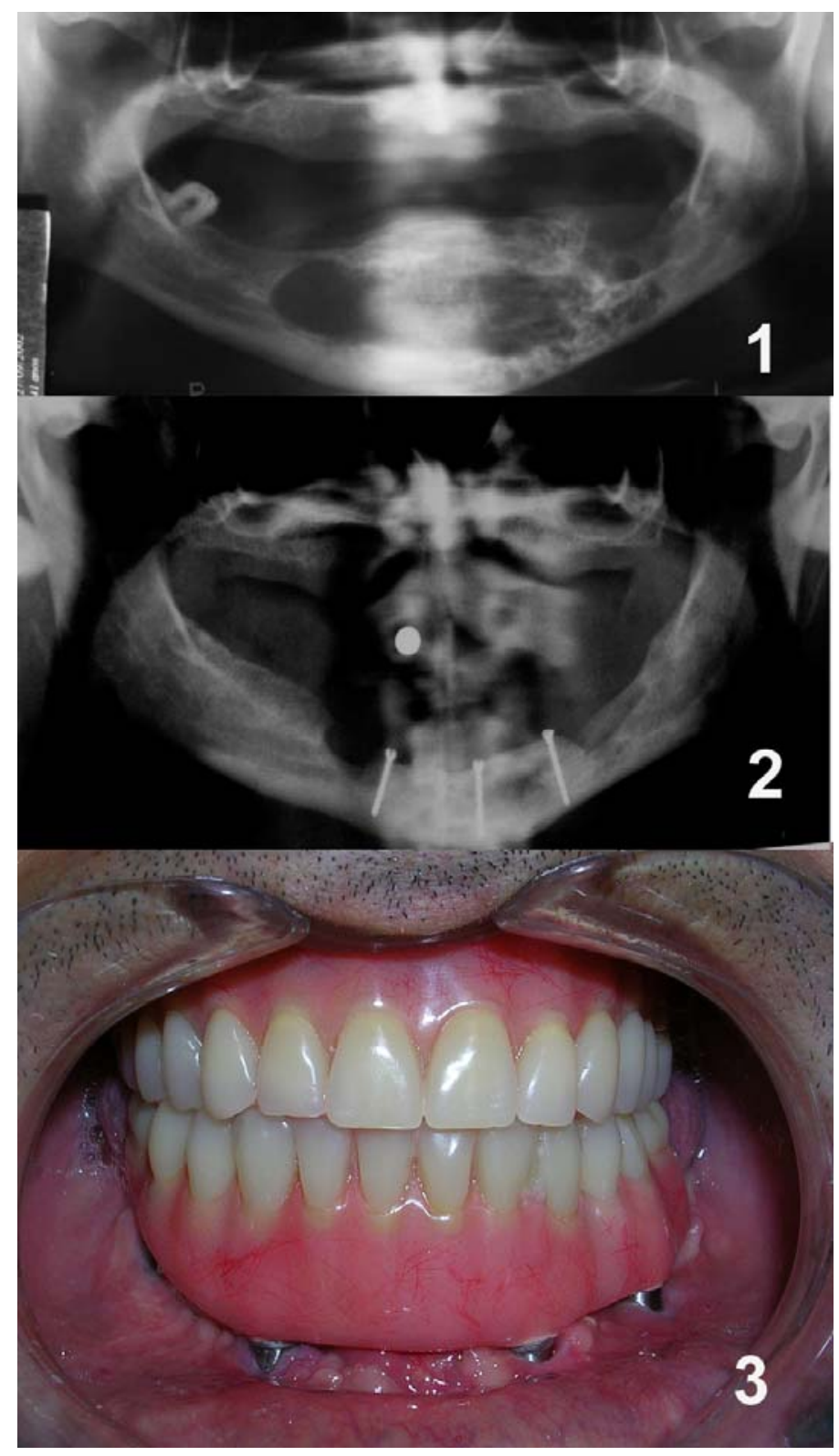


APÊNDICE R - 1. Recidiva de ameloblastoma em partes moles de região ressecada há 30 anos; 2. TC evidencia lesão de aspecto misto ocupando fossa infratemporal e deformando a parede lateral do seio maxilar direito; 3. Radiografia lateral oblíqua de mandíbula, realizada após a ressecção mandibular, mostrando imagem radiopaca que sugere fragmento ósseo residual; 4. Aspecto clínico após ressecção do tumor de partes moles e reconstrução com retalho peitoral

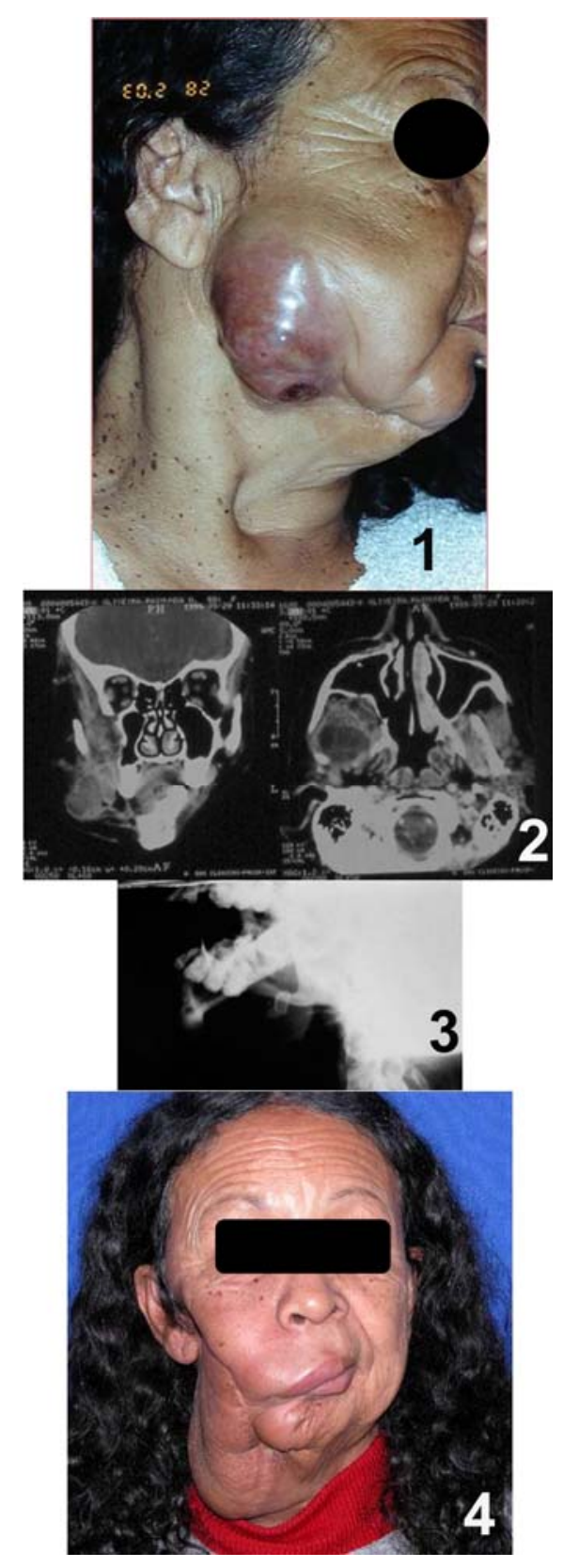


APÊNDICE S - 1. Radiografia panorâmica mostrando imagem radiolúcida multilocular e reabsorção de ápices radiculares; 2. Aspecto transcirúrgico, onde se observa preservação de trave óssea na porção superior da mandíbula (provável foco de lesão residual); 3. Imagem radiolúcida circunscrita em porção superior do rebordo alveolar, indicando "recidiva" 10 meses após tratamento por curetagem; 4. Tratamento cirúrgico da recidiva feito de forma localizada sob anestesia local

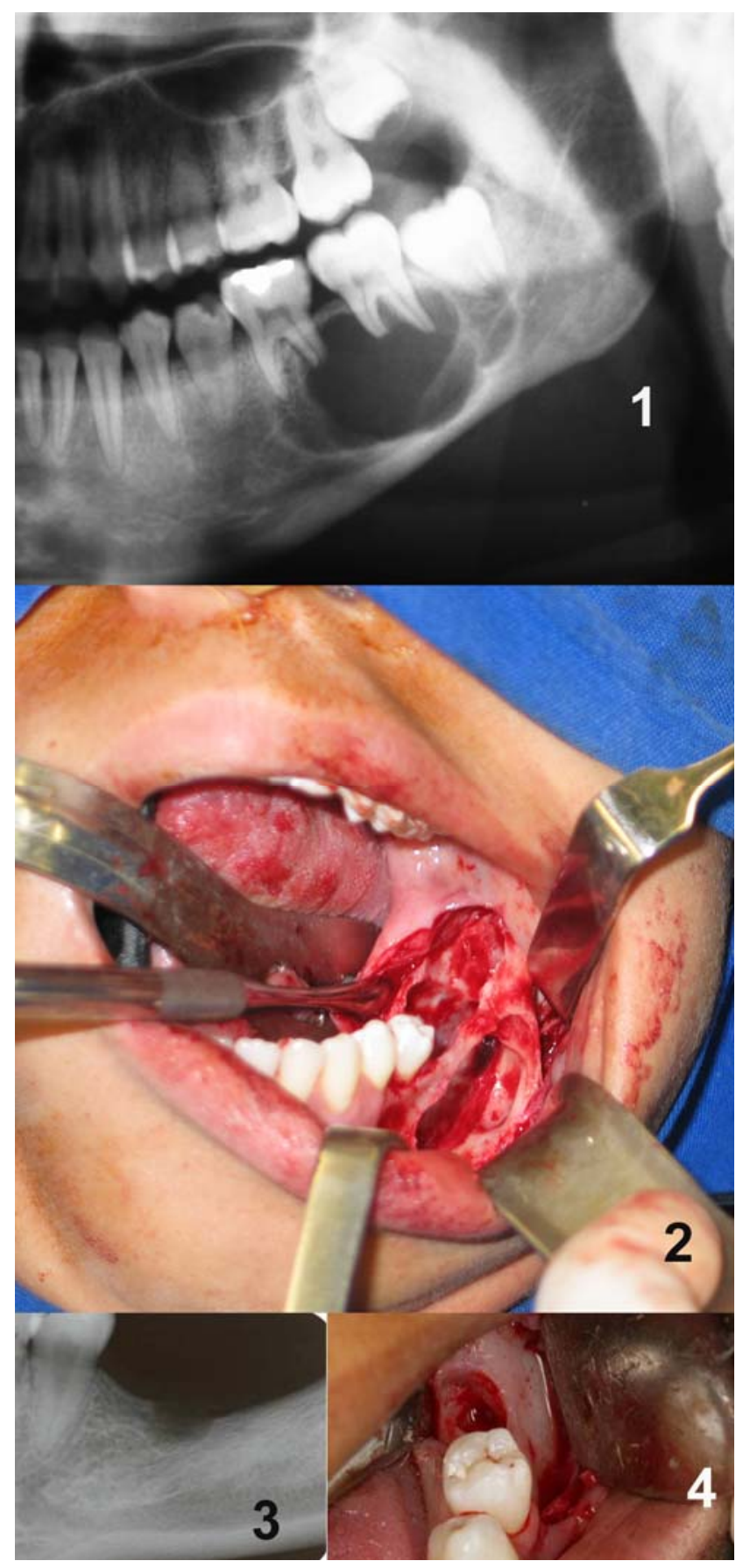


APÊNDICE T - 1. Aspecto radiográfico com 2 anos de controle pós-operatório de ameloblastoma em corpo direito de mandíbula, demonstrando reparação óssea satisfatória; 2. Imagem radiográfica de extensa lesão osteolítica de corpo mandibular direito, representando recidiva diagnosticada nove anos após o tratamento inicial por curetagem e crioterapia

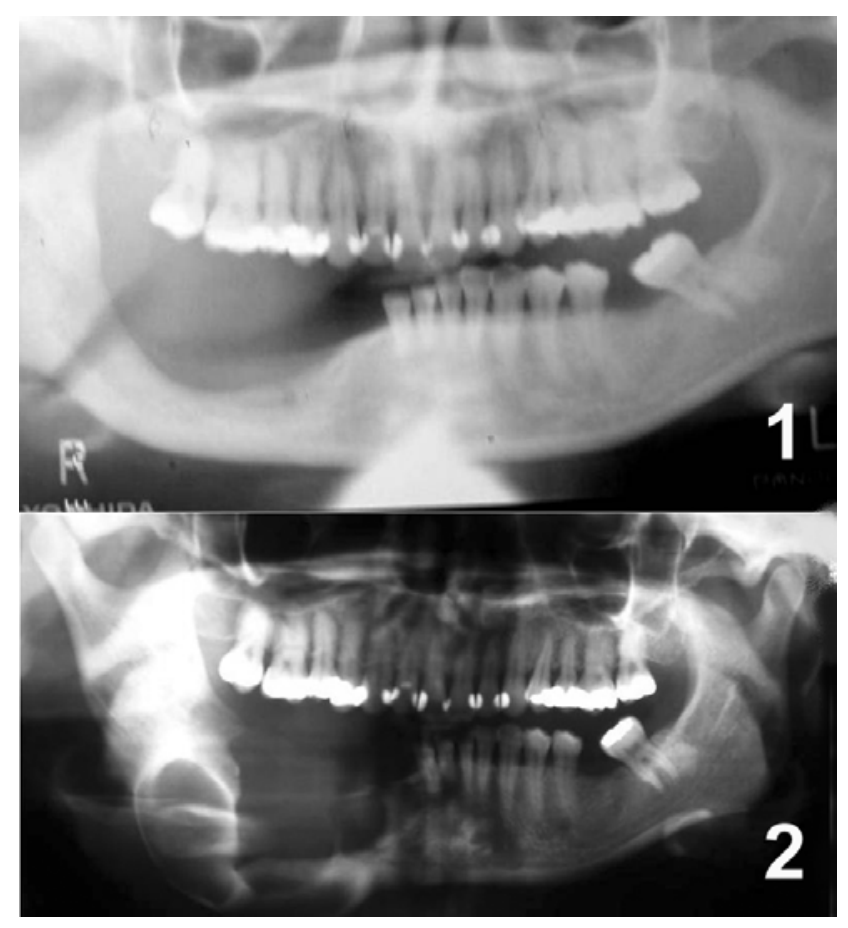


APÊNDICE U - 1. Radiografia panorâmica mostrando recidiva de ameloblastoma em coto distal da ressecção e sobre a costela utilizada na reconstrução mandibular; 2. Aspecto transoperatório, onde se evidencia integridade da costela, que não apresenta envolvimento tumoral; 3. Radiografia panorâmica de quatro anos de controle pósoperatório, mostrando ausência de recidiva

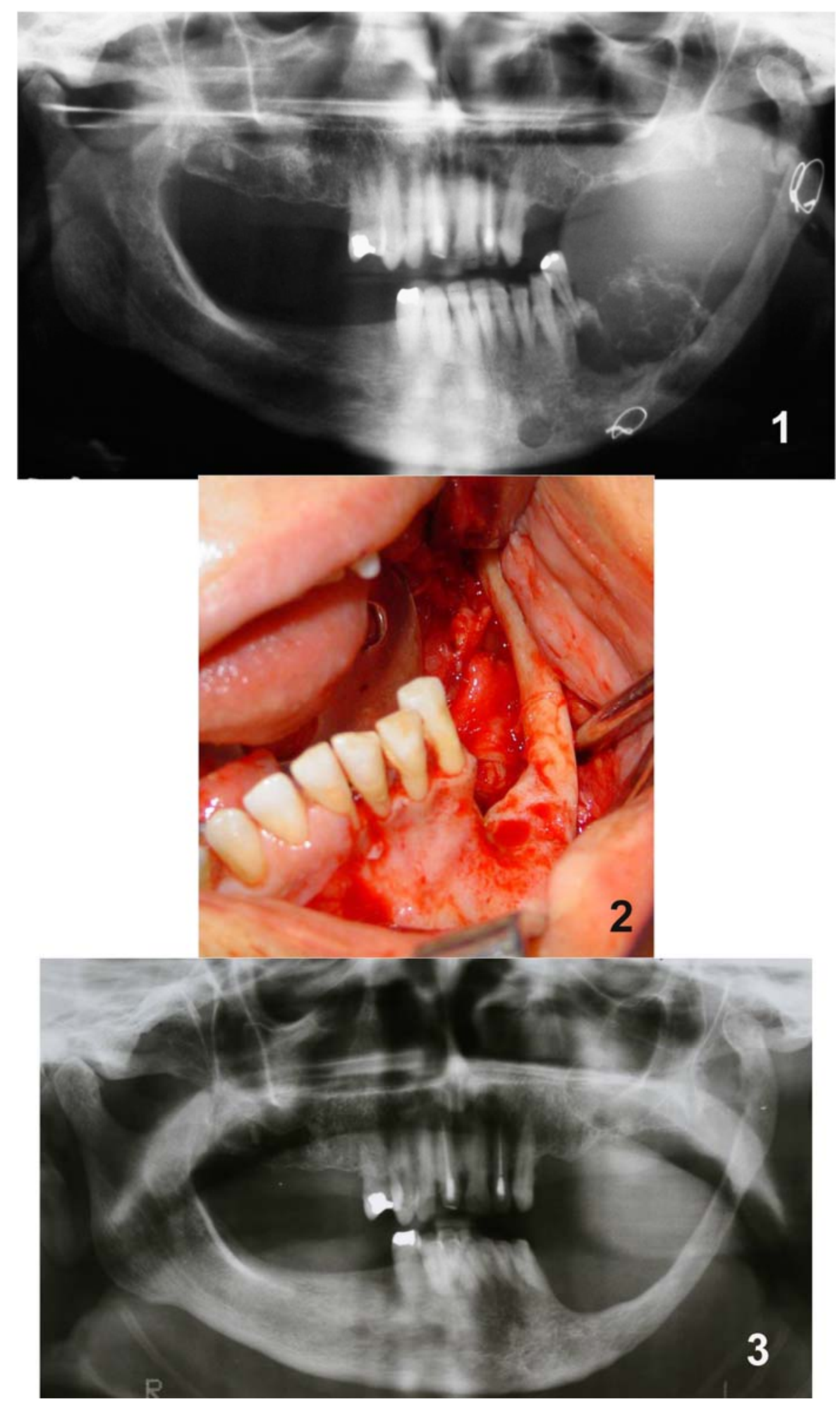




\section{ANEXOS}




\section{UNIVERSIDADE DE SÃO PAULO \\ FACULDADE DE ODONTOLOGIA}

$2^{\mathrm{a}}$. via

\section{PARECER DE APROVAÇÃO \\ Protocolo 35/07}

Com base em parecer de relator, o Comitê de Ética em Pesquisa APROVOU o protocolo de pesquisa "ESTUDO CLínICO, RADIOGRÁFICO, MICROSCÓPICO E TERAPÊUTICO DE AMELOBLASTOMAS", de responsabilidade do Pesquisador: ANDRÉ CAROLI ROCHA, sob orientação do Professor Doutor JAYRO GUIMARÃES JUNIOR.

Tendo em vista a legislação vigente, devem ser encaminhados a este Comitê relatórios anuais referentes ao andamento da pesquisa e ao término cópia do trabalho em "cd". Qualquer emenda do projeto original deve ser apresentada a este CEP para apreciação, de forma clara e sucinta, identificando a parte do protocolo a ser modificada e suas justificativas.

São Paulo, 24 de junho de 2008

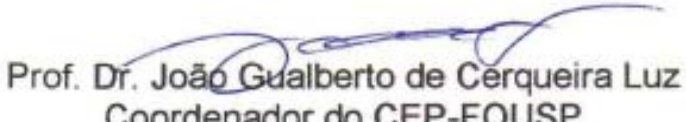

Coordenador do CEP-FOUSP 
ANEXO B - Caso relatado por Pizer, Page; Svirsky (2002). Notar preservação dos dentes associados ao tumor após tratamento por curetagem sob anestesia local

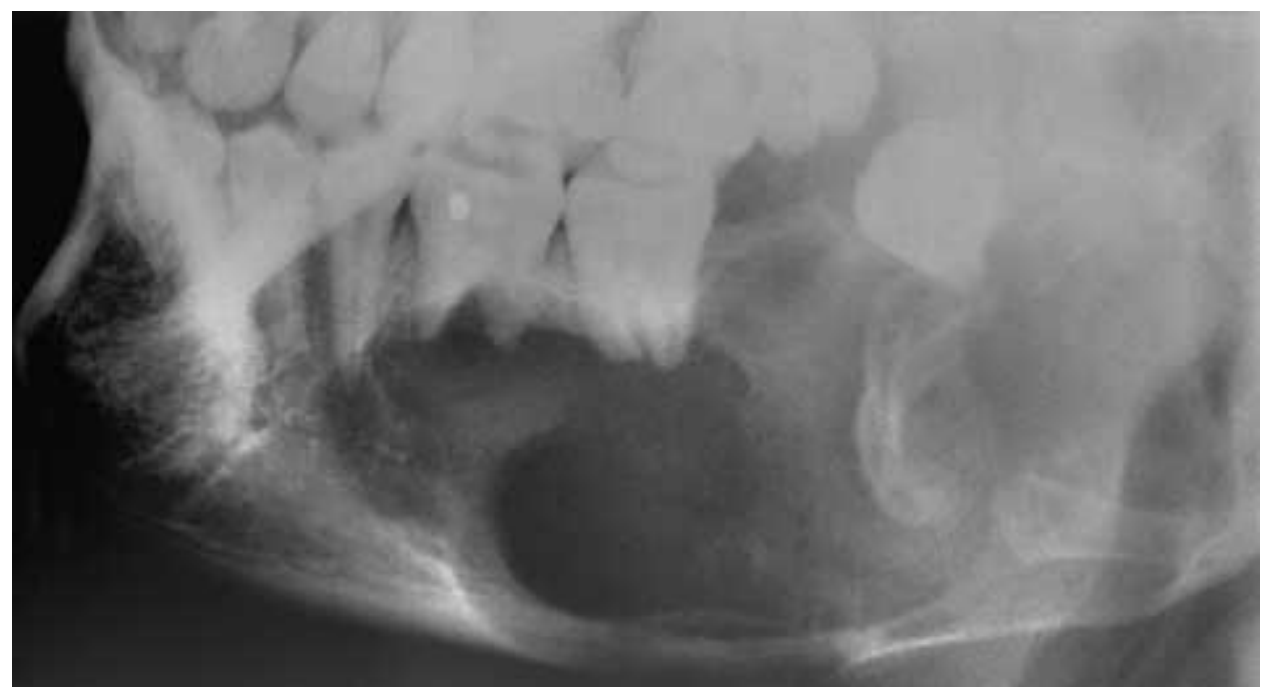

Lateral oblique radiograph of the right $m$ andible showing increased lucency in the posteroinferior aspect of the involved area. Note the thin inferior border of the mandible in the second molar region.

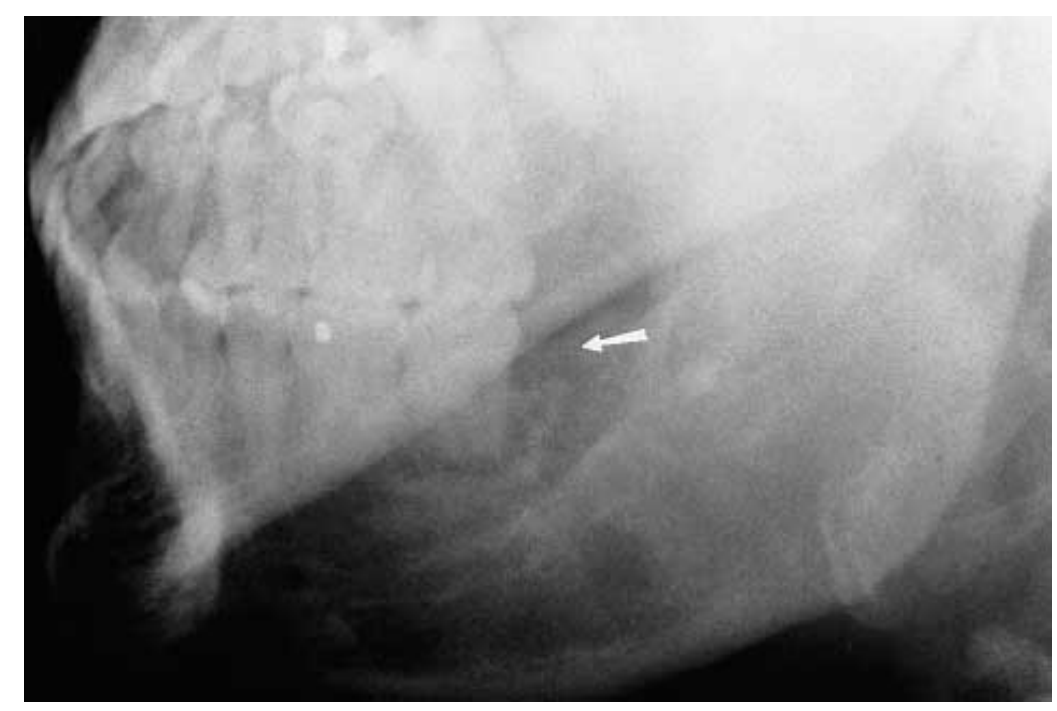

Lateral oblique radiograph of the right mandible taken in October 1991 reveals a slight change in the continuity of the superiorcortex just posterior to the second molar (arrow). 